\title{
One-Pot Synthesis of $N$-Imidoyl-(1H)-Indoles via Palladium-Catalyzed Oxidative Insertion Domino Reaction with Isocyanide and Arylboronic Acid
}

Shou-Wei Tao, Jing-Ya Zhou, Rui-Qing Liu, Yong-Ming Zhu*

${ }^{\dagger}$ College of Pharmaceutical Sciences, Soochow University, Suzhou

215123, China 


\section{Contents}

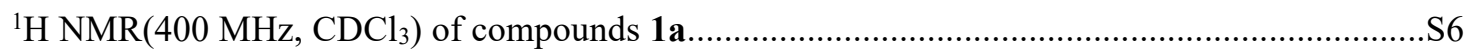

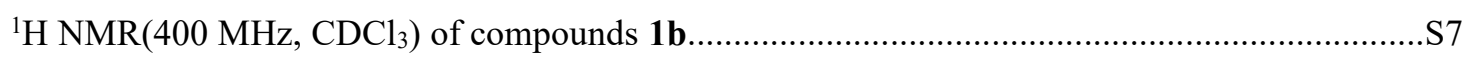

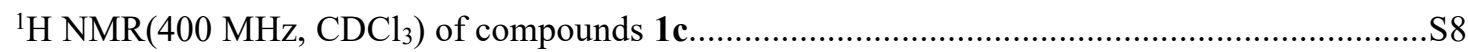

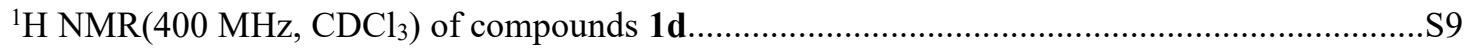

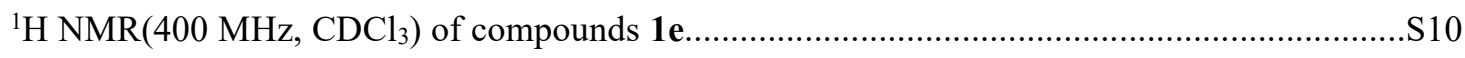

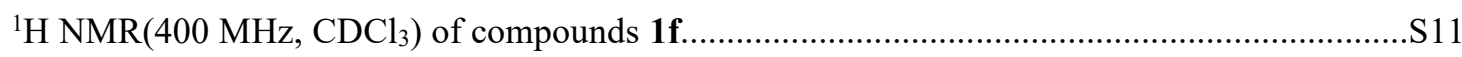

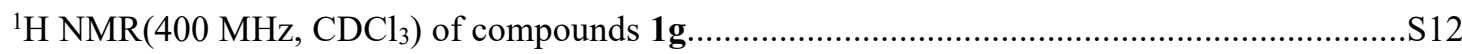

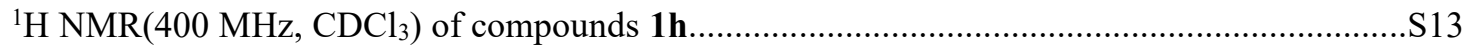

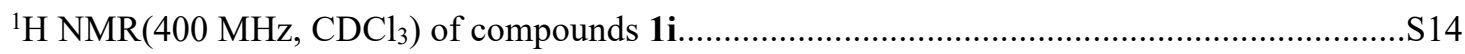

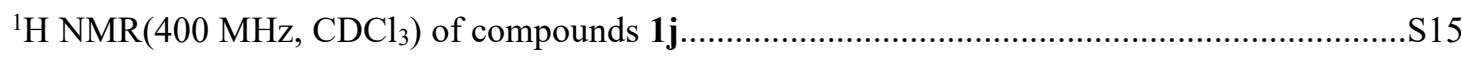

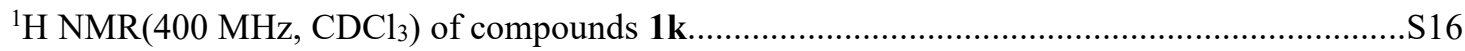

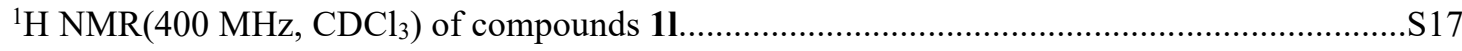

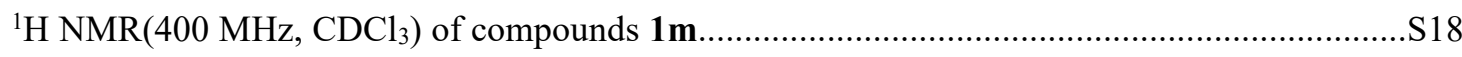

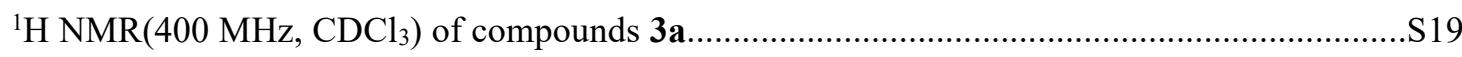

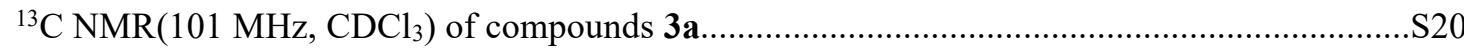

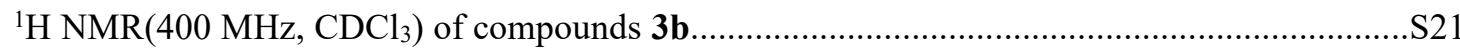

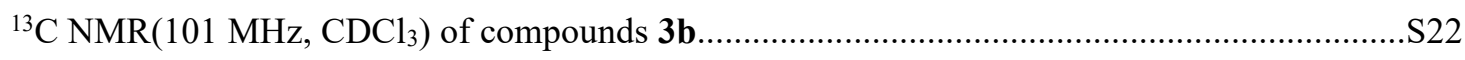

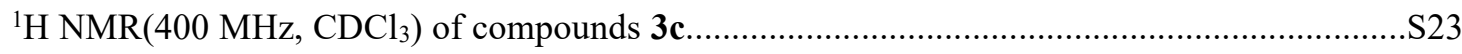

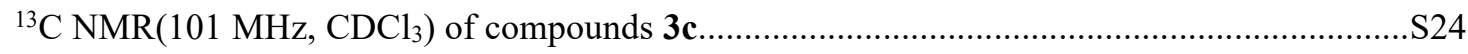

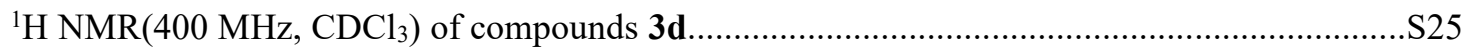


${ }^{13} \mathrm{C} \mathrm{NMR}\left(101 \mathrm{MHz}, \mathrm{CDCl}_{3}\right)$ of compounds 3d.... . $\mathrm{S} 26$

${ }^{1} \mathrm{H}$ NMR(400 MHz, $\left.\mathrm{CDCl}_{3}\right)$ of compounds $\mathbf{3 e}$ ...S27

${ }^{13} \mathrm{C} \mathrm{NMR}\left(101 \mathrm{MHz}, \mathrm{CDCl}_{3}\right)$ of compounds $3 \mathbf{e}$. ..S28

${ }^{1} \mathrm{H}$ NMR(400 MHz, $\left.\mathrm{CDCl}_{3}\right)$ of compounds $\mathbf{3 f}$. .S29

${ }^{13} \mathrm{C} \mathrm{NMR}\left(101 \mathrm{MHz}, \mathrm{CDCl}_{3}\right)$ of compounds $\mathbf{3 f}$. ..S30

${ }^{1} \mathrm{H}$ NMR(400 MHz, $\mathrm{CDCl}_{3}$ ) of compounds $\mathbf{3 g}$ S31

${ }^{13} \mathrm{C} \mathrm{NMR}\left(101 \mathrm{MHz}, \mathrm{CDCl}_{3}\right)$ of compounds $\mathbf{3 g}$. ..S32

${ }^{1} \mathrm{H} \mathrm{NMR}\left(400 \mathrm{MHz}, \mathrm{CDCl}_{3}\right)$ of compounds $\mathbf{3 h}$ S33

${ }^{13} \mathrm{C} \mathrm{NMR}\left(101 \mathrm{MHz}, \mathrm{CDCl}_{3}\right)$ of compounds $\mathbf{3 h}$ ..S34

${ }^{1} \mathrm{H}$ NMR(400 MHz, $\left.\mathrm{CDCl}_{3}\right)$ of compounds $\mathbf{3 i}$. S35

${ }^{13} \mathrm{C} \mathrm{NMR}\left(101 \mathrm{MHz}, \mathrm{CDCl}_{3}\right)$ of compounds $\mathbf{3 i}$ S36

${ }^{1} \mathrm{H}$ NMR(400 MHz, $\left.\mathrm{CDCl}_{3}\right)$ of compounds $\mathbf{3 j}$ S37

${ }^{13} \mathrm{C}$ NMR(101 MHz, $\left.\mathrm{CDCl}_{3}\right)$ of compounds $\mathbf{3 j}$ S38

${ }^{1} \mathrm{H} \mathrm{NMR}\left(400 \mathrm{MHz}, \mathrm{CDCl}_{3}\right)$ of compounds $\mathbf{3 k}$ S39

${ }^{13} \mathrm{C} \mathrm{NMR}\left(101 \mathrm{MHz}, \mathrm{CDCl}_{3}\right)$ of compounds $\mathbf{3 k}$ ..S40

${ }^{1} \mathrm{H}$ NMR(400 MHz, $\left.\mathrm{CDCl}_{3}\right)$ of compounds 31 S41

${ }^{13} \mathrm{C} \mathrm{NMR}\left(101 \mathrm{MHz}, \mathrm{CDCl}_{3}\right)$ of compounds 31 $\mathrm{S} 42$

${ }^{1} \mathrm{H} \mathrm{NMR}\left(400 \mathrm{MHz}, \mathrm{CDCl}_{3}\right)$ of compounds $\mathbf{3 m}$ $\mathrm{S} 43$

${ }^{13} \mathrm{C} \mathrm{NMR}\left(101 \mathrm{MHz}, \mathrm{CDCl}_{3}\right)$ of compounds $\mathbf{3 m}$ ..S44

${ }^{1} \mathrm{H}$ NMR(400 MHz, $\left.\mathrm{CDCl}_{3}\right)$ of compounds $\mathbf{3 n}$ .S45

${ }^{13} \mathrm{C} \mathrm{NMR}\left(101 \mathrm{MHz}, \mathrm{CDCl}_{3}\right)$ of compounds $\mathbf{3 n}$ ..S46

${ }^{1} \mathrm{H} \mathrm{NMR}\left(400 \mathrm{MHz}, \mathrm{CDCl}_{3}\right)$ of compounds $3 \mathbf{o}$ 
${ }^{13} \mathrm{C} \mathrm{NMR}\left(101 \mathrm{MHz}, \mathrm{CDCl}_{3}\right)$ of compounds $\mathbf{3 o}$ . $\mathrm{S} 48$

${ }^{1} \mathrm{H} \mathrm{NMR}\left(400 \mathrm{MHz}, \mathrm{CDCl}_{3}\right)$ of compounds $\mathbf{3 p}$ S49

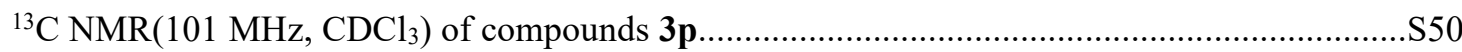

${ }^{1} \mathrm{H} \mathrm{NMR}\left(400 \mathrm{MHz}, \mathrm{CDCl}_{3}\right)$ of compounds $\mathbf{4 b}$ .S51

${ }^{13} \mathrm{C} \mathrm{NMR}\left(101 \mathrm{MHz}, \mathrm{CDCl}_{3}\right)$ of compounds $\mathbf{4 b}$ ..S52

${ }^{1} \mathrm{H} \mathrm{NMR}\left(400 \mathrm{MHz}, \mathrm{CDCl}_{3}\right)$ of compounds $\mathbf{4 c}$ S53

${ }^{13} \mathrm{C} \mathrm{NMR}\left(101 \mathrm{MHz}, \mathrm{CDCl}_{3}\right)$ of compounds $4 \mathbf{c}$ ..S54

${ }^{1} \mathrm{H} \mathrm{NMR}\left(400 \mathrm{MHz}, \mathrm{CDCl}_{3}\right)$ of compounds $\mathbf{4 d}$ .. $\mathrm{S} 55$

${ }^{13} \mathrm{C} \mathrm{NMR}\left(101 \mathrm{MHz}, \mathrm{CDCl}_{3}\right)$ of compounds $\mathbf{4 d}$ ..S56

${ }^{1} \mathrm{H} \mathrm{NMR}\left(400 \mathrm{MHz}, \mathrm{CDCl}_{3}\right)$ of compounds $\mathbf{4 e}$ S57

${ }^{13} \mathrm{C} \mathrm{NMR}\left(101 \mathrm{MHz}, \mathrm{CDCl}_{3}\right)$ of compounds $4 \mathbf{e}$ ..S58

${ }^{1} \mathrm{H} \mathrm{NMR}\left(400 \mathrm{MHz}, \mathrm{CDCl}_{3}\right)$ of compounds $\mathbf{4 f}$. .S59

${ }^{13} \mathrm{C} \mathrm{NMR}\left(101 \mathrm{MHz}, \mathrm{CDCl}_{3}\right)$ of compounds $4 \mathbf{f}$. .S60

${ }^{1} \mathrm{H} \mathrm{NMR}\left(400 \mathrm{MHz}, \mathrm{CDCl}_{3}\right)$ of compounds $\mathbf{4 g}$ S61

${ }^{13} \mathrm{C} \mathrm{NMR}\left(101 \mathrm{MHz}, \mathrm{CDCl}_{3}\right)$ of compounds $\mathbf{4 g}$. ..S62

${ }^{1} \mathrm{H} \mathrm{NMR}\left(400 \mathrm{MHz}, \mathrm{CDCl}_{3}\right)$ of compounds $\mathbf{4 h}$ ..S63

${ }^{13} \mathrm{C} \mathrm{NMR}\left(101 \mathrm{MHz}, \mathrm{CDCl}_{3}\right)$ of compounds $\mathbf{4 h}$ ..S64

${ }^{1} \mathrm{H} \mathrm{NMR}\left(400 \mathrm{MHz}, \mathrm{CDCl}_{3}\right)$ of compounds $\mathbf{4 i}$. S65

${ }^{13} \mathrm{C}$ NMR(101 MHz, $\left.\mathrm{CDCl}_{3}\right)$ of compounds $4 \mathbf{i}$ ..S66

${ }^{1} \mathrm{H}$ NMR(400 MHz, $\left.\mathrm{CDCl}_{3}\right)$ of compounds $\mathbf{4 j}$ ..S67

${ }^{13} \mathrm{C}$ NMR(101 MHz, $\left.\mathrm{CDCl}_{3}\right)$ of compounds $\mathbf{4 j}$ ..S68

${ }^{1} \mathrm{H} \mathrm{NMR}\left(400 \mathrm{MHz}, \mathrm{CDCl}_{3}\right)$ of compounds $\mathbf{4 k}$ ..S69 
${ }^{13} \mathrm{C} \mathrm{NMR}\left(101 \mathrm{MHz}, \mathrm{CDCl}_{3}\right)$ of compounds $4 \mathbf{k}$ . $\mathrm{S} 70$

${ }^{1} \mathrm{H}$ NMR(400 MHz, $\left.\mathrm{CDCl}_{3}\right)$ of compounds $4 \mathbf{l}$. S71

${ }^{13} \mathrm{C} \mathrm{NMR}\left(101 \mathrm{MHz}, \mathrm{CDCl}_{3}\right)$ of compounds $\mathbf{4 l}$. S72

${ }^{1} \mathrm{H}$ NMR(400 MHz, $\left.\mathrm{CDCl}_{3}\right)$ of compounds $\mathbf{4 m}$ .S73

${ }^{13} \mathrm{C} \mathrm{NMR}\left(101 \mathrm{MHz}, \mathrm{CDCl}_{3}\right)$ of compounds $\mathbf{4 m}$. ..S74

${ }^{1} \mathrm{H}$ NMR(400 MHz, $\left.\mathrm{CDCl}_{3}\right)$ of compounds $\mathbf{5 b}$. S75

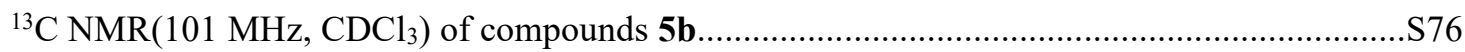

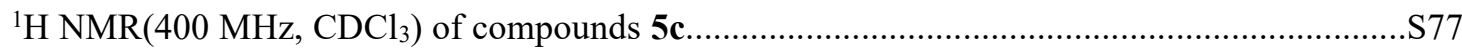

${ }^{13} \mathrm{C}$ NMR(101 MHz, $\left.\mathrm{CDCl}_{3}\right)$ of compounds $\mathbf{5 c}$ ..S78 


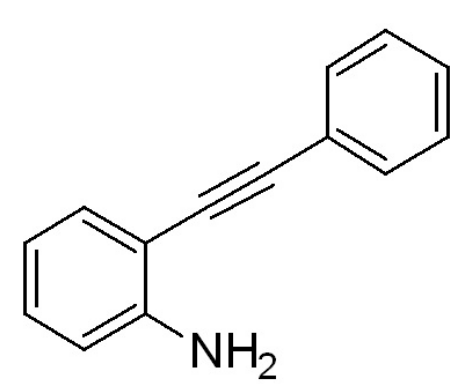

$1 \mathrm{a}$

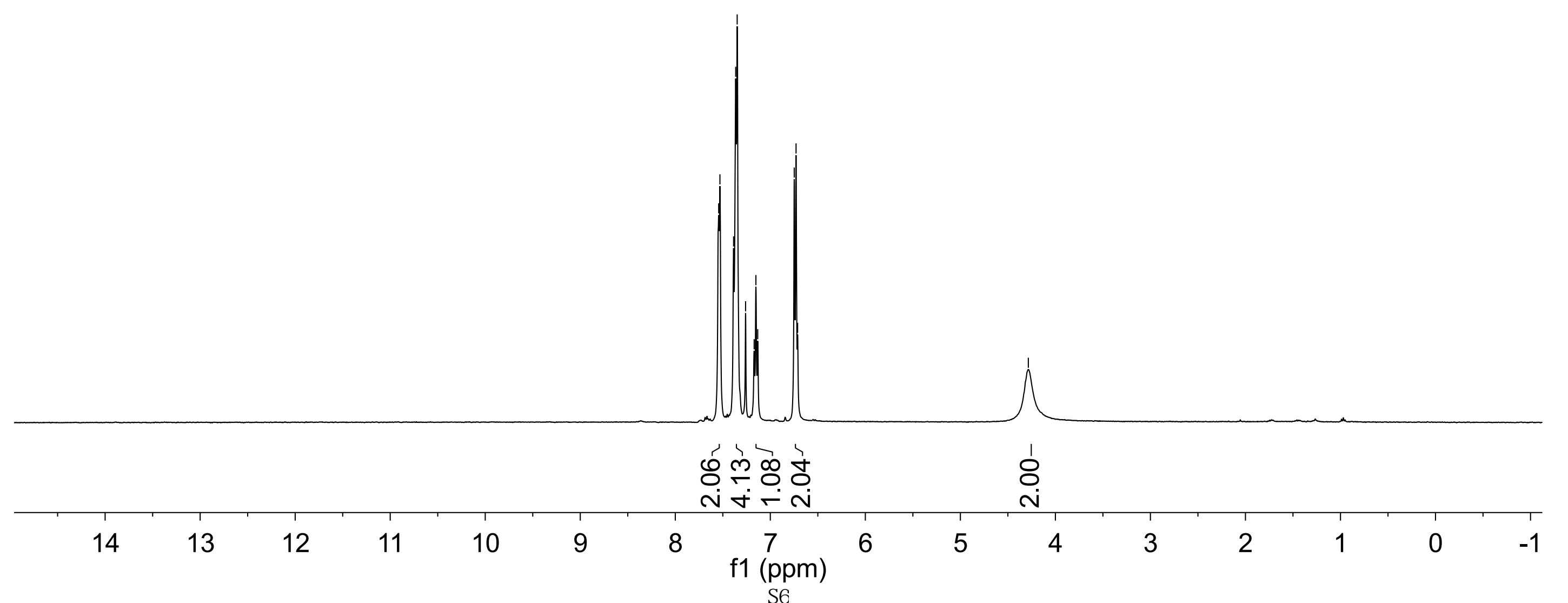




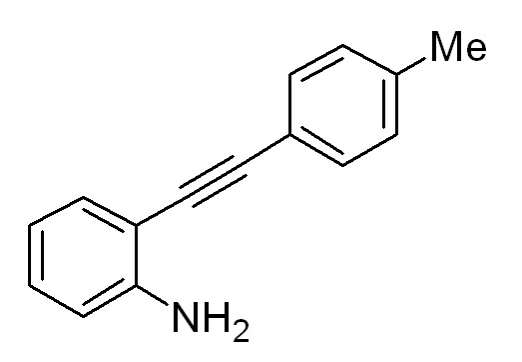

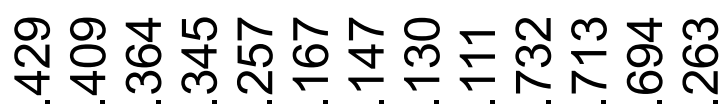

N

1b

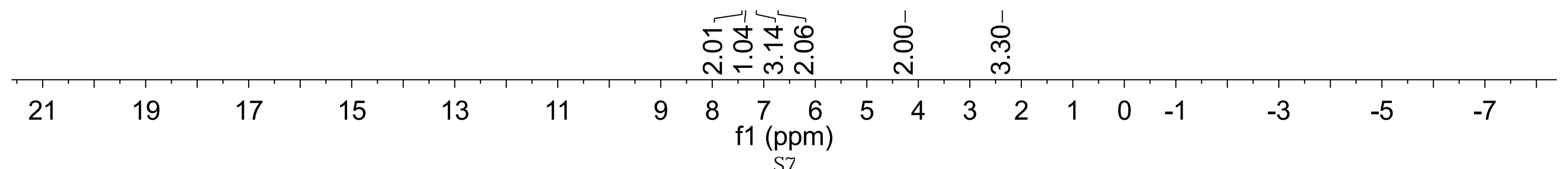




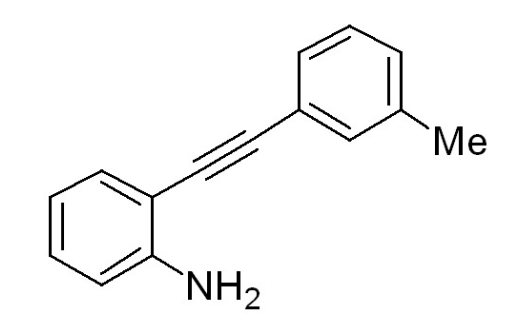

๘ூ

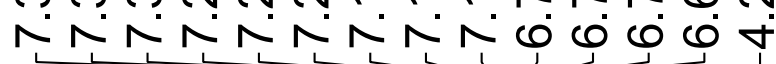

1c

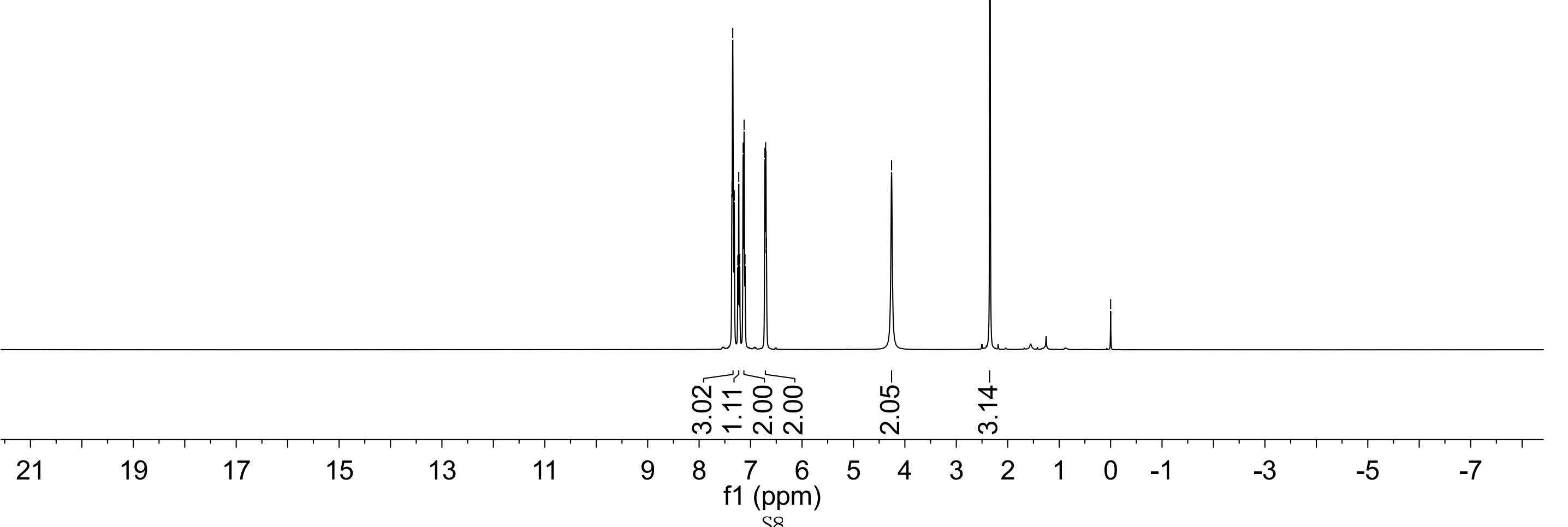




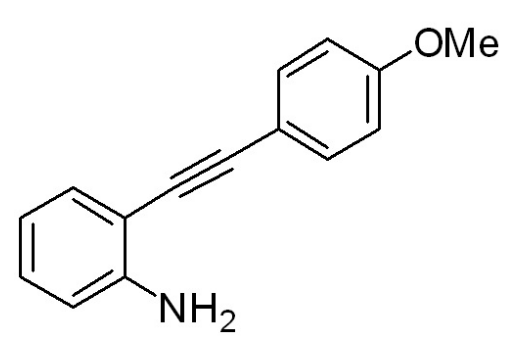

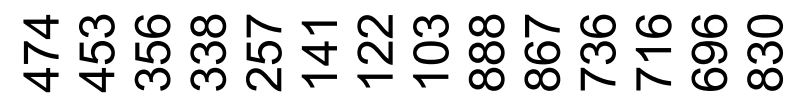

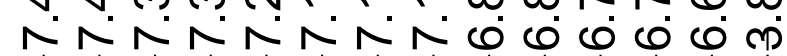

$1 d$ 


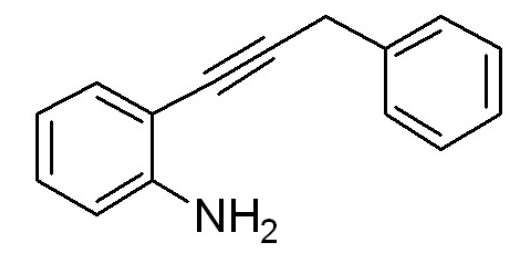

$1 \mathrm{e}$

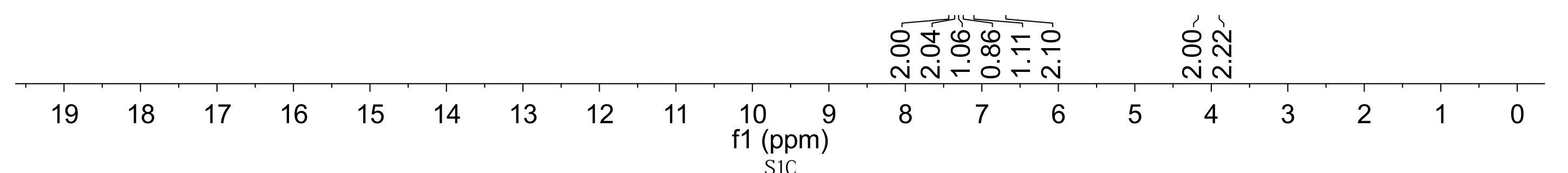




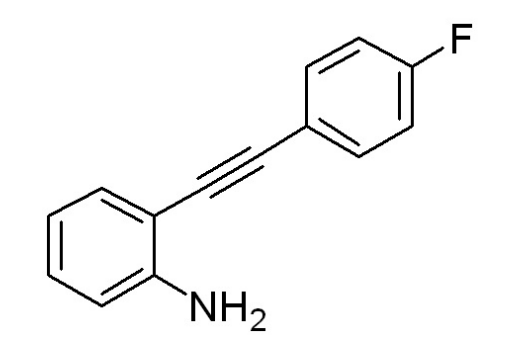

бே

N $N$ N

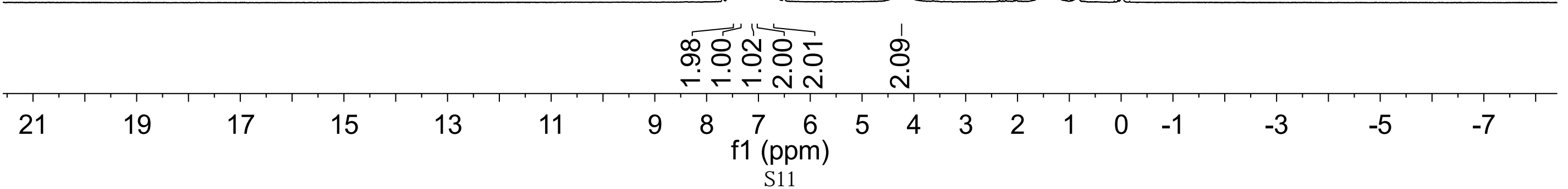




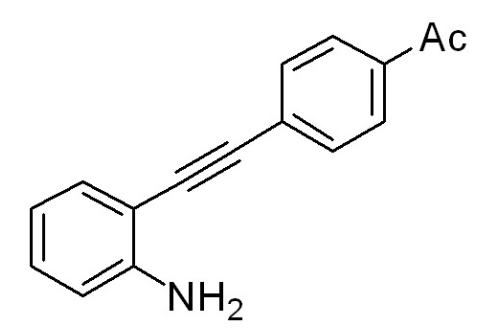

の

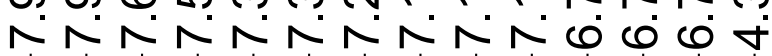

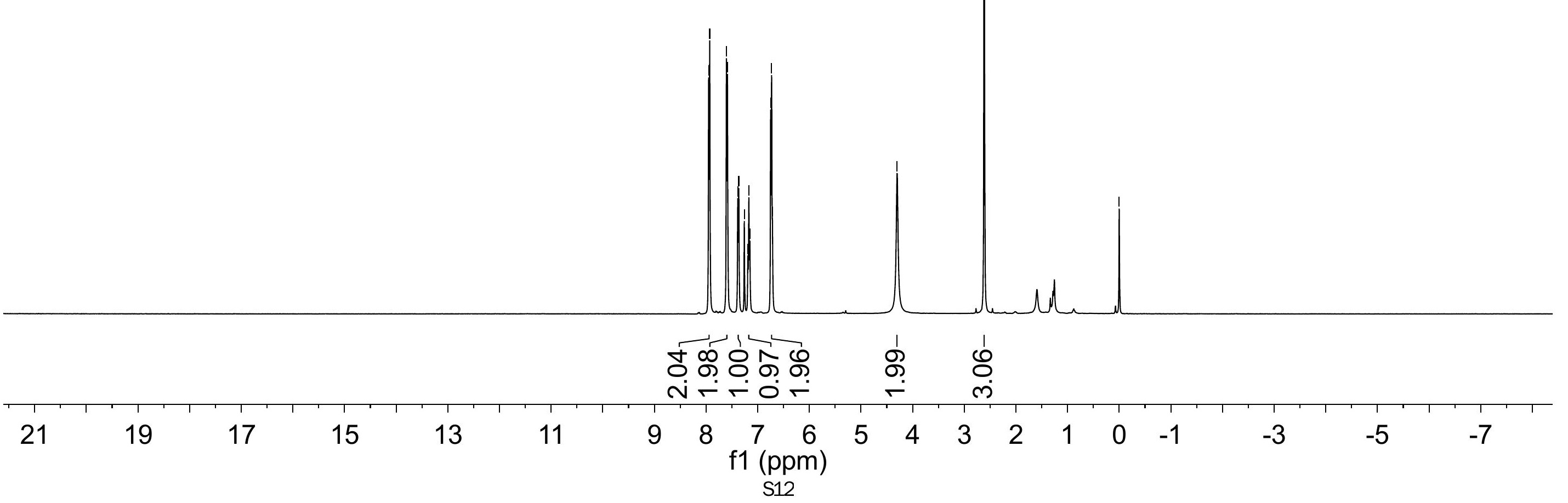




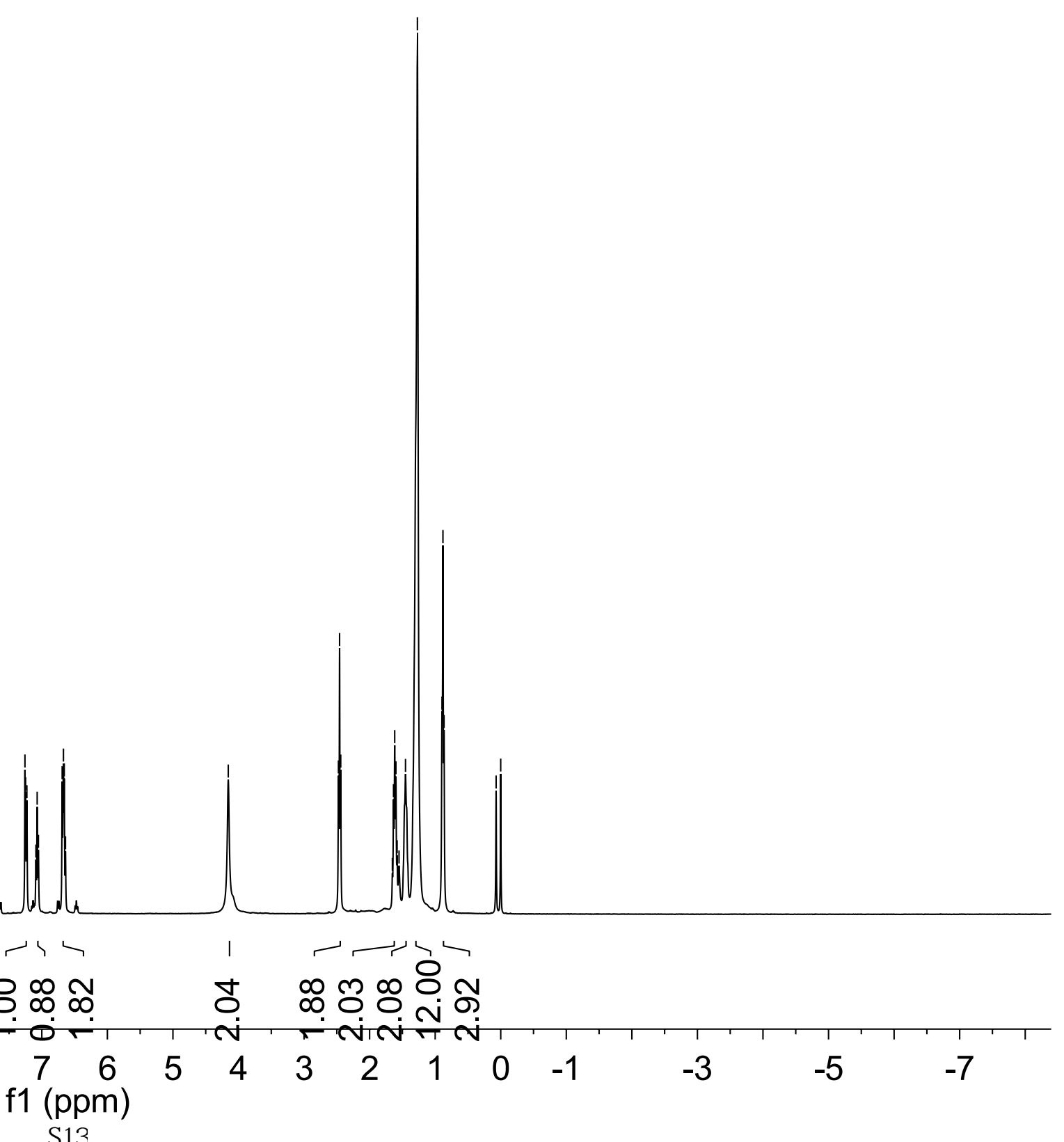




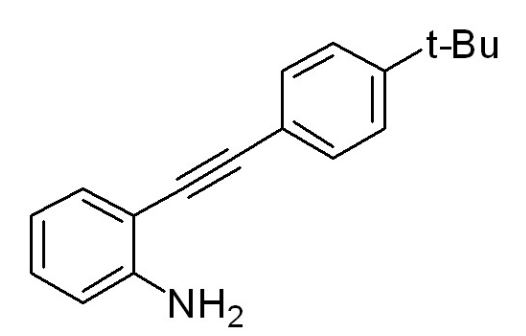

$1 \mathrm{i}$

テ

寸

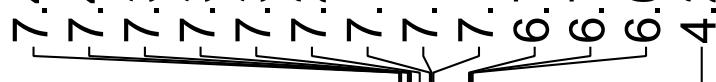

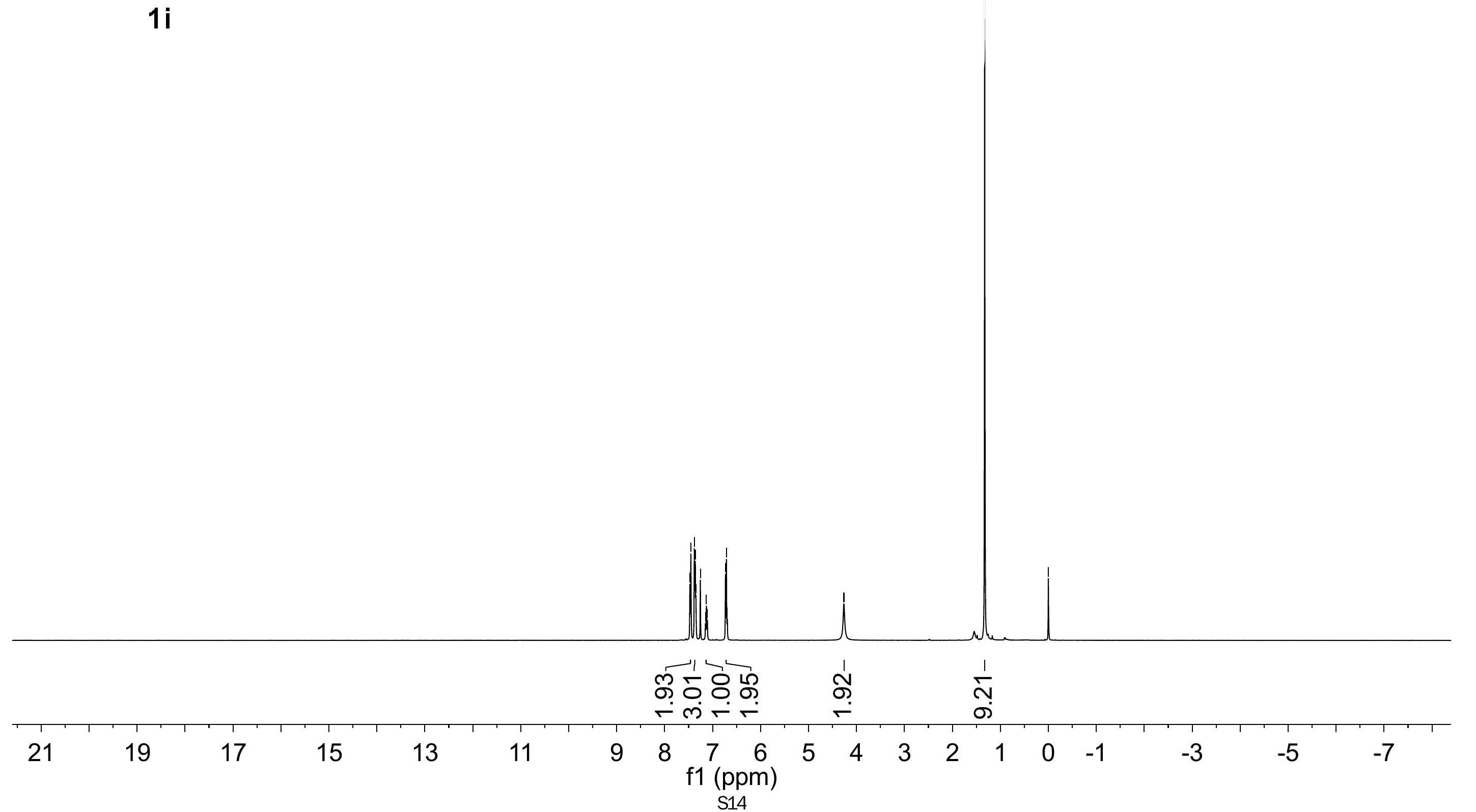




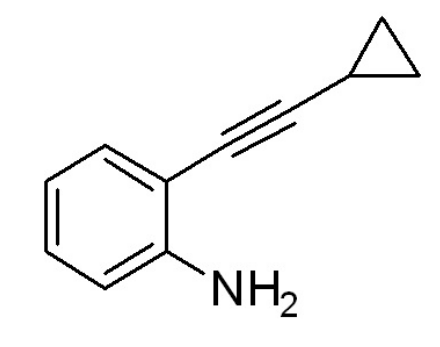

N

1j

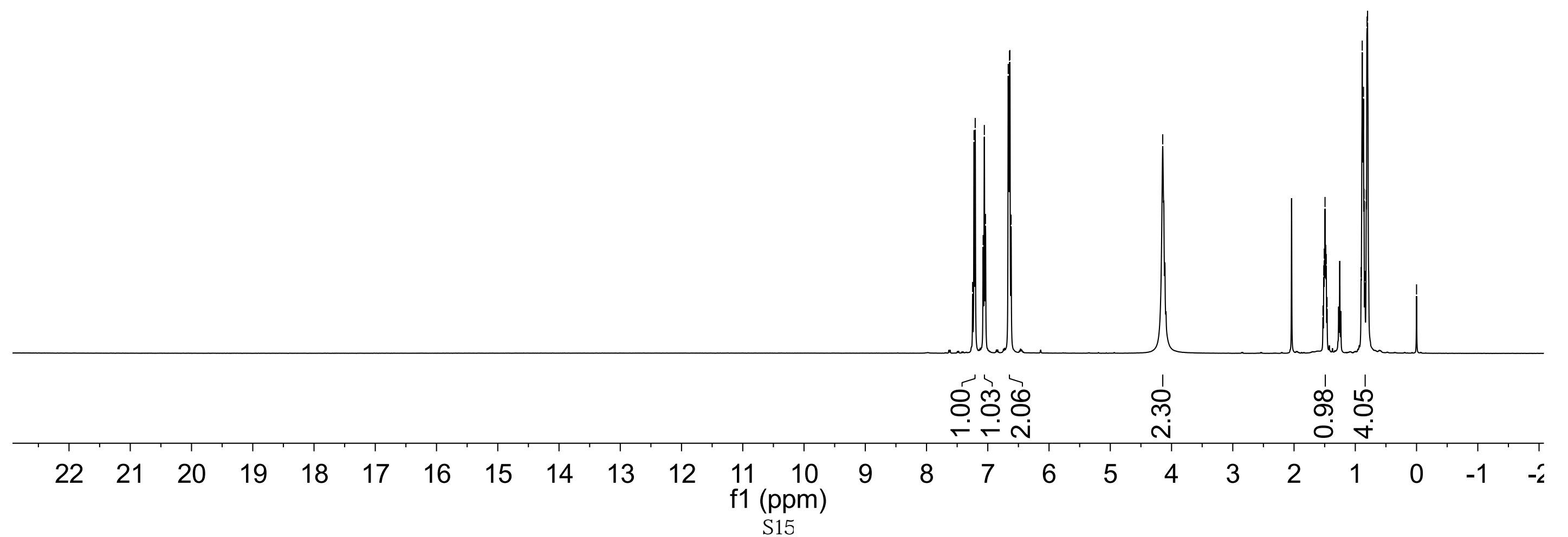




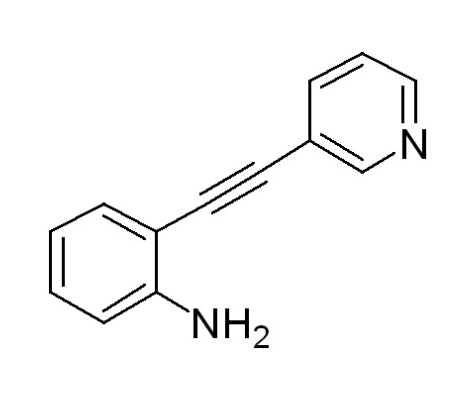

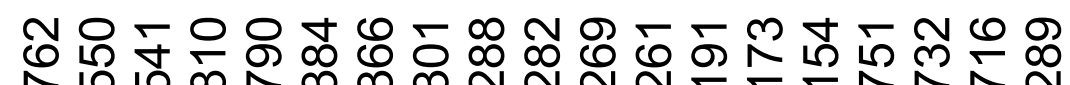
地

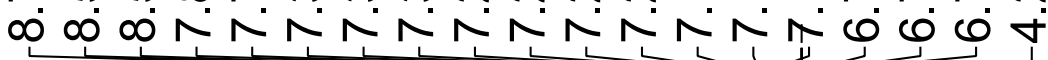

$1 k$

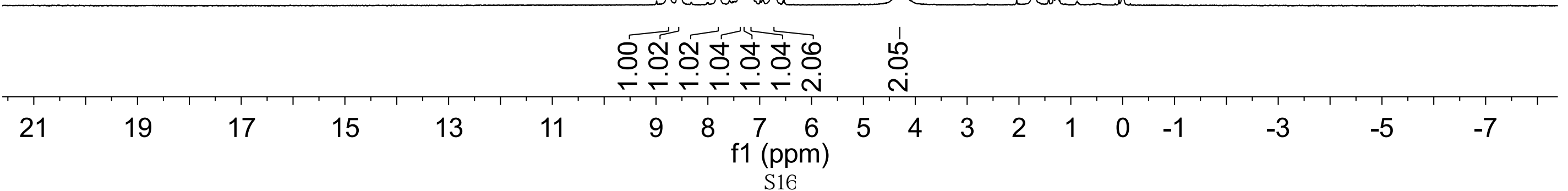




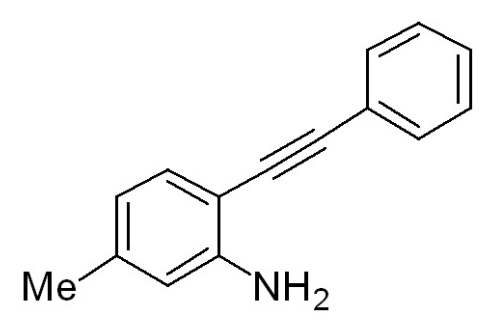

11

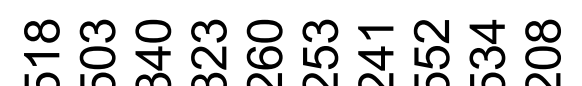
NN№̂

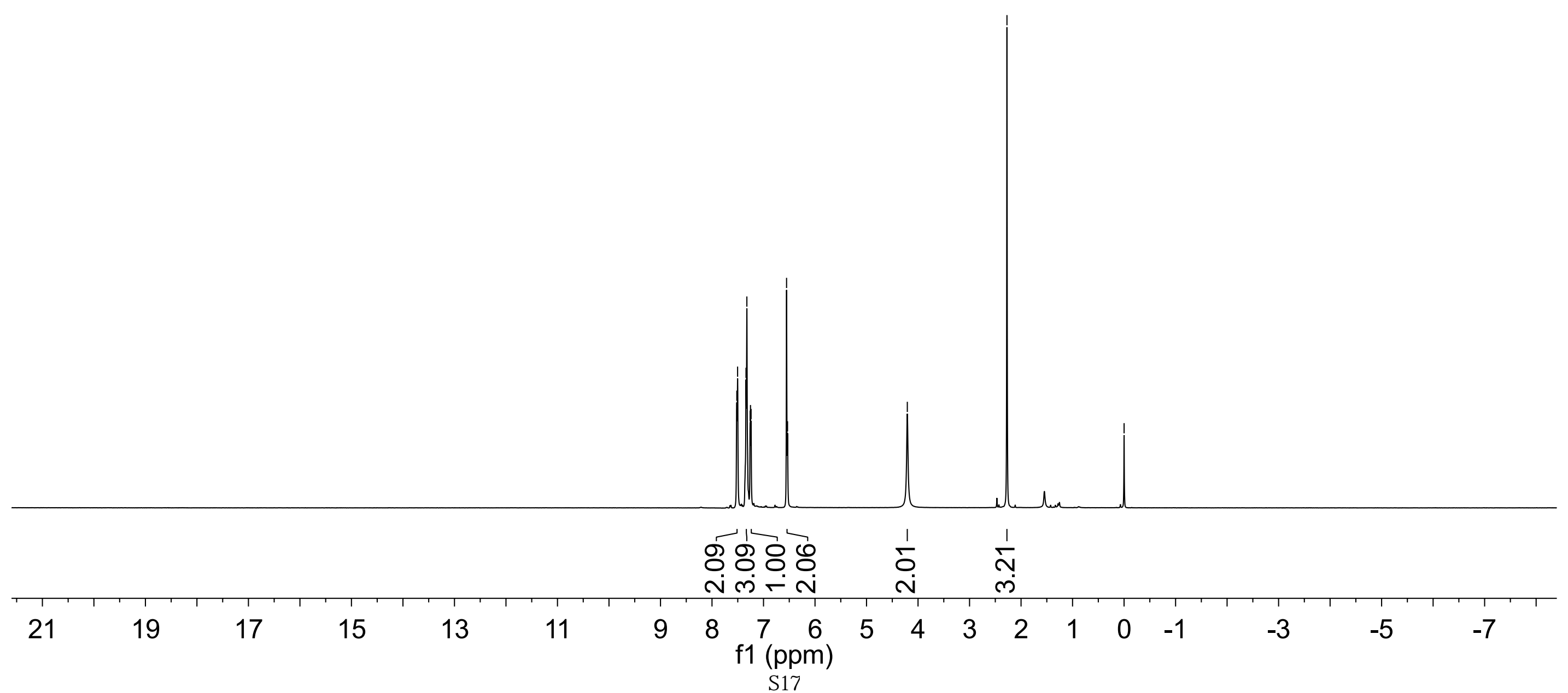




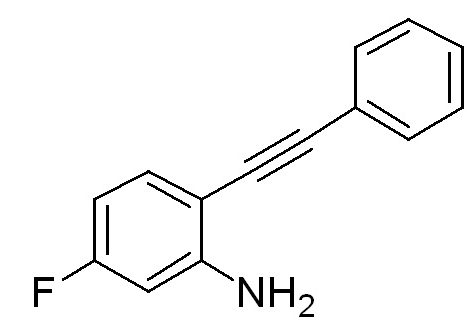

$1 \mathrm{~m}$

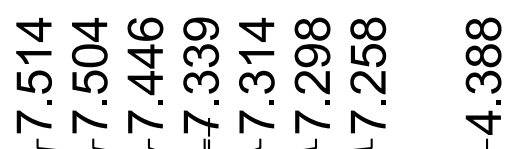

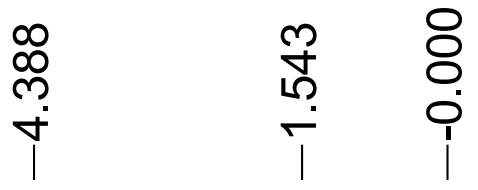

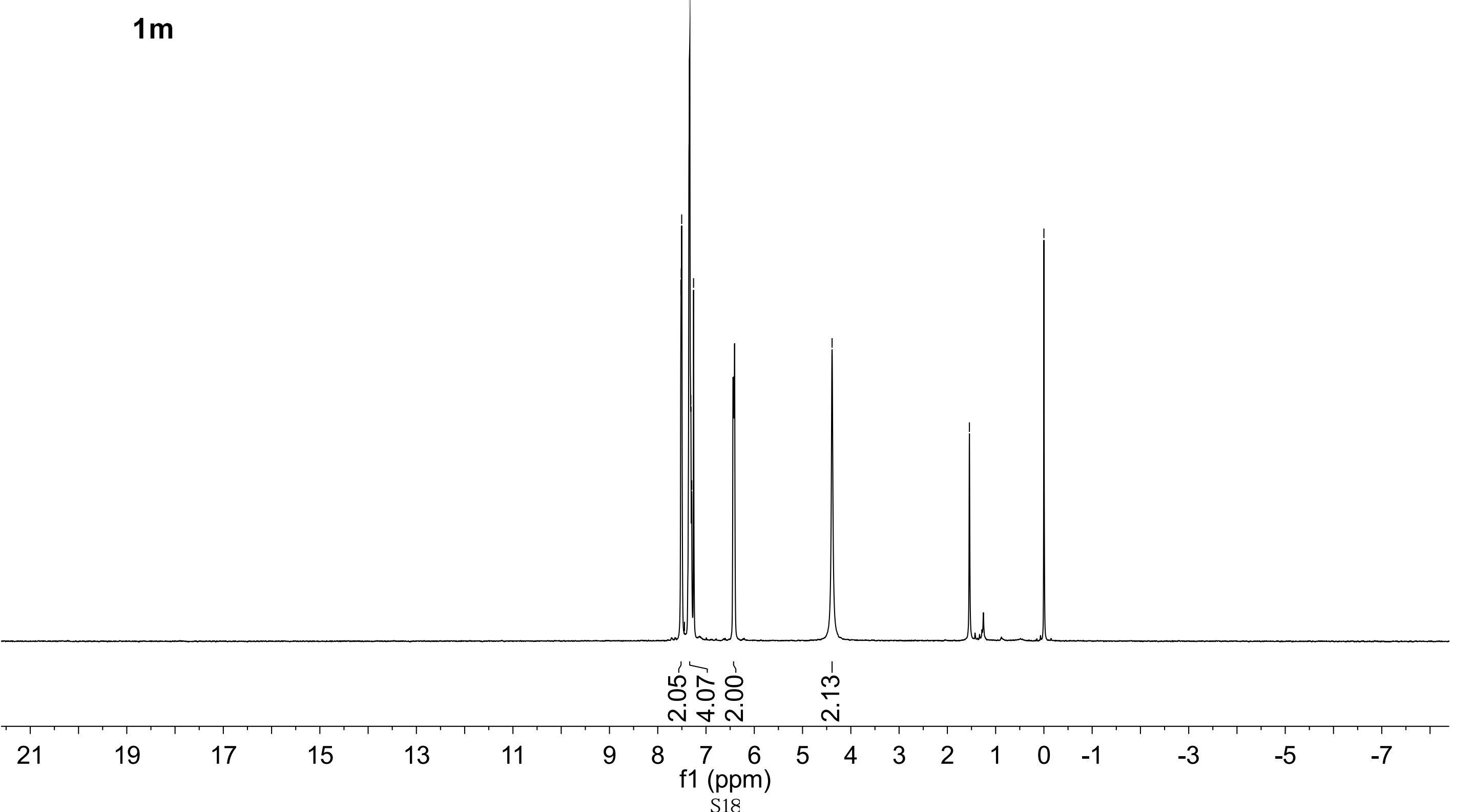




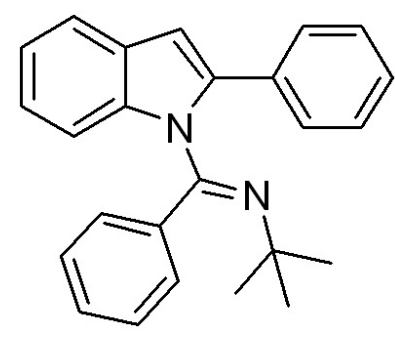

$3 a$

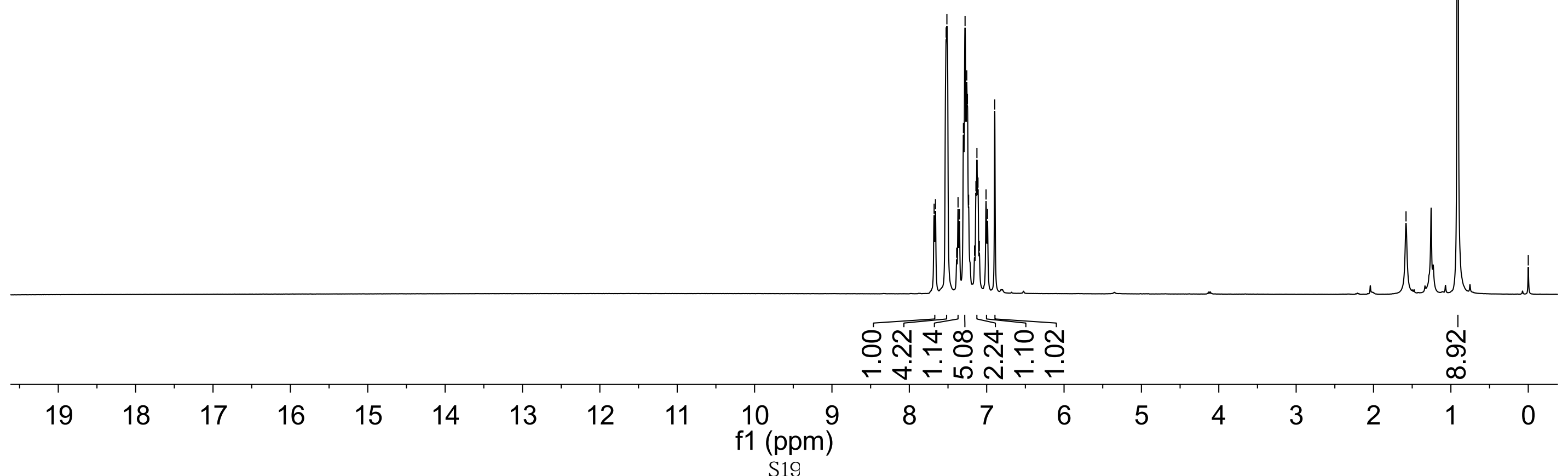




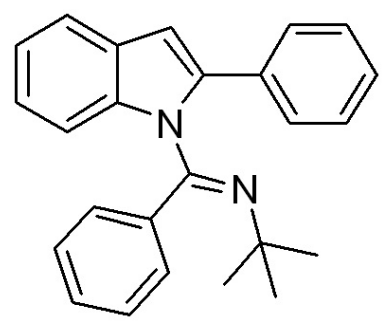

$3 a$

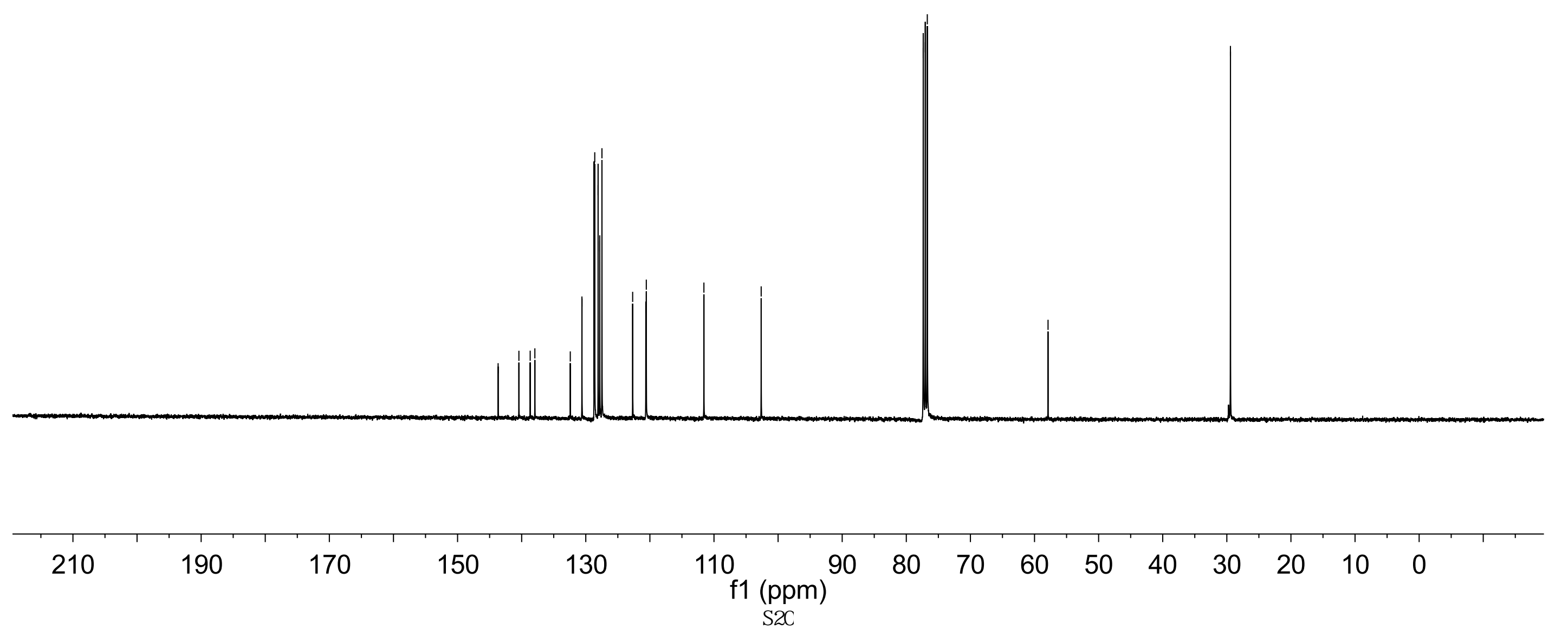




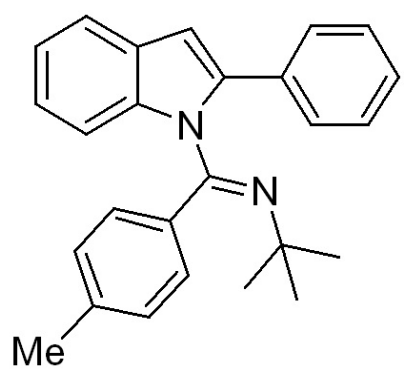

$3 b$

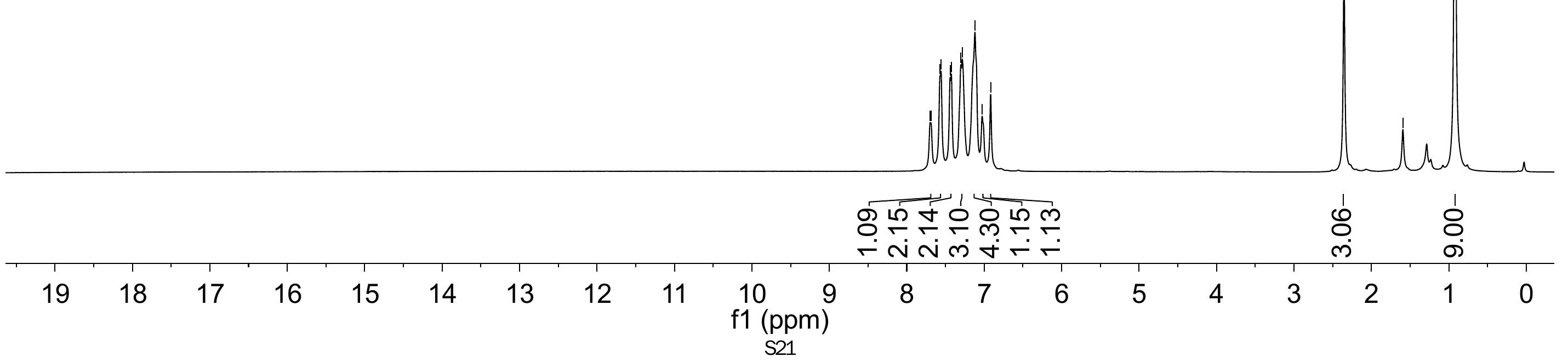


$3 b$

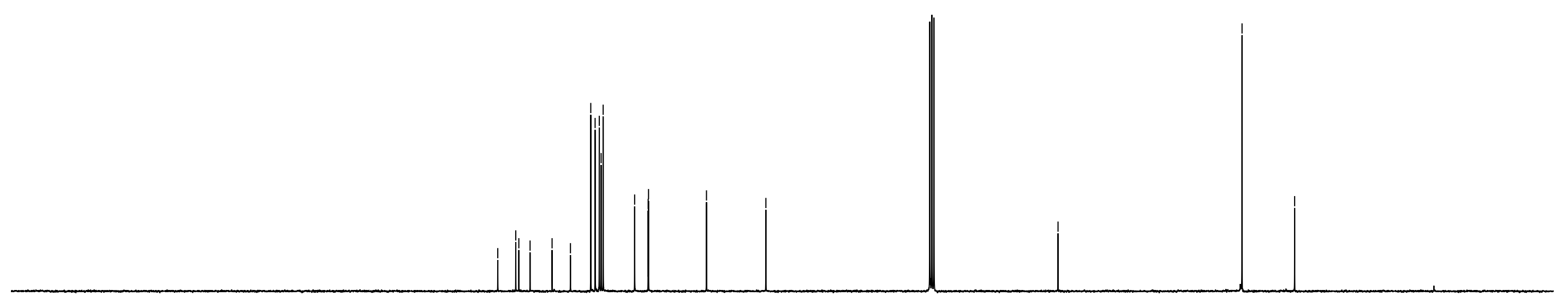

\begin{tabular}{llllllllllllllllll}
\hline 210 & 190 & 170 & 150 & 130 & $\begin{array}{c}110 \\
\mathrm{f} 1(\mathrm{ppm})\end{array}$ & 90 & 80 & 70 & 60 & 50 & 40 & 30 & 20 & 10 & 0 & 1
\end{tabular}




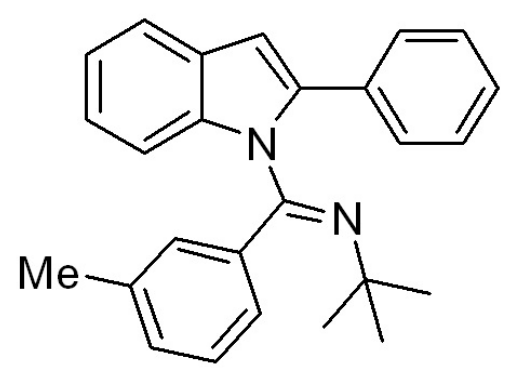

$3 c$

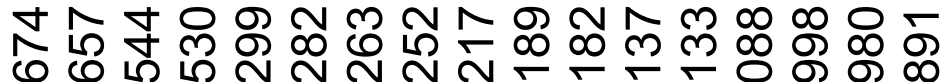

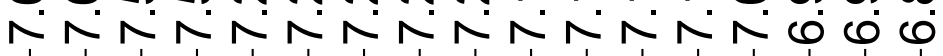

ㅁํㅇ

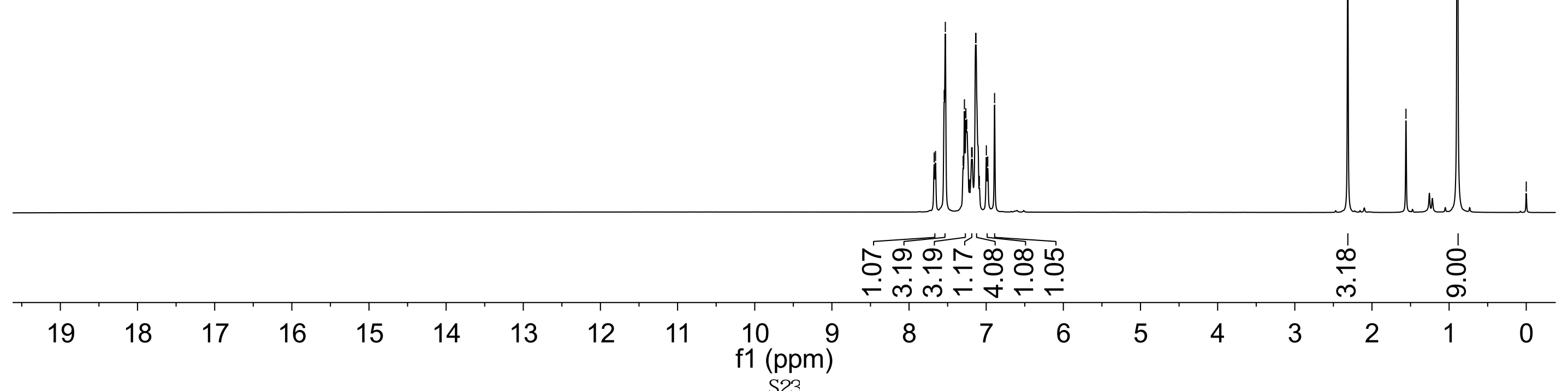


$3 c$

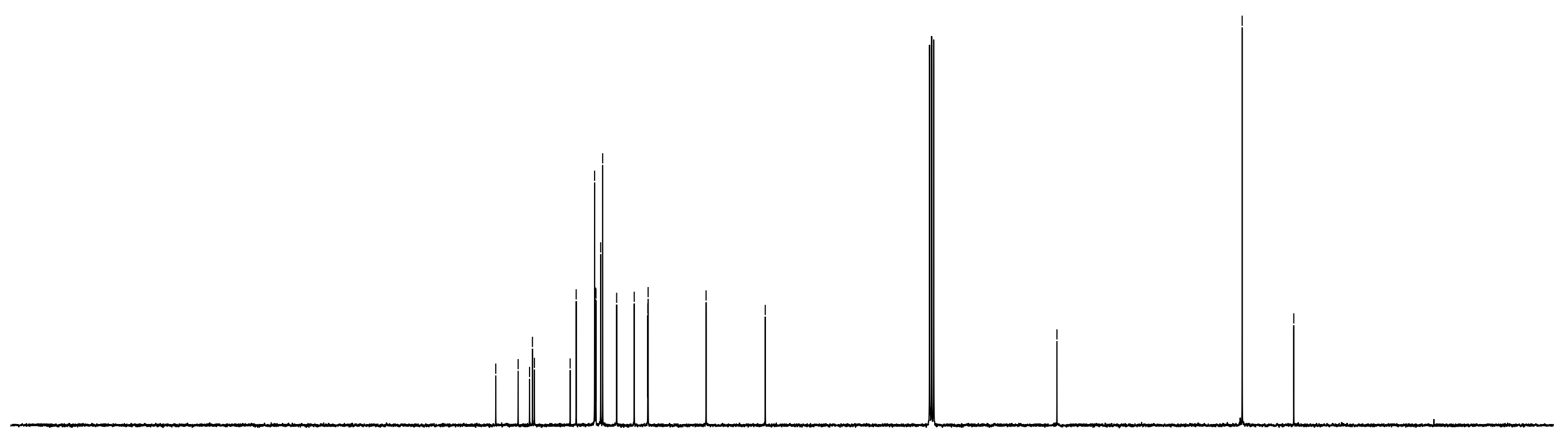

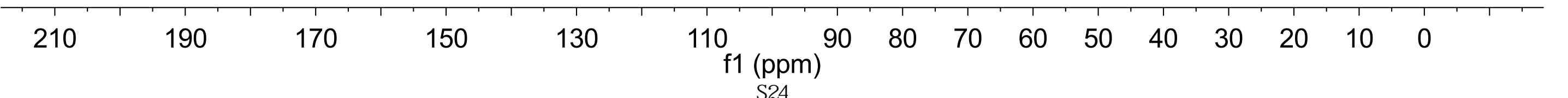



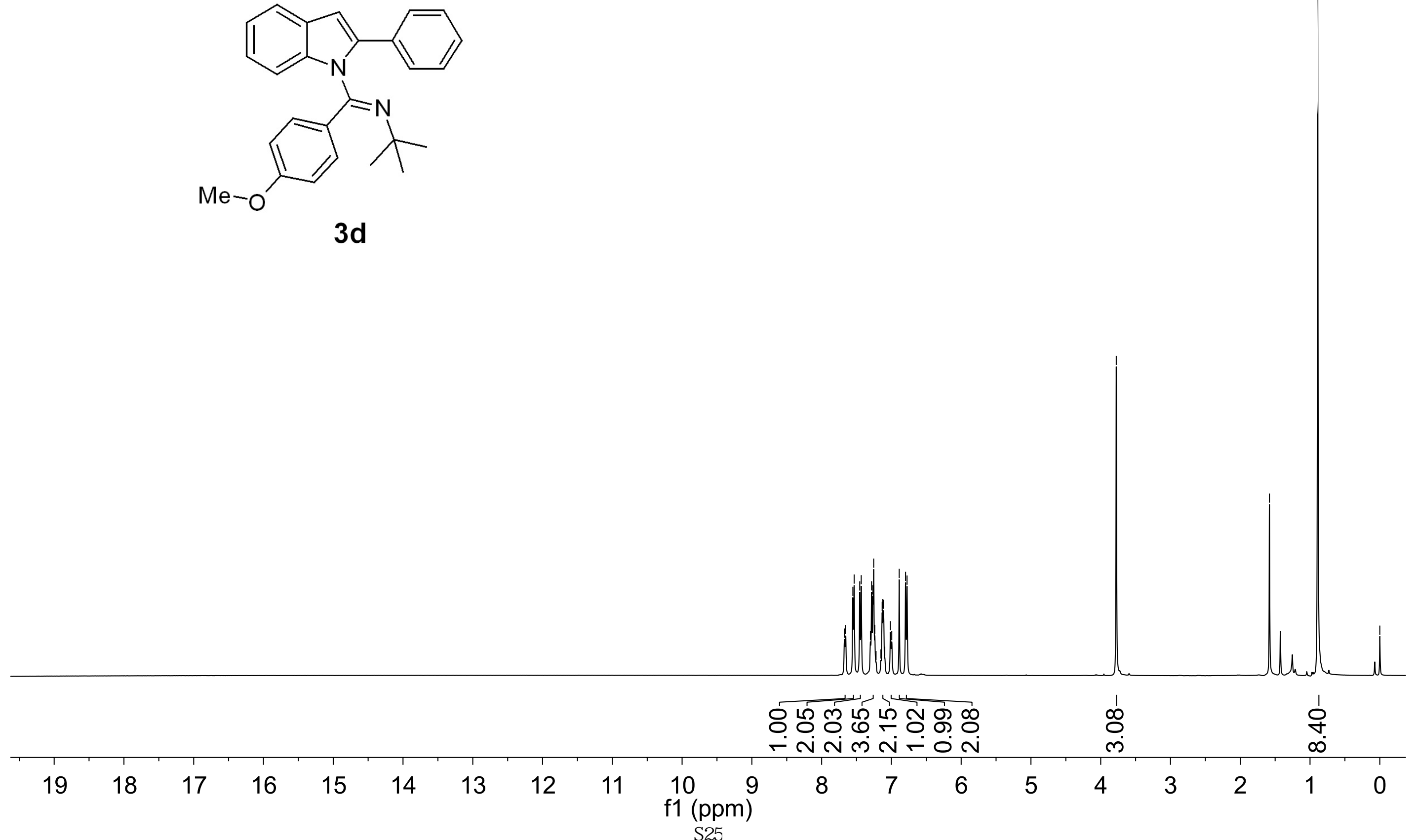


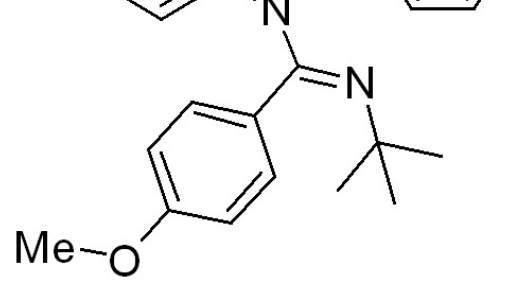

?

\section{$3 d$}

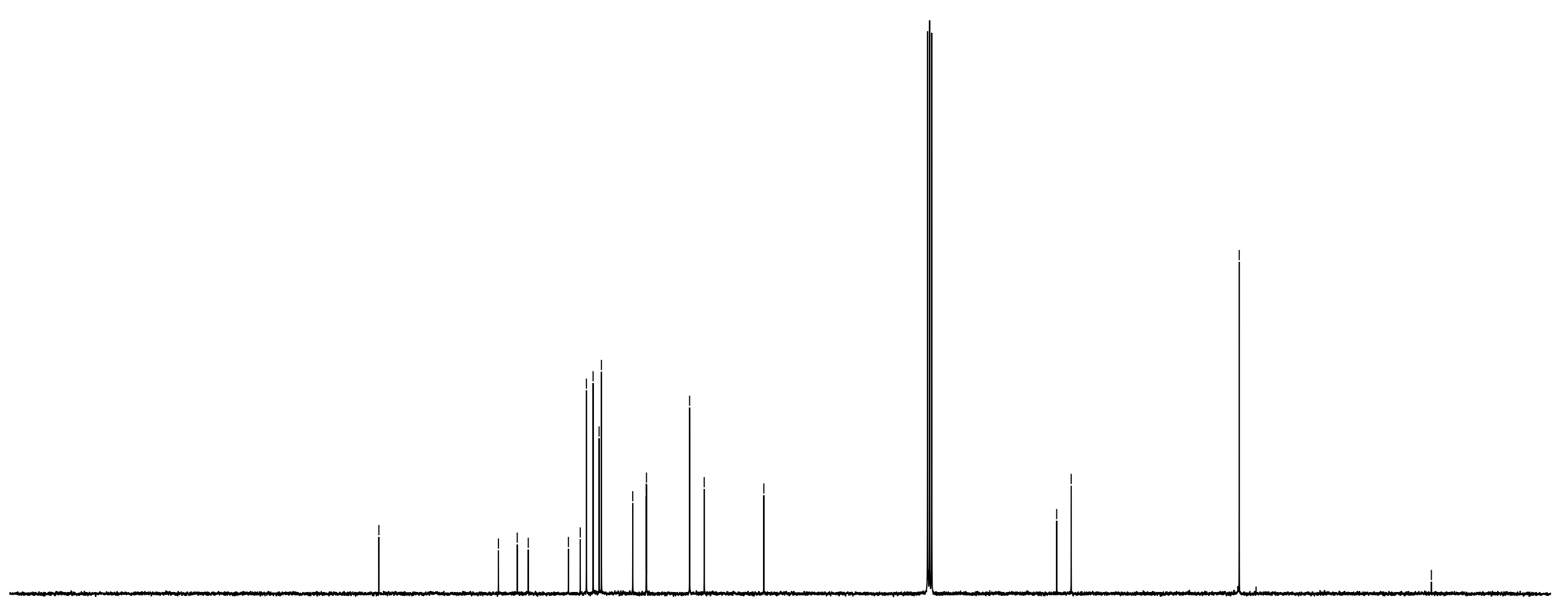

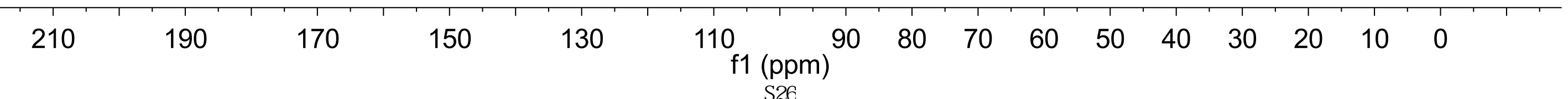



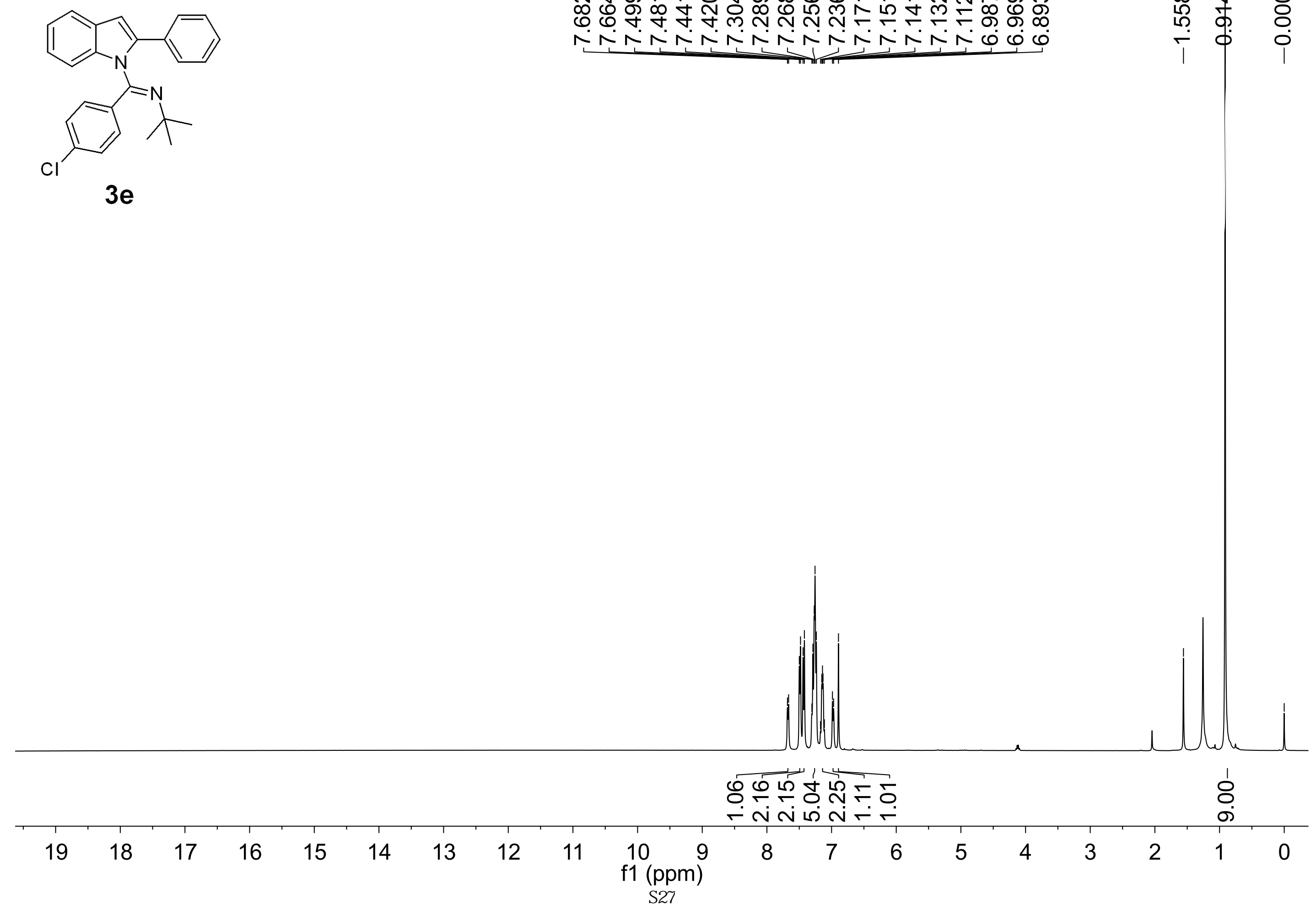


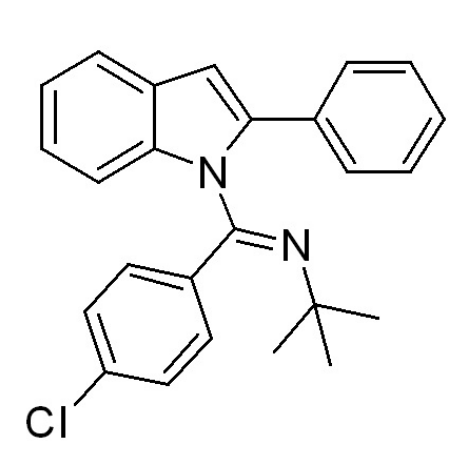

\section{$3 e$}

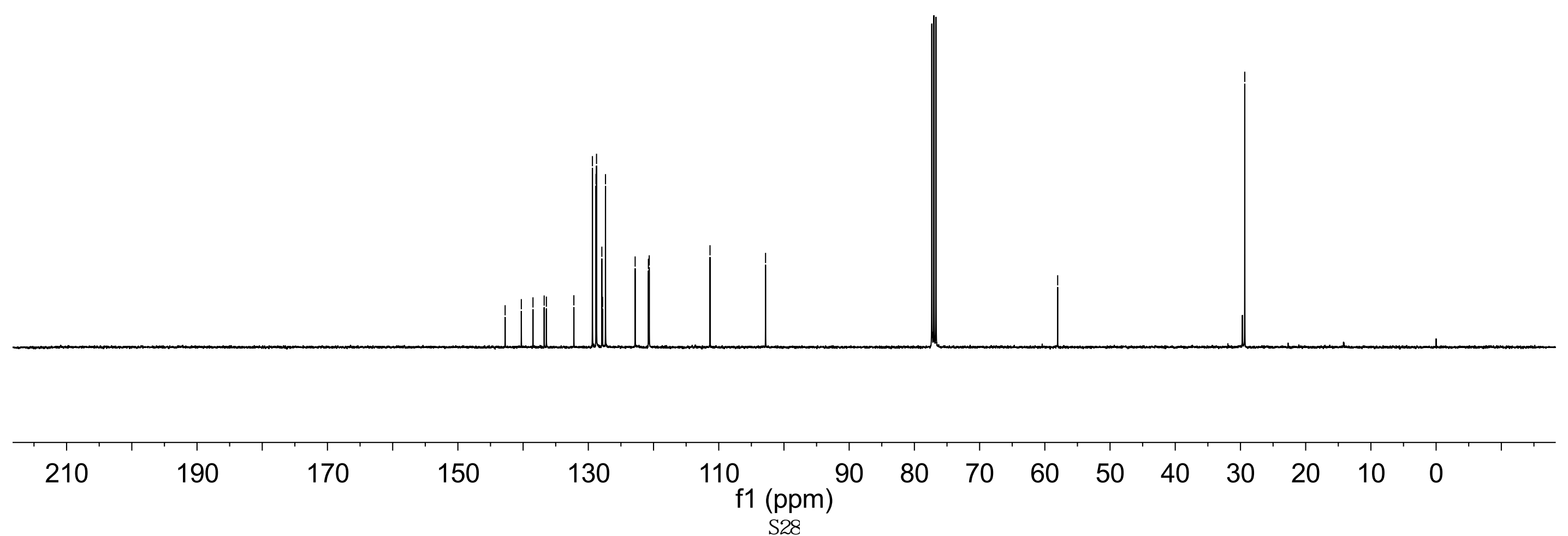




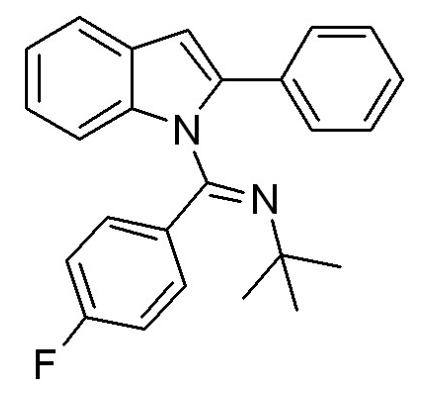

$3 f$

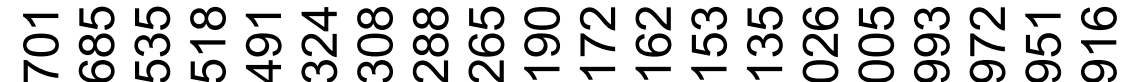

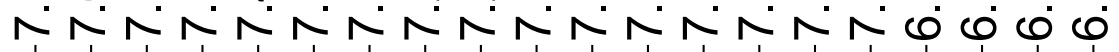

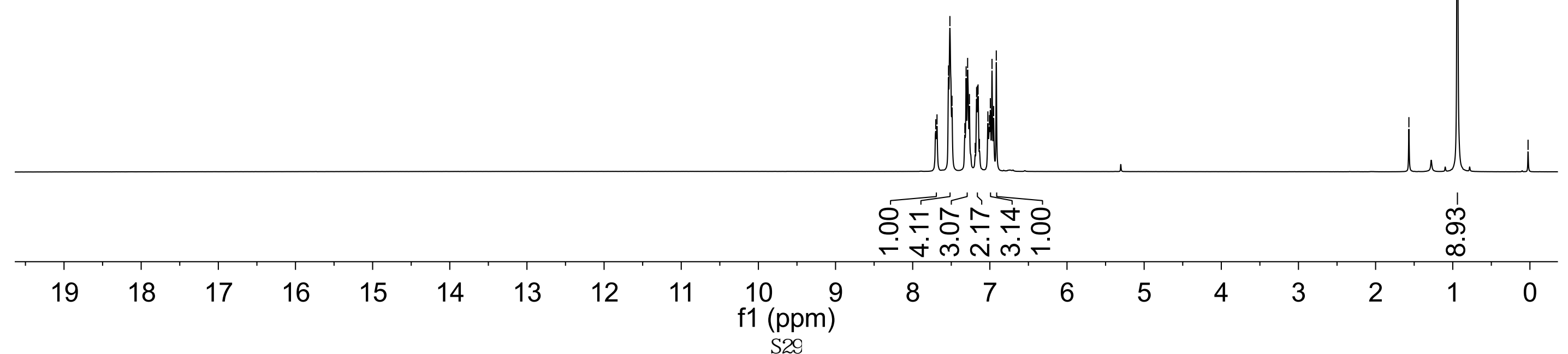


$3 f$

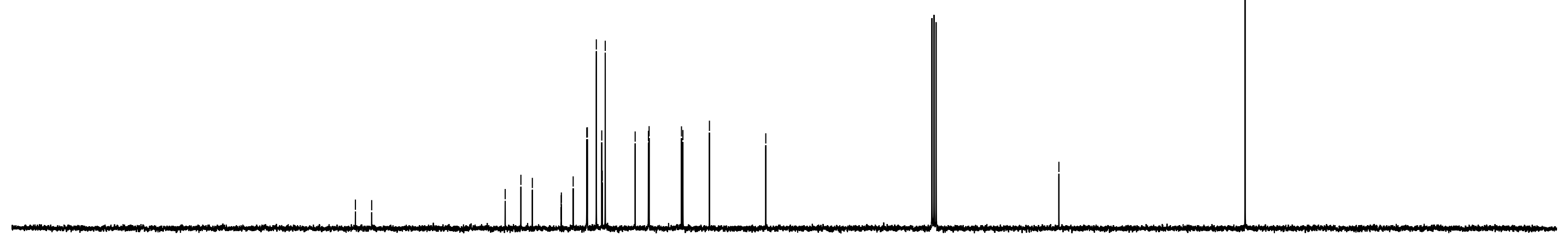

\begin{tabular}{|c|c|c|c|c|c|c|c|c|c|c|c|c|c|c|c|}
\hline 210 & 190 & 170 & 150 & 130 & ${ }_{\mathrm{f} 1}^{110}$ & & 80 & 70 & 60 & 50 & 40 & 30 & 20 & 10 & 0 \\
\hline
\end{tabular}




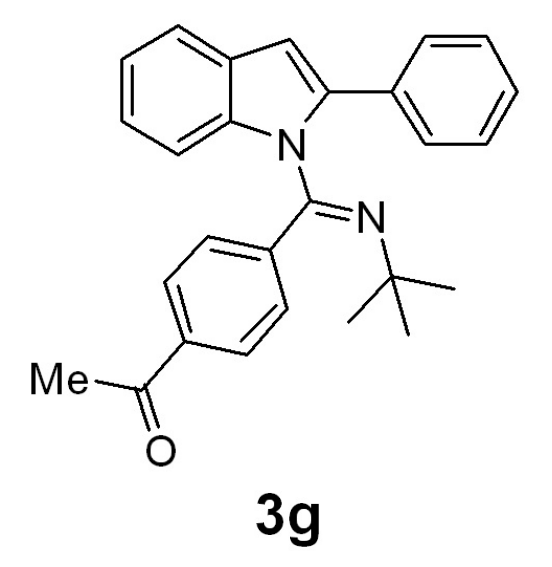

$3 g$

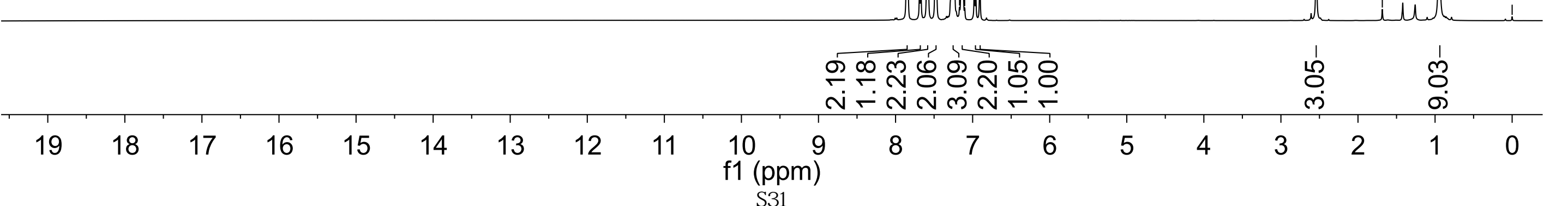



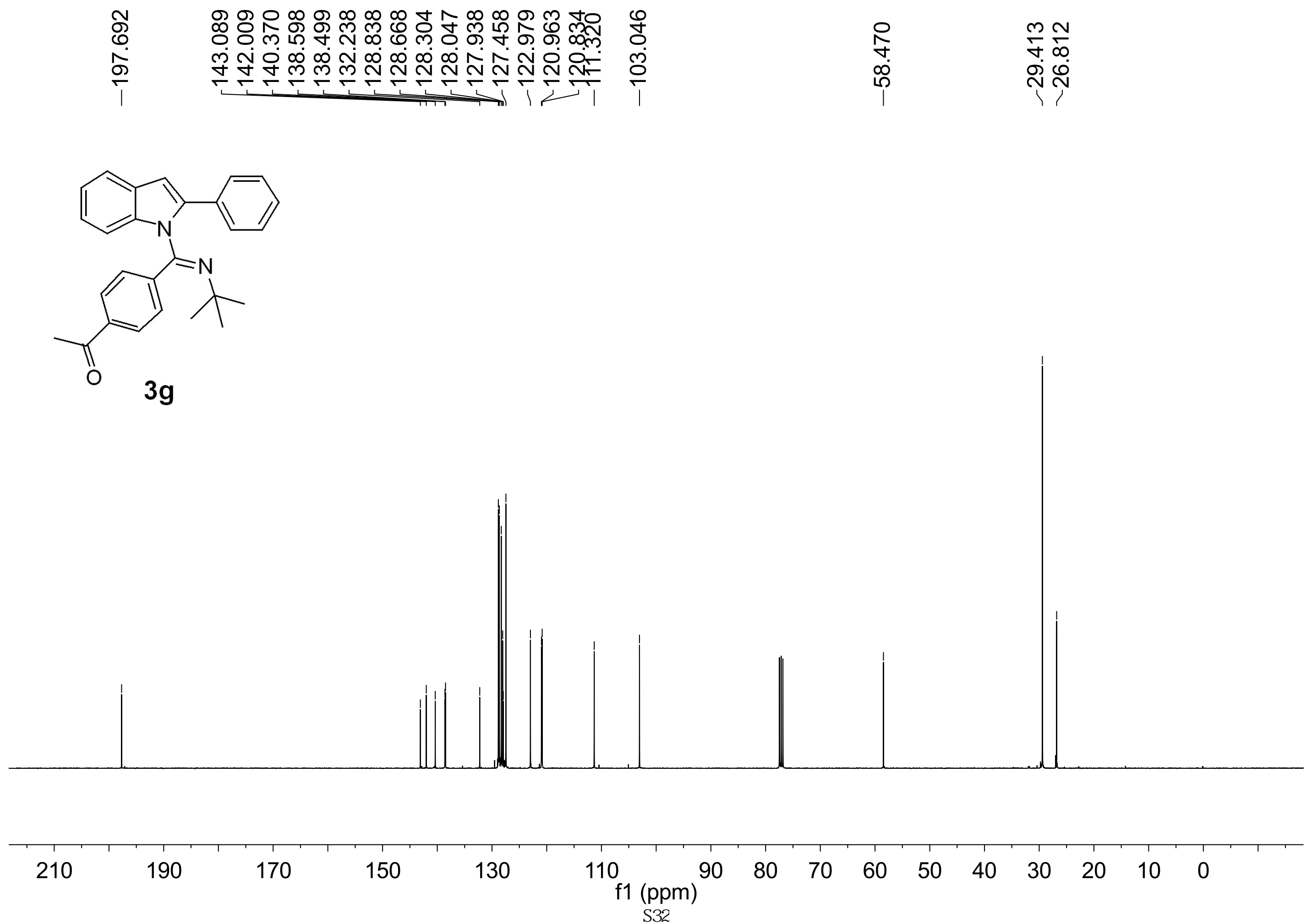


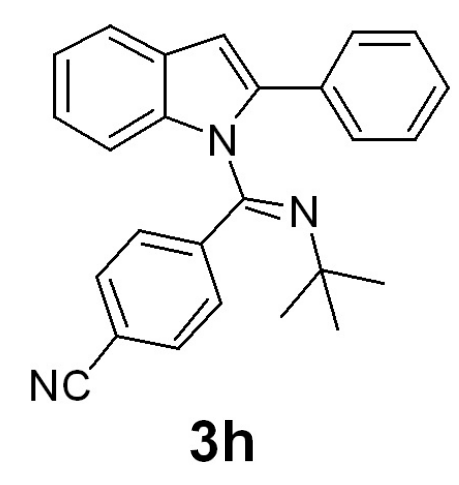

\section{$3 h$}

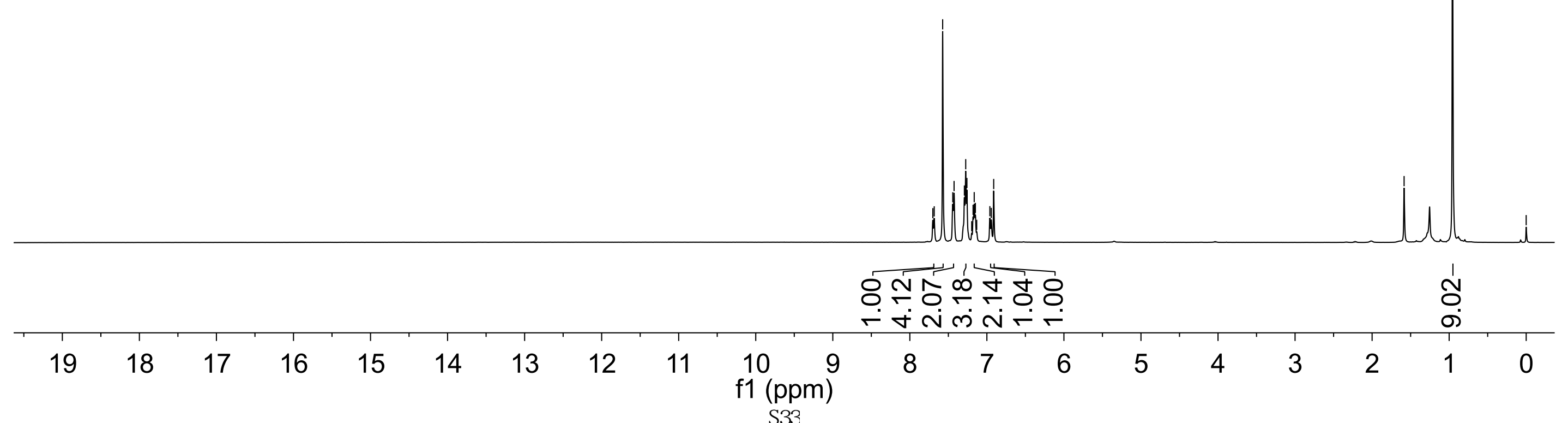


$3 h$

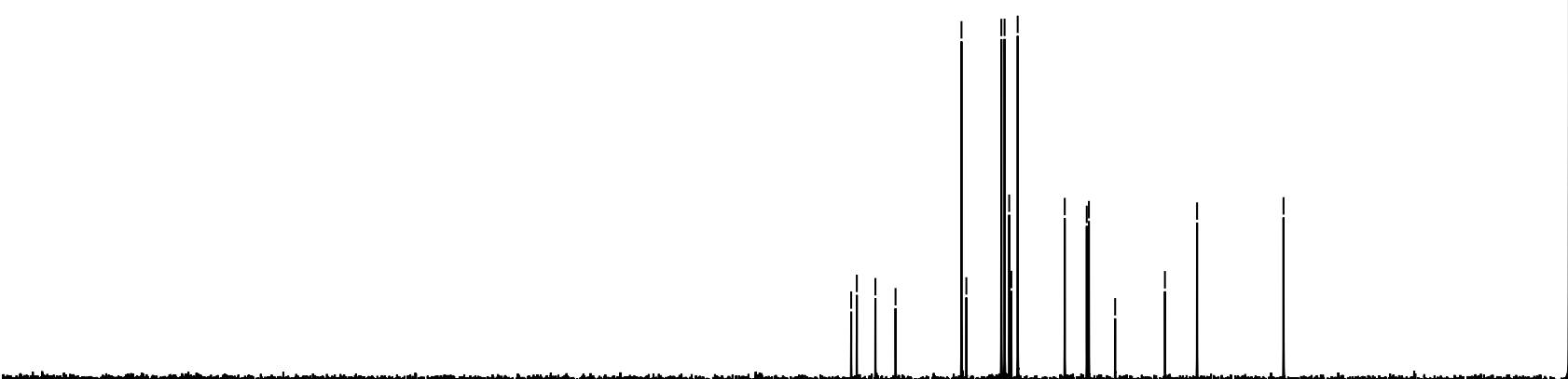

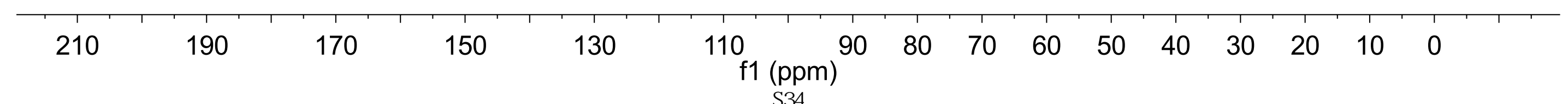



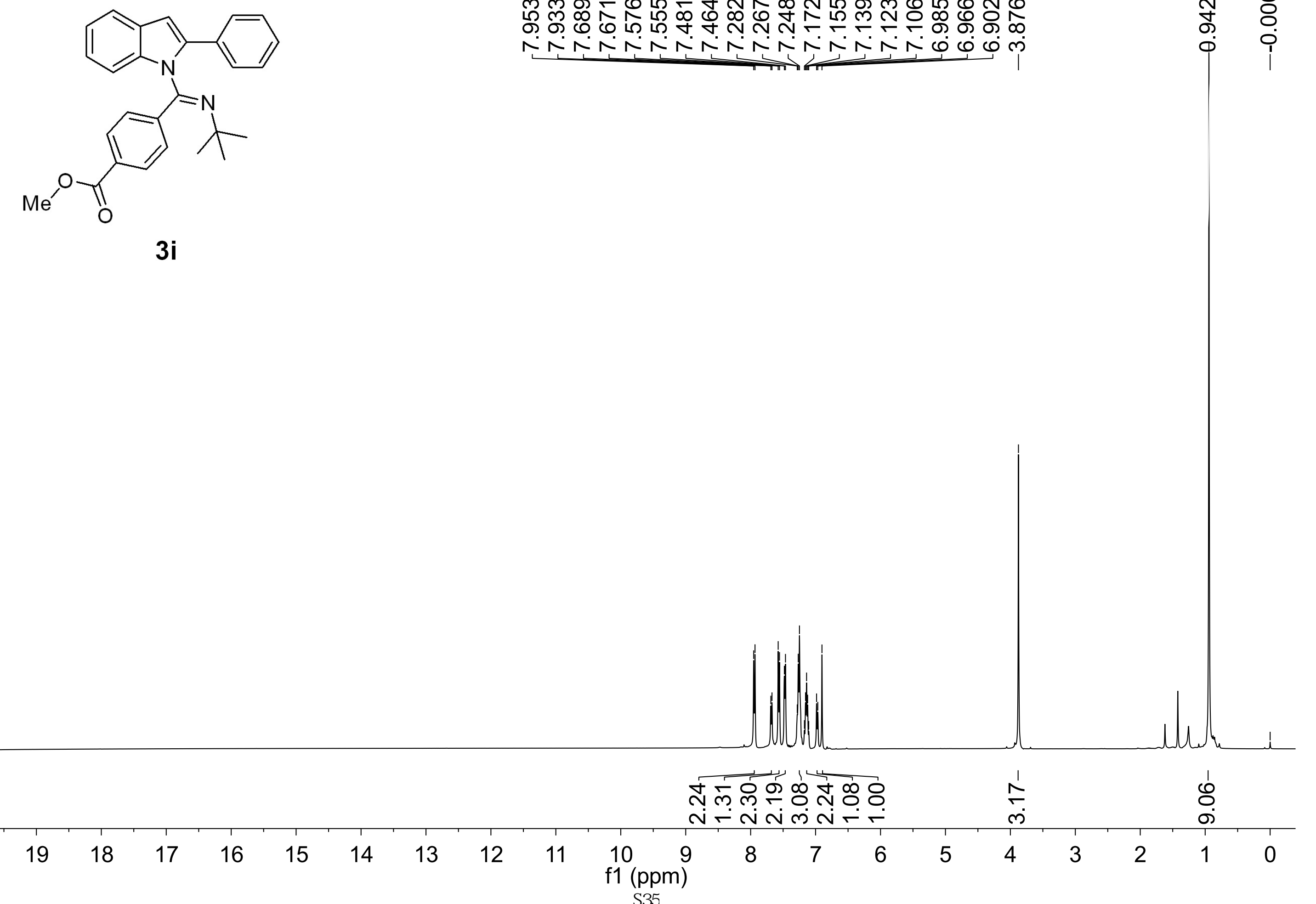


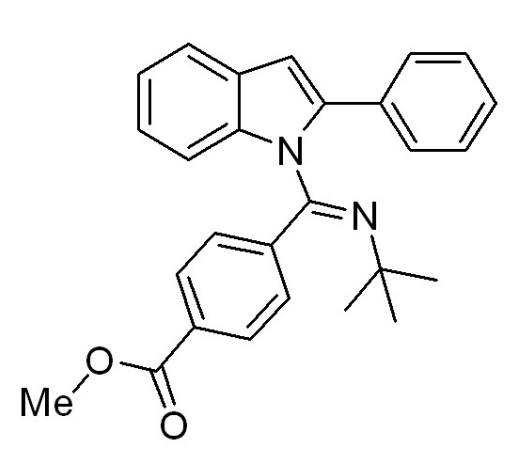

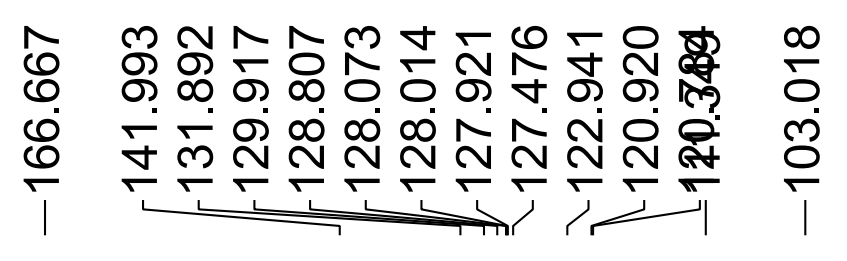

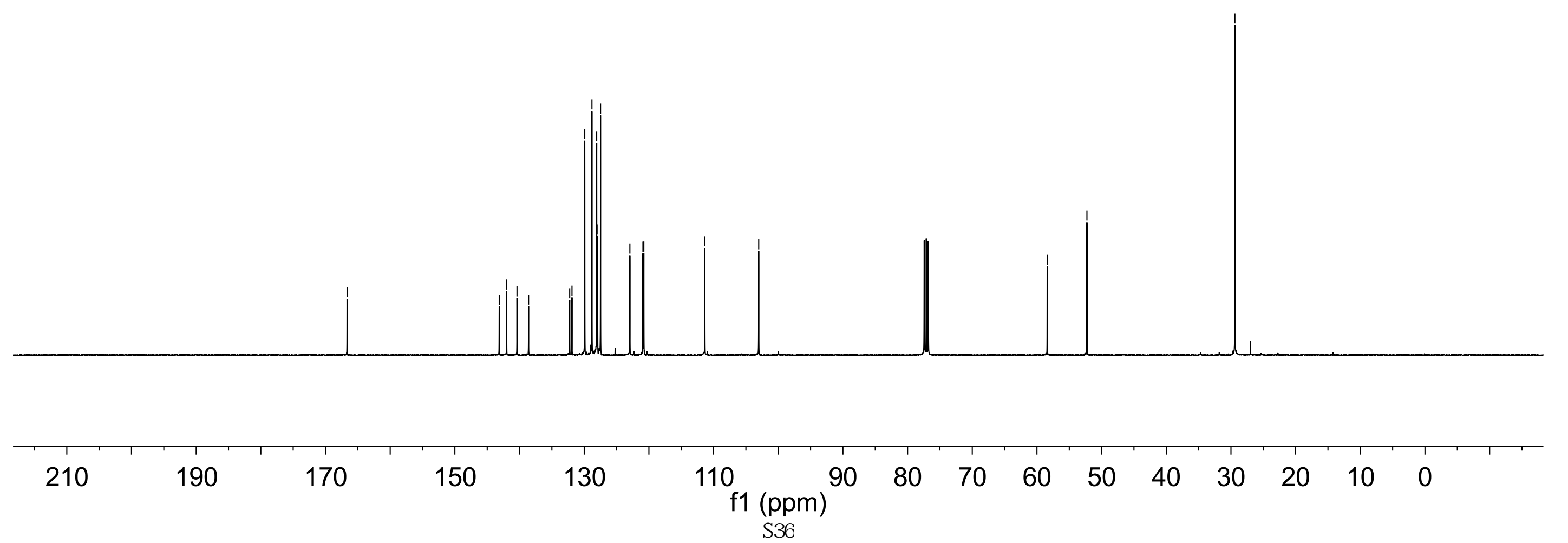




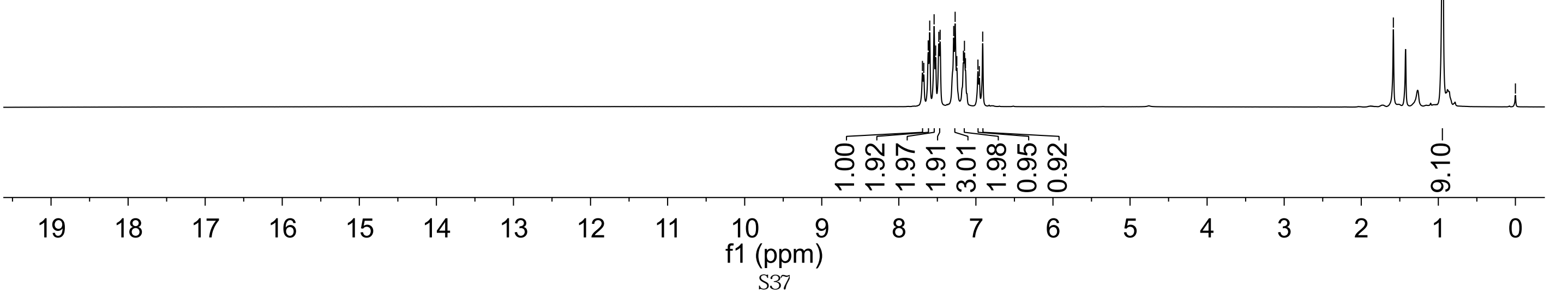




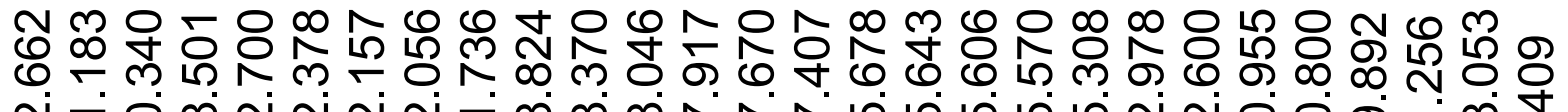

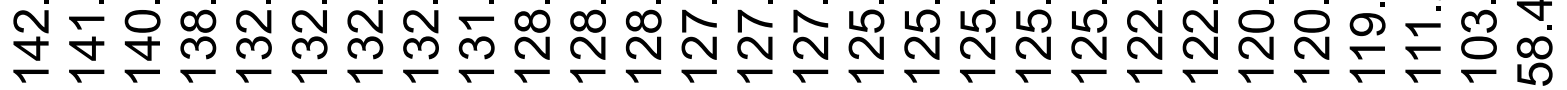

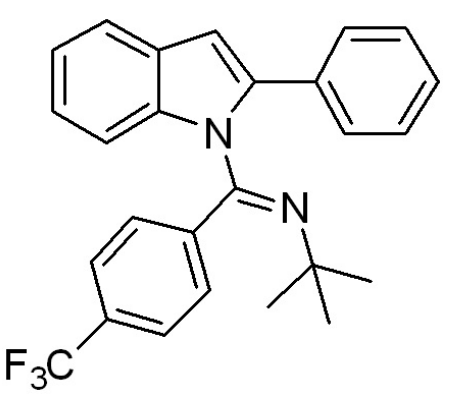

3j

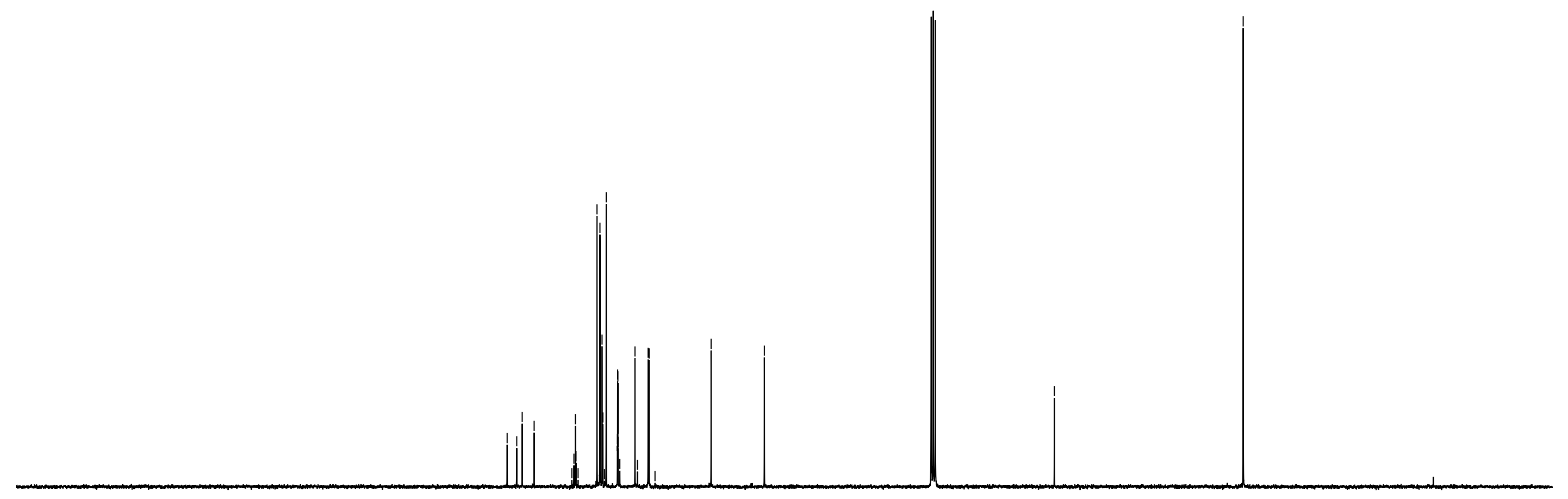

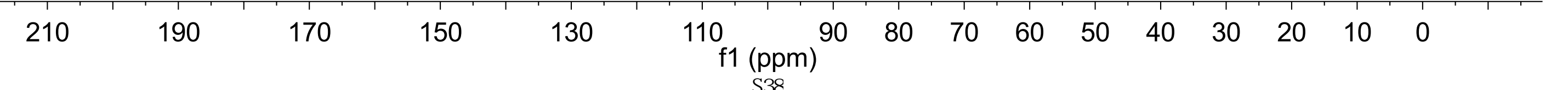




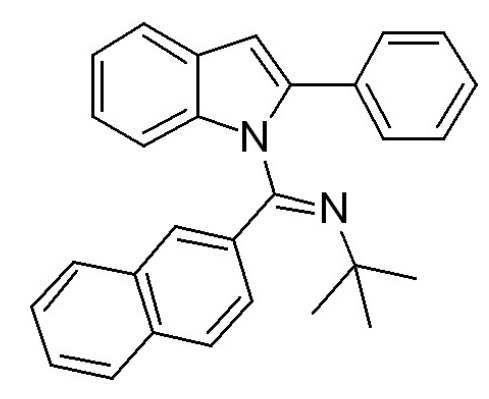

$3 \mathrm{k}$

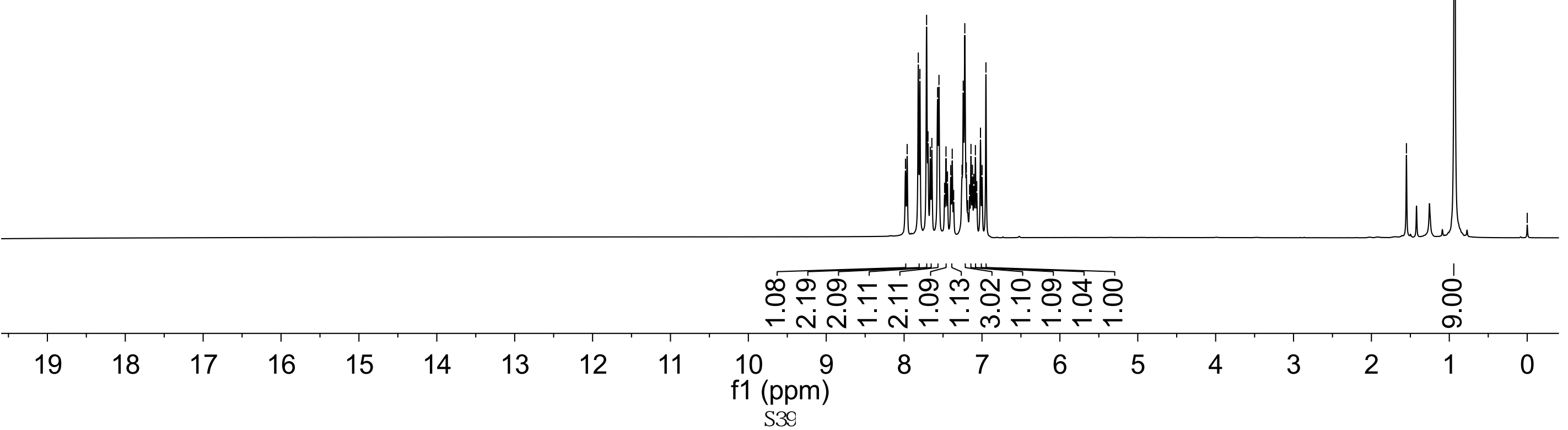




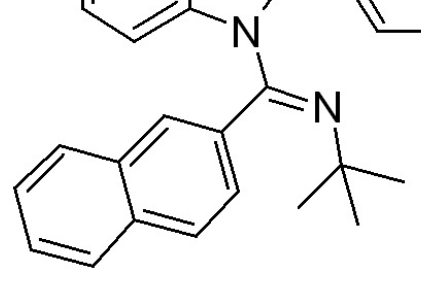

$3 k$

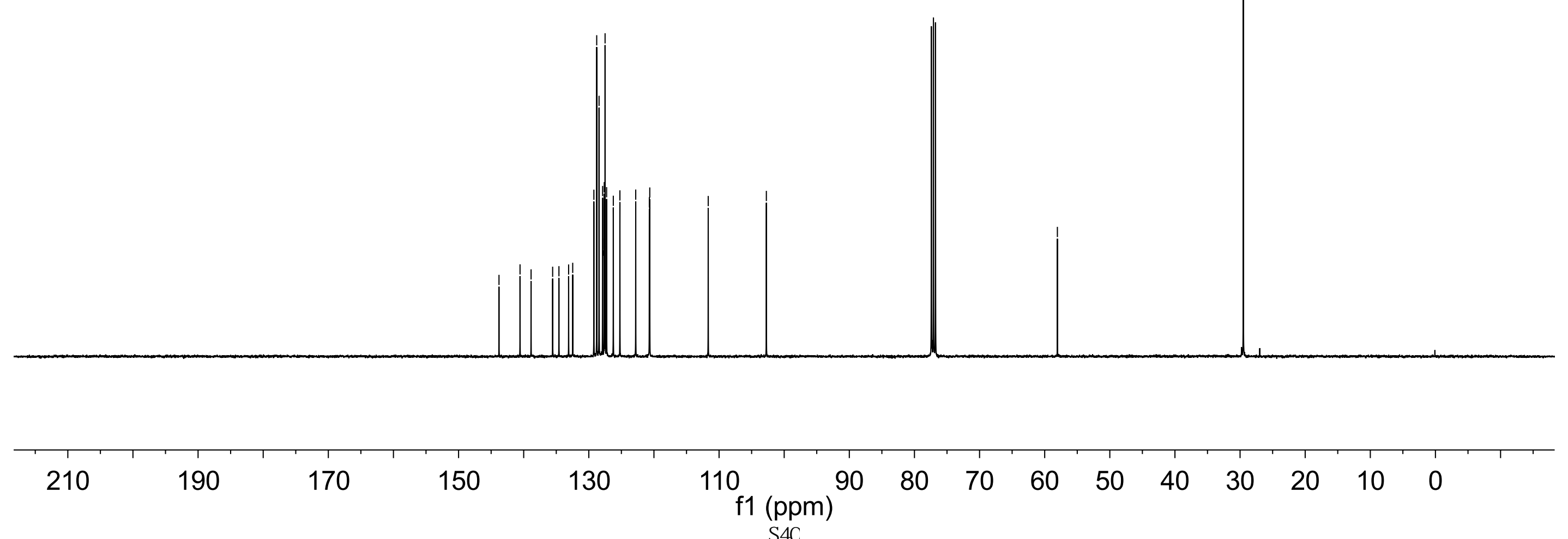




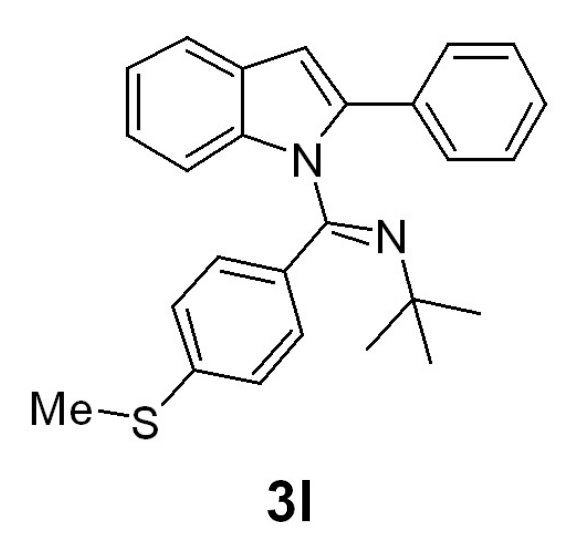

슈 ब

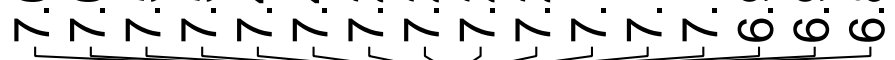

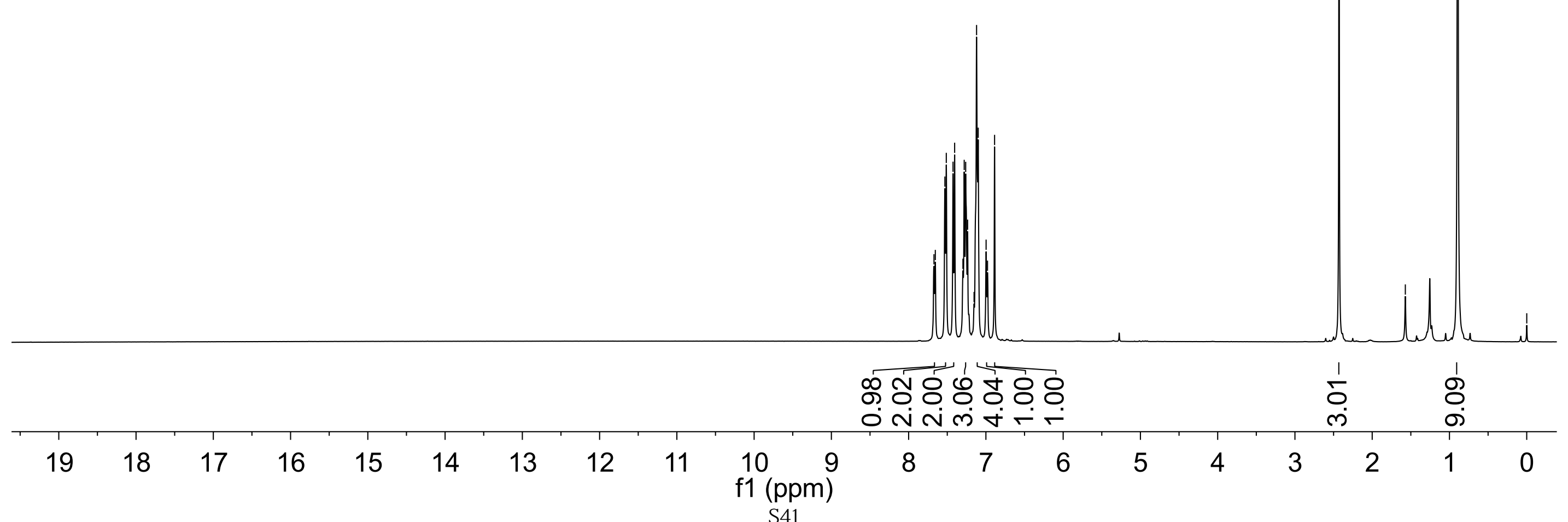



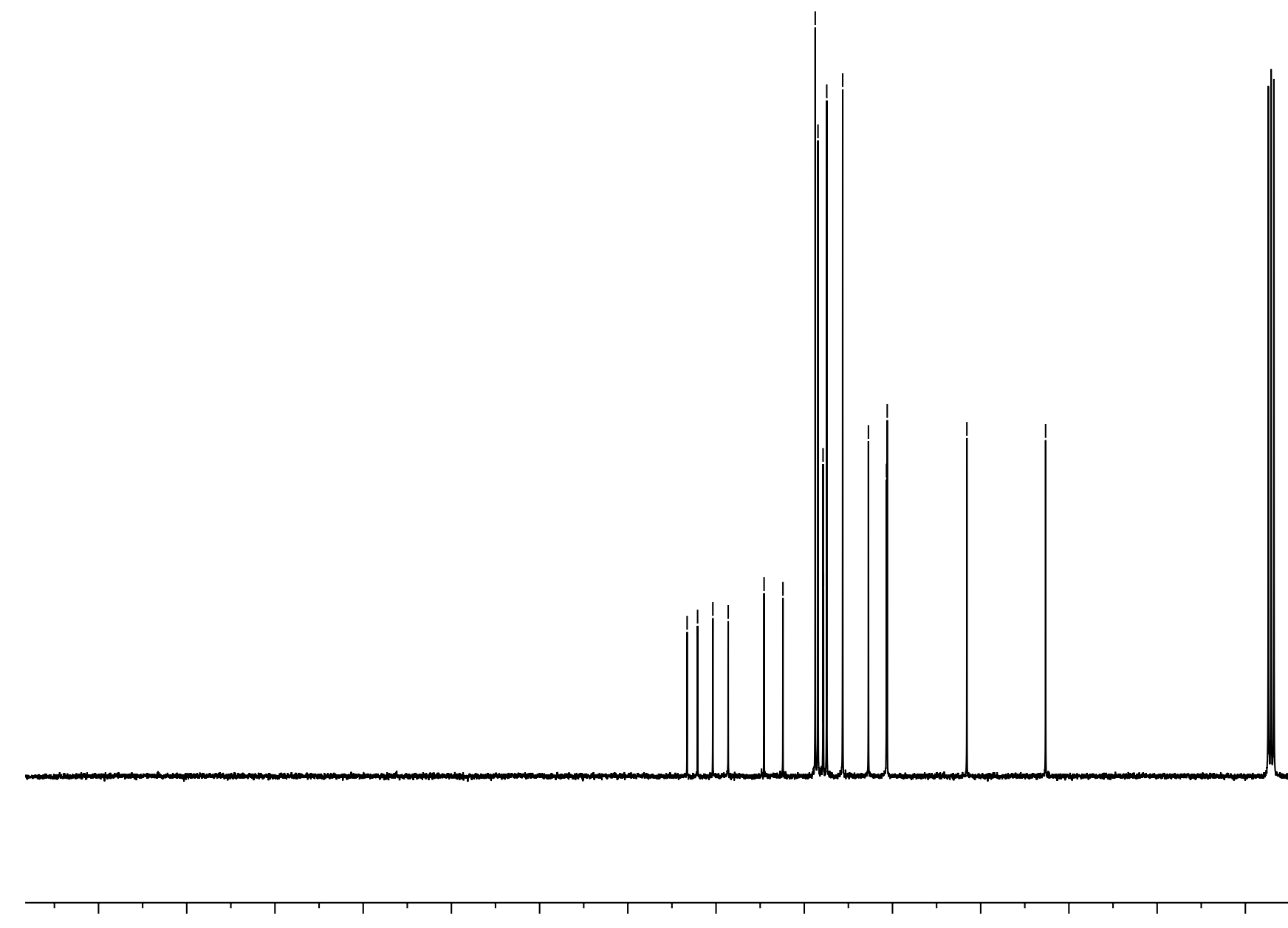


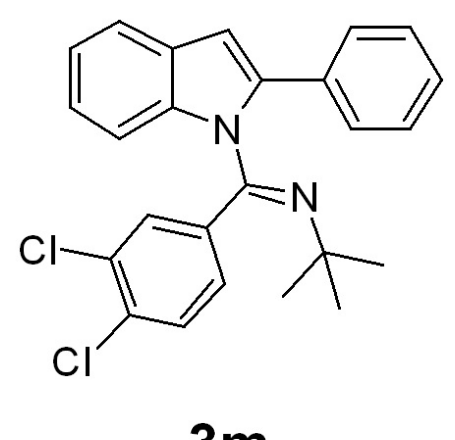

$3 m$
L

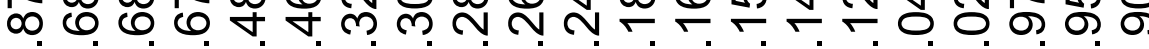
N N N N N N N N N N N N

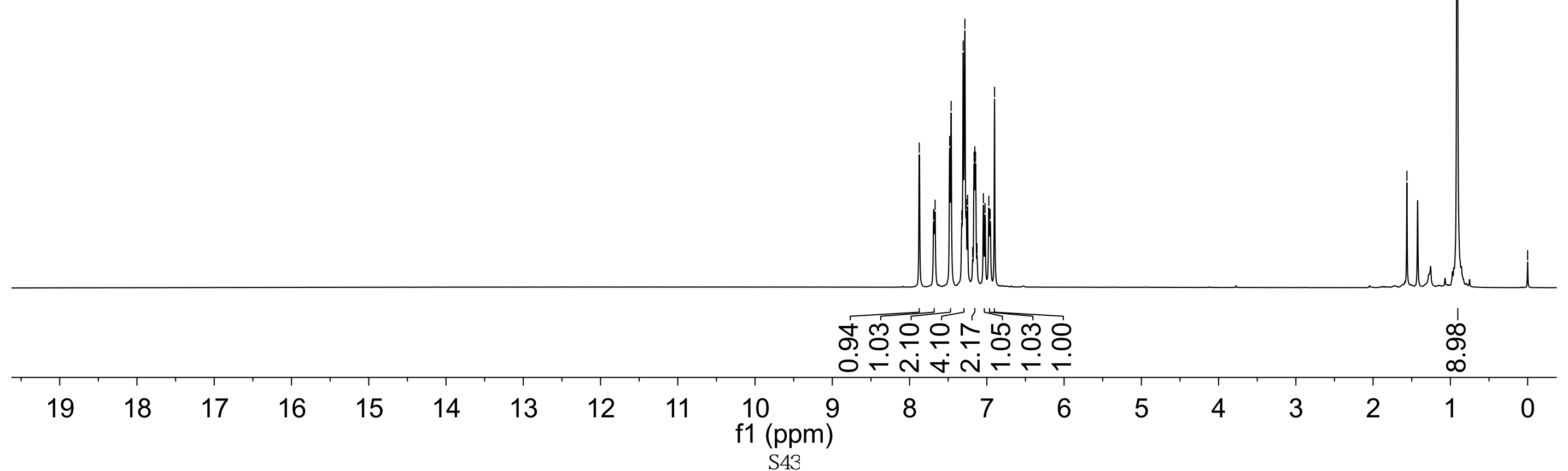




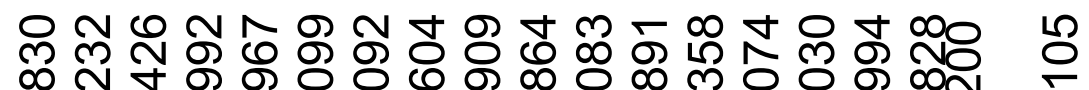

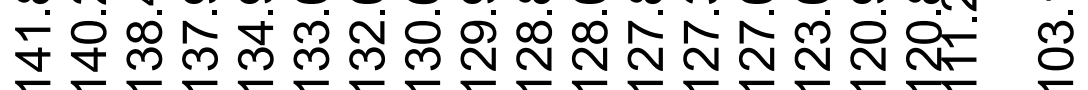

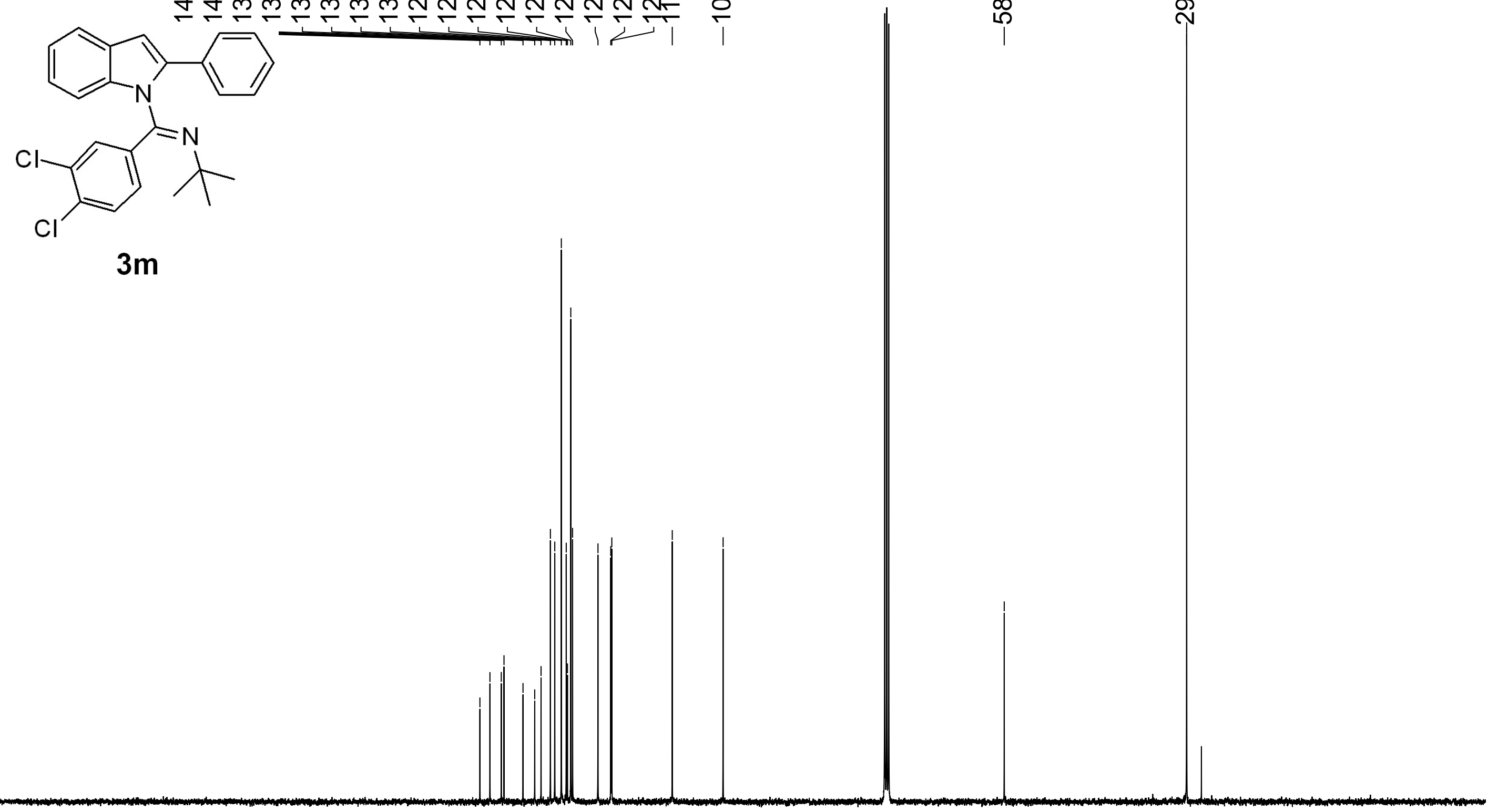

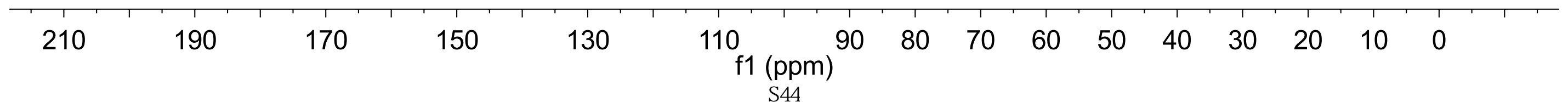




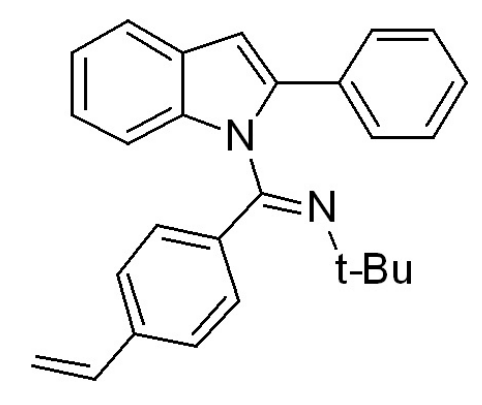

$3 n$

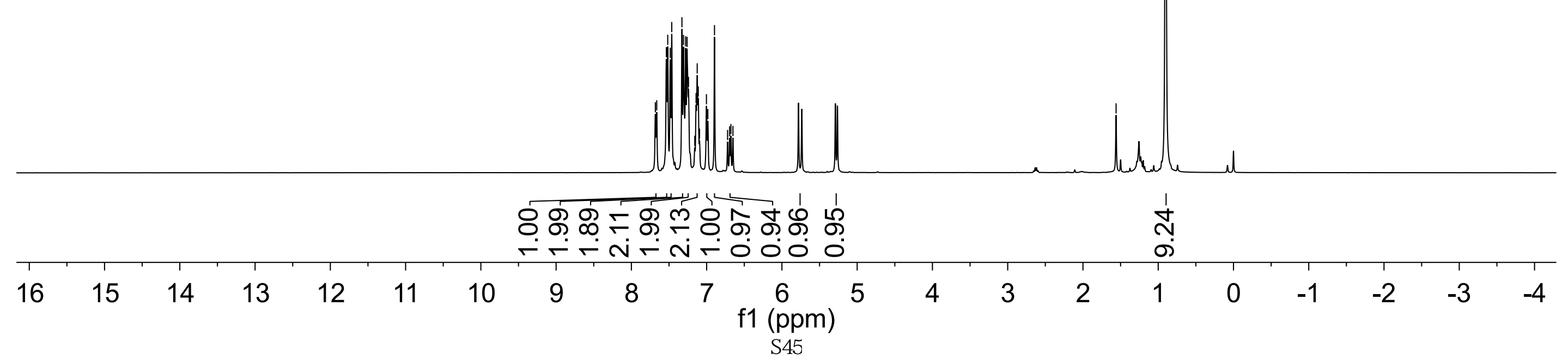




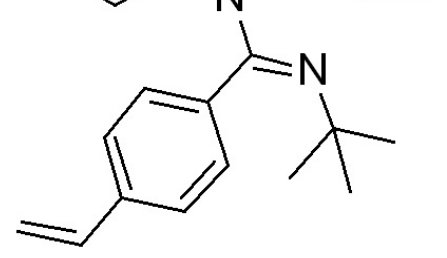

$3 n$

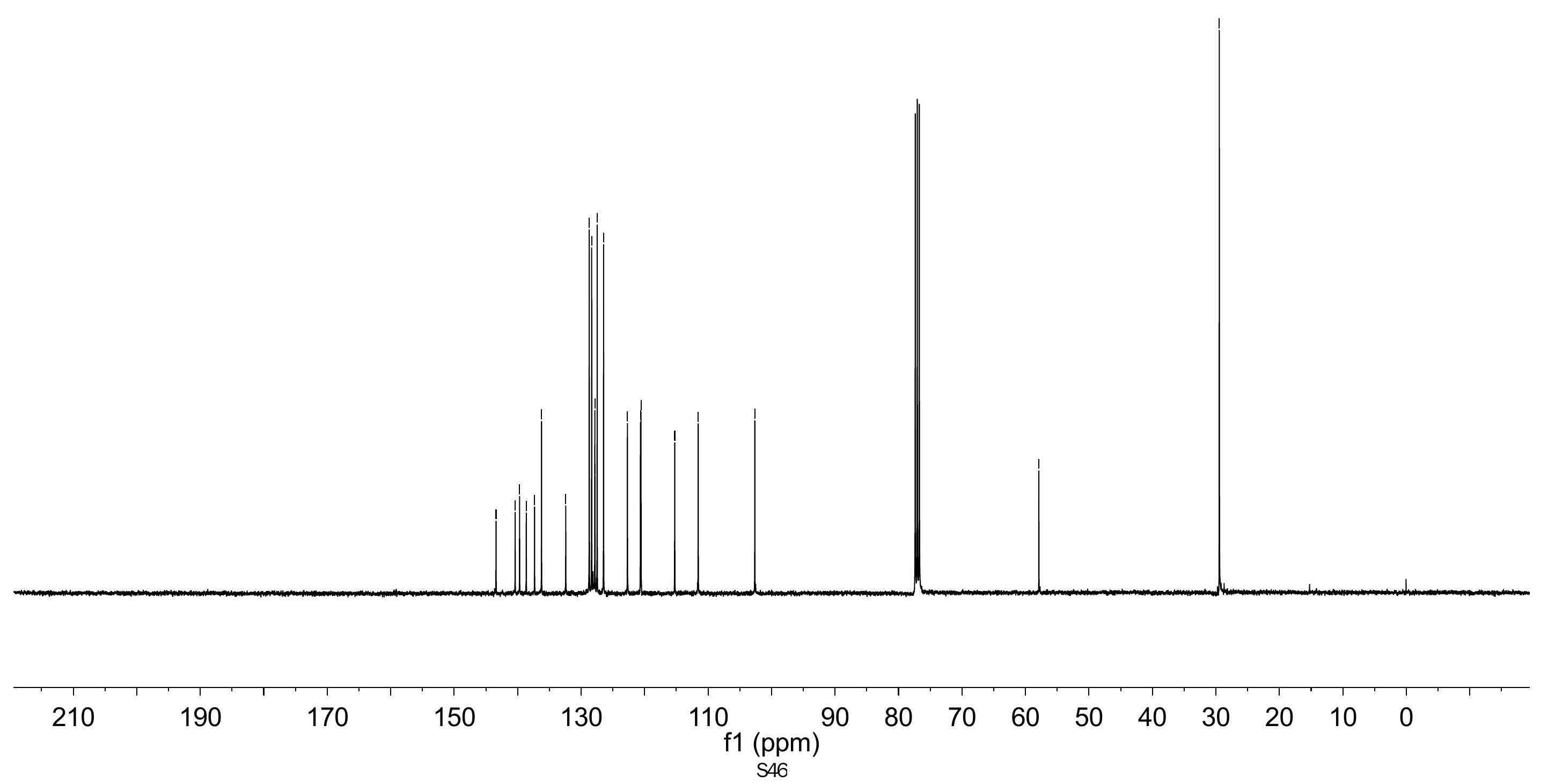




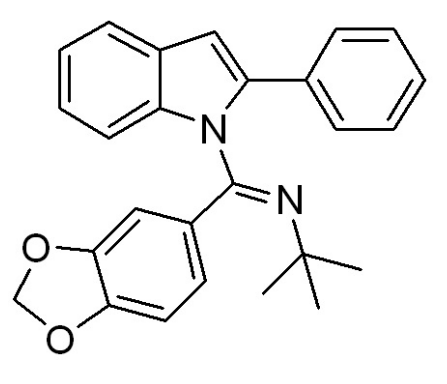

30

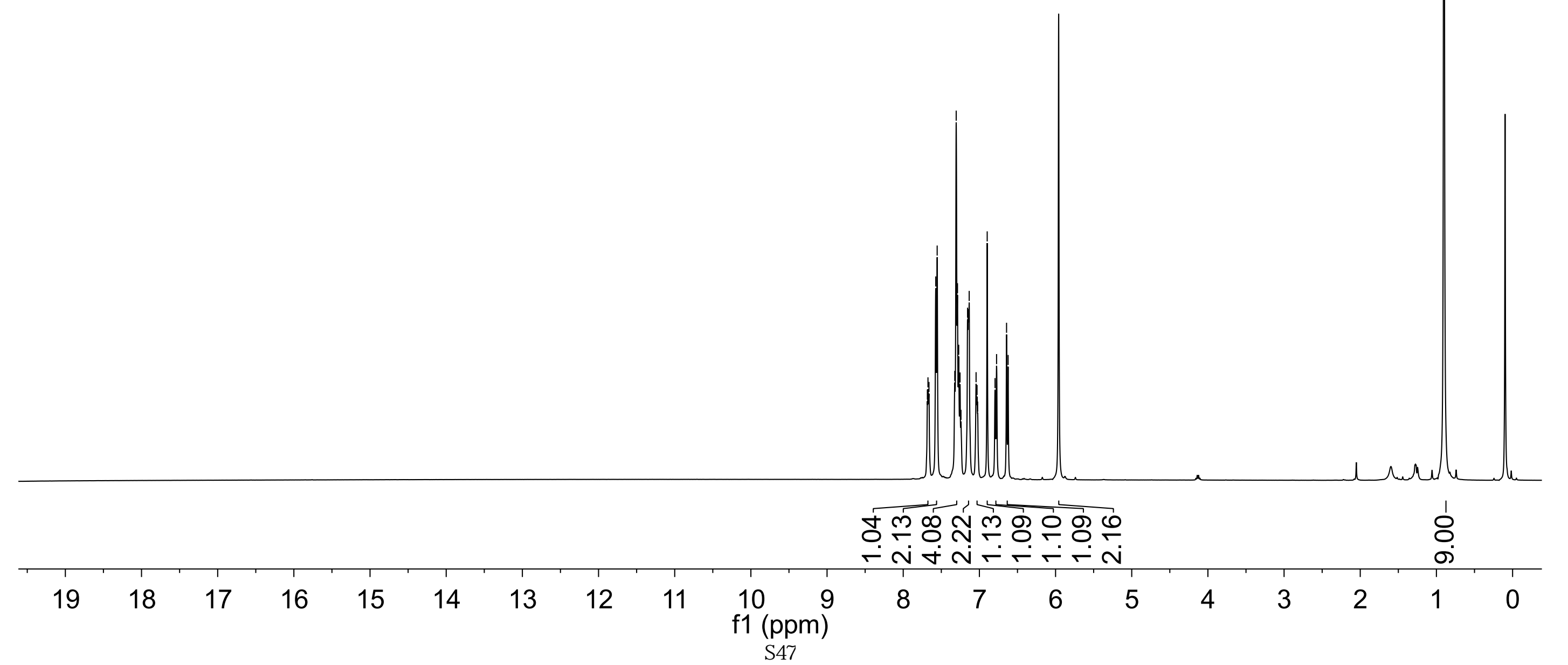




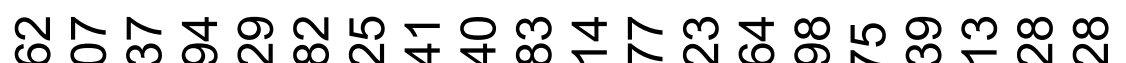

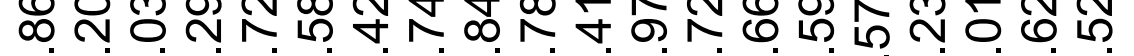

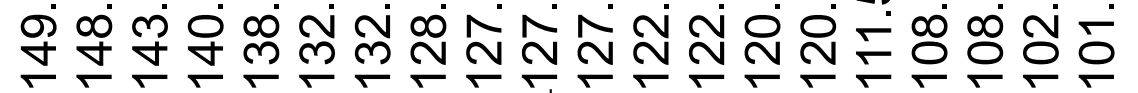

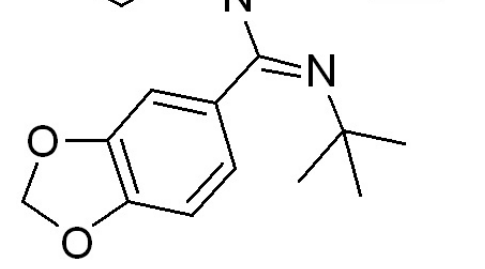

30
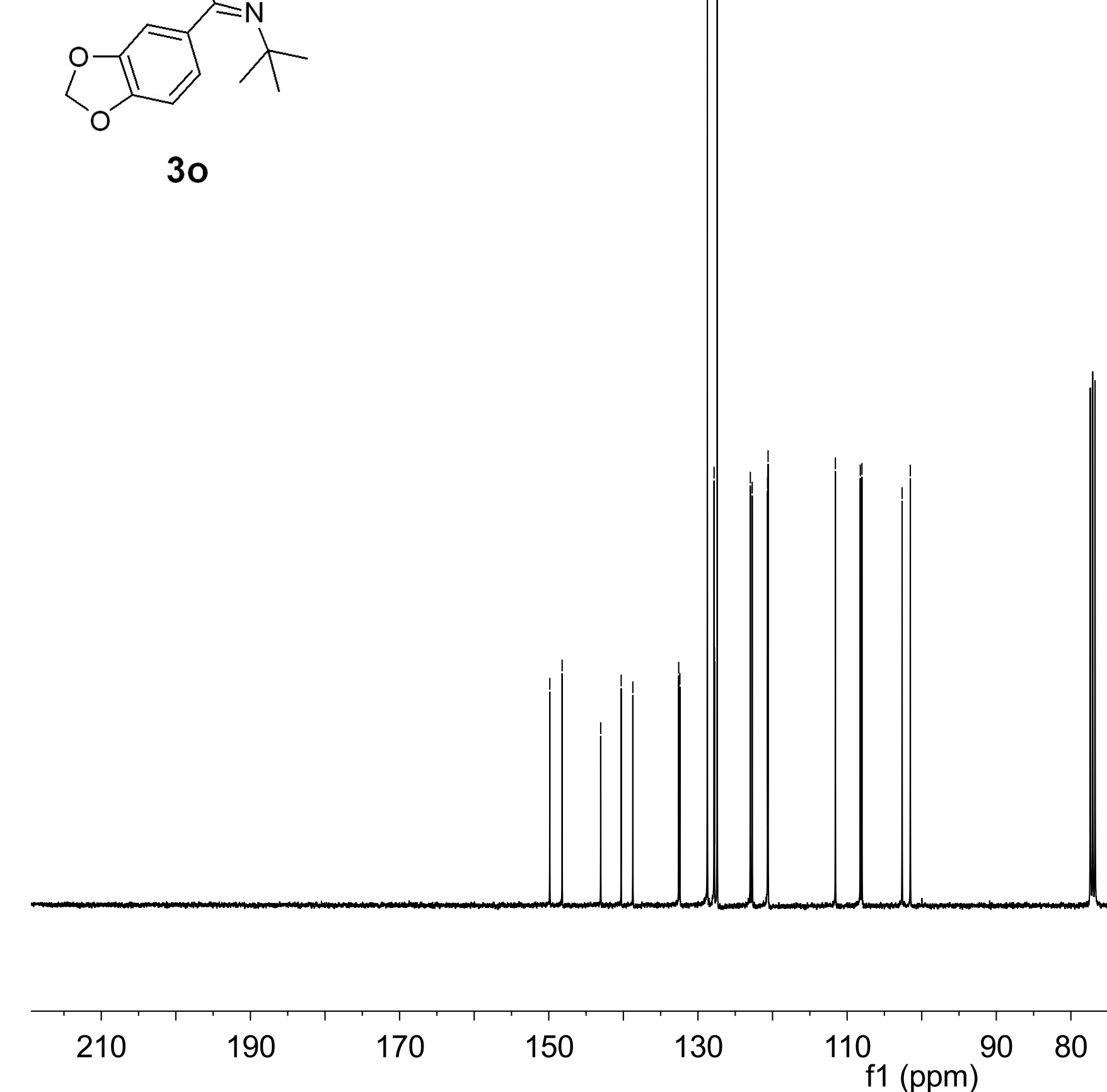

210

190

170

150

130

110

90

80

70

60

50 f1 (ppm)

$\begin{array}{lllll}40 & 30 & 20 & 10 & 0\end{array}$ 


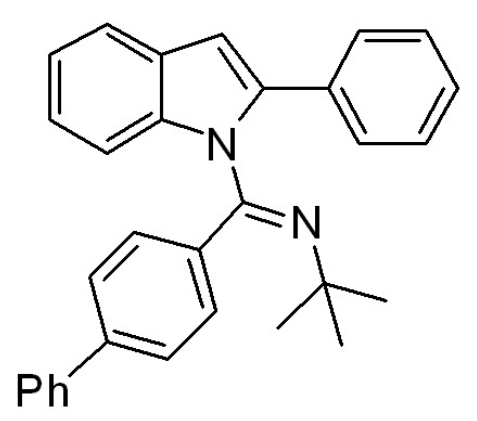

$3 p$

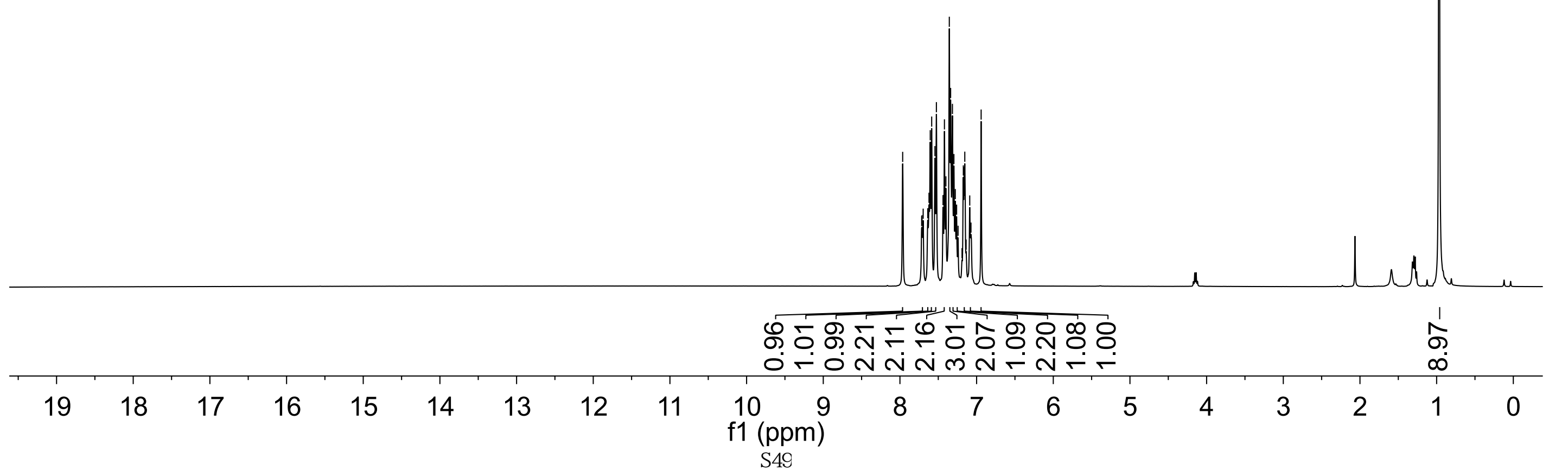




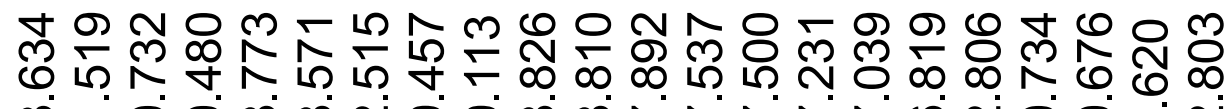

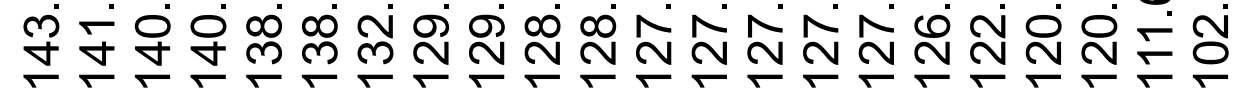

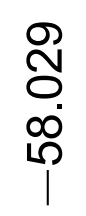

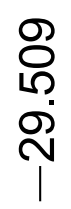

$\rightarrow$

$3 p$

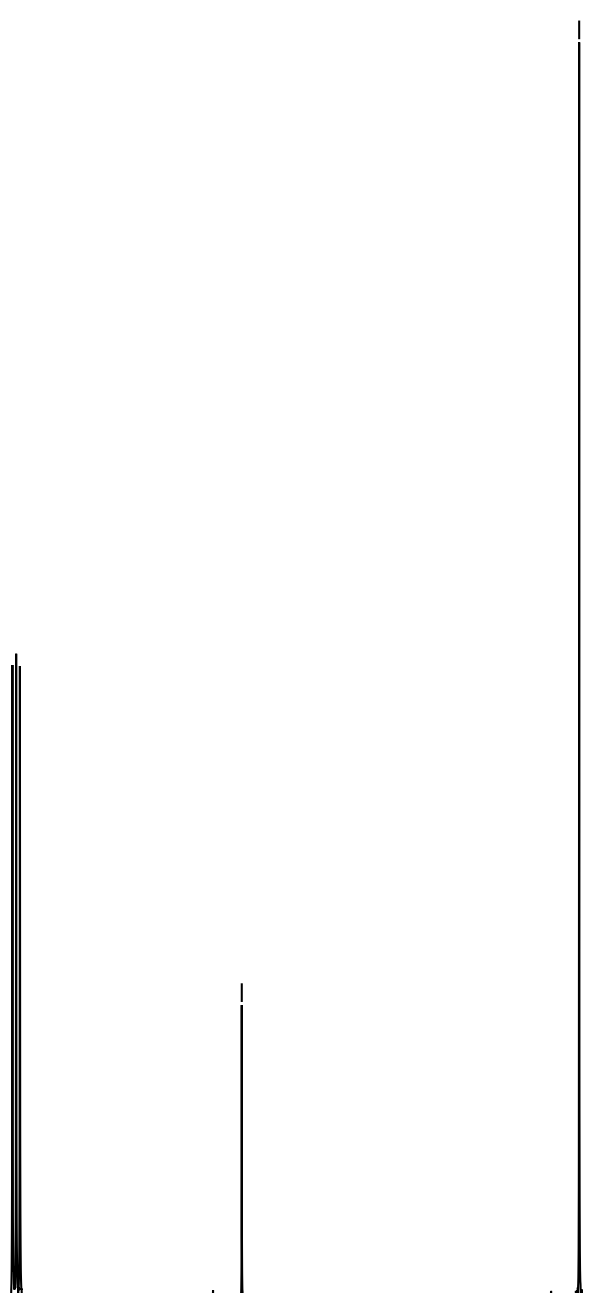


$4 b$

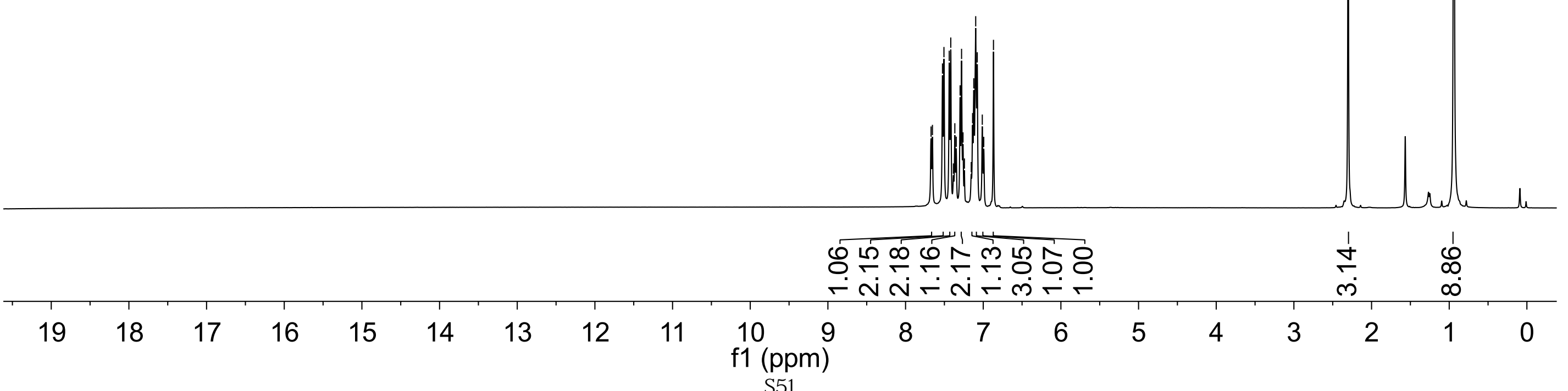




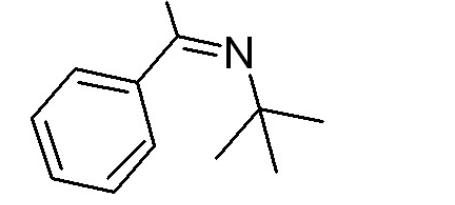

ป

4b

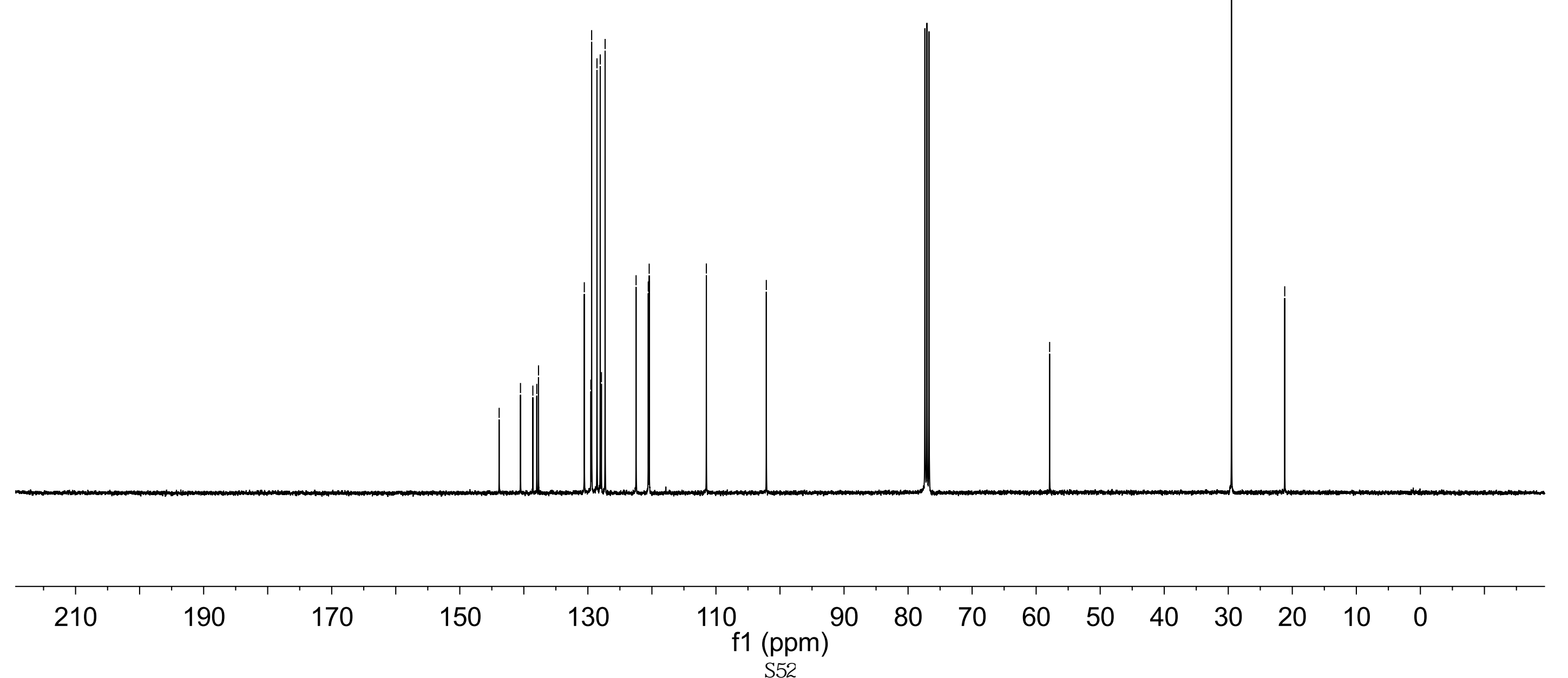



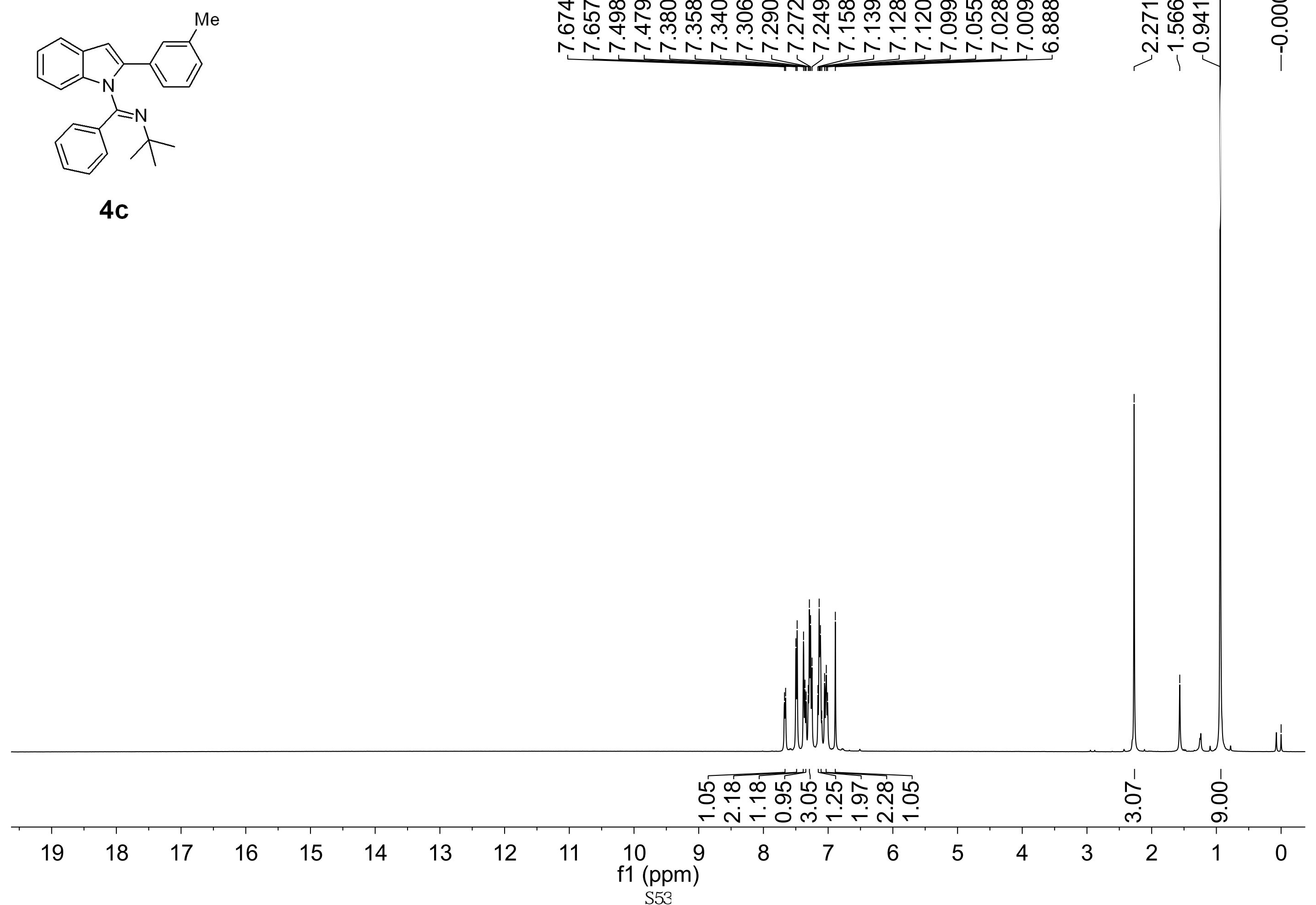


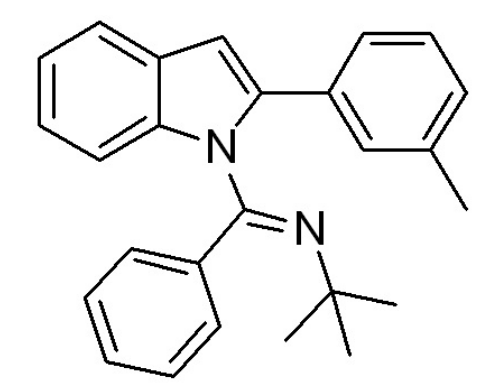

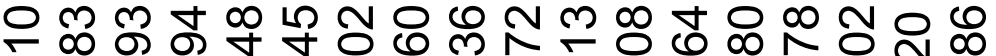

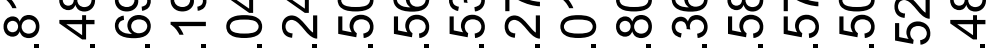

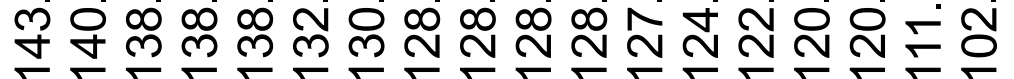

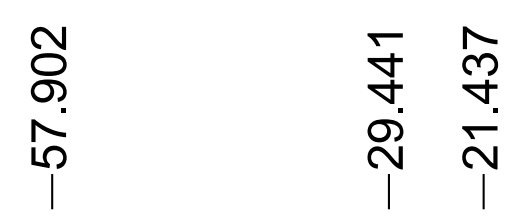

${ }^{13} \mathrm{CNMR}\left(101 \mathrm{MHz}, \mathrm{CDCl}_{3}\right.$ ) $\delta 143.81$ (s), 140.48 (s), 138.69 (s), 138.19 (s), 138.05 (s), 132.24 (s), 130.50 (s), 128.56 (s), 128.54 (s), 128.27 (s), 128.01 (s), 127.81 (s), 124.36 (s), $122.58(\mathrm{~s}), 120.58$ (s), $120.50(\mathrm{~s}), 111.52(\mathrm{~s}), 102.49$ (s), $57.90(\mathrm{~s}), 29.44(\mathrm{~s}), 21.44(\mathrm{~s})$.

4c

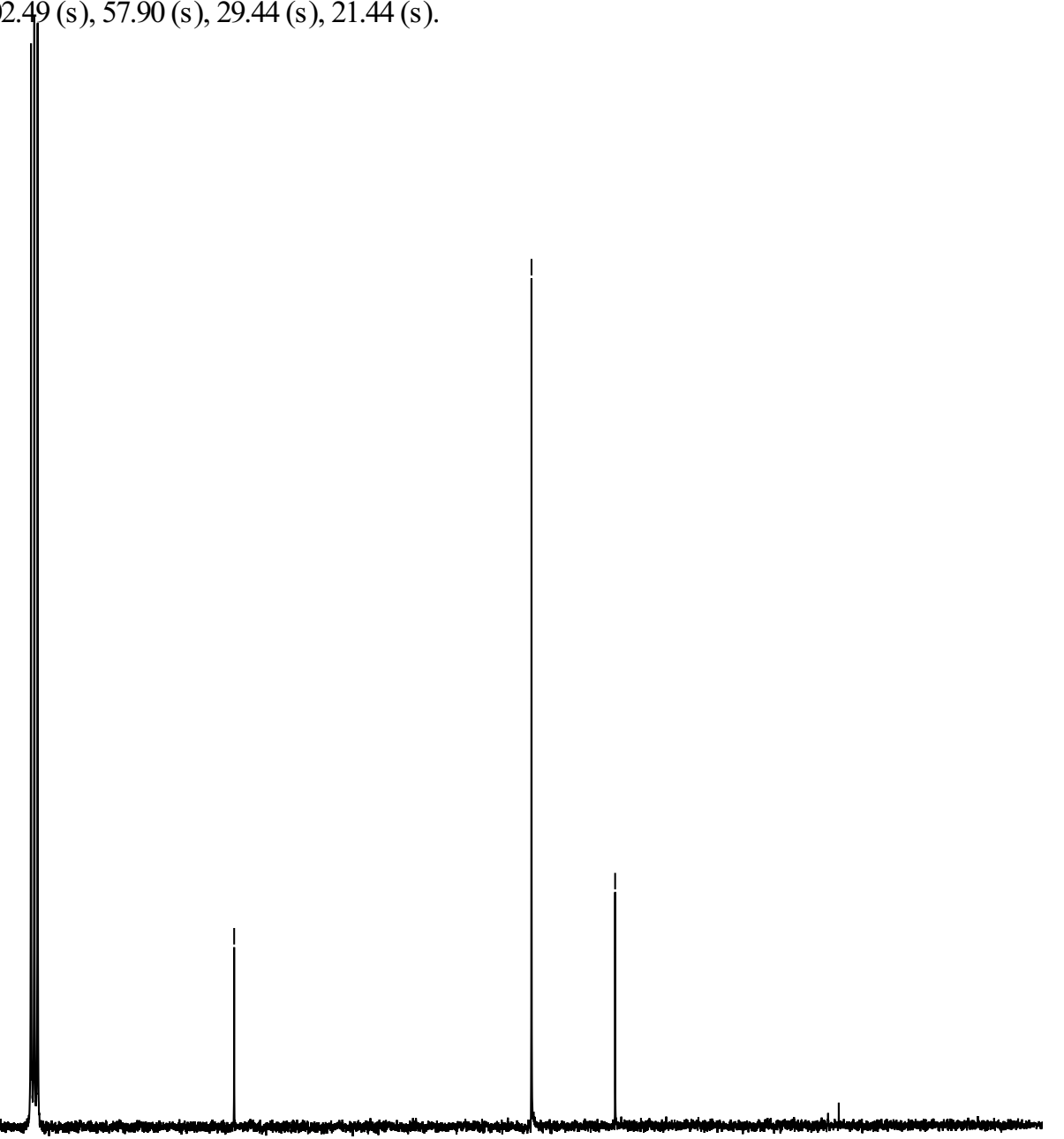


4d

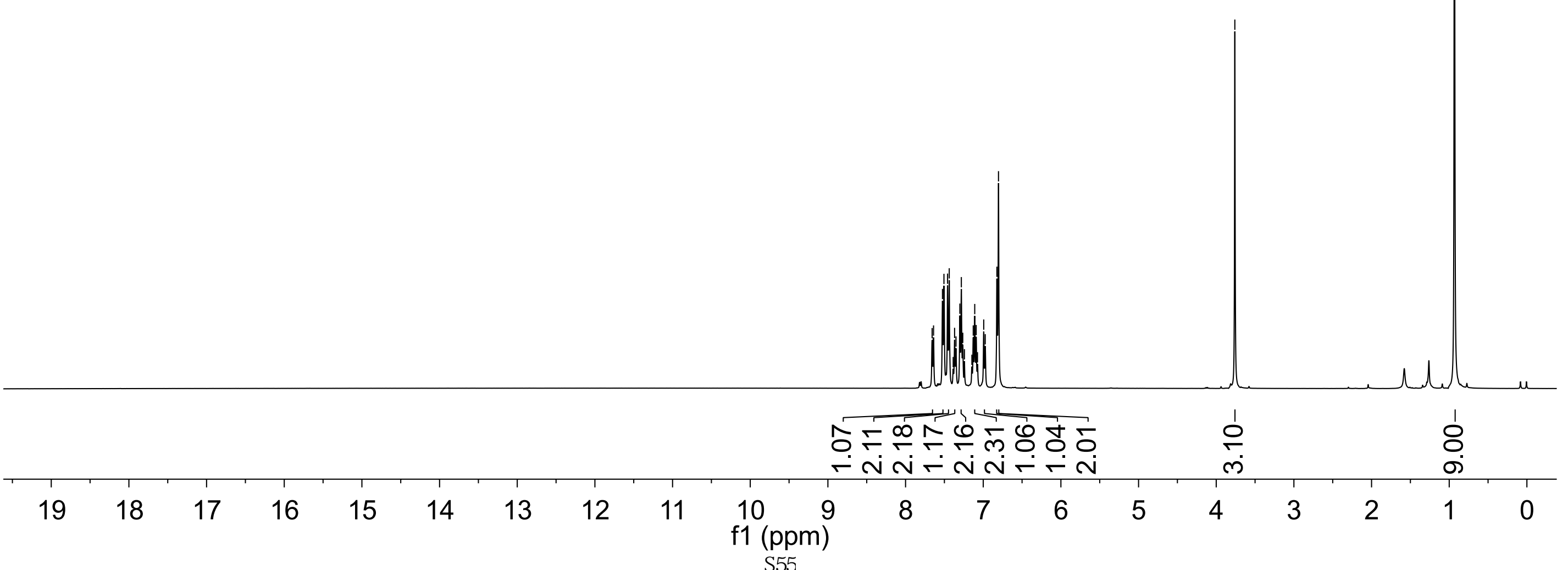




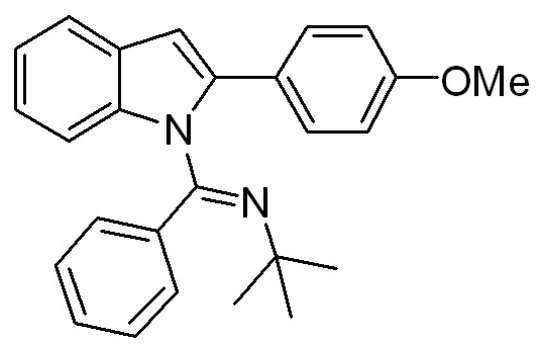

4d

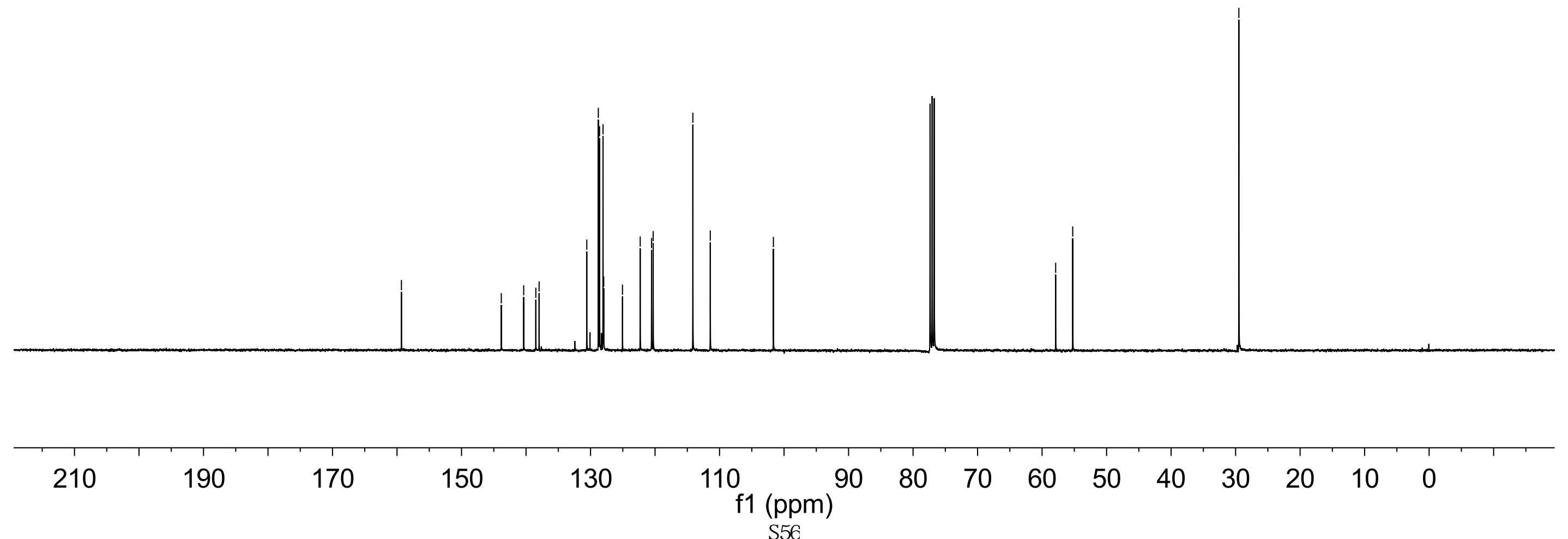




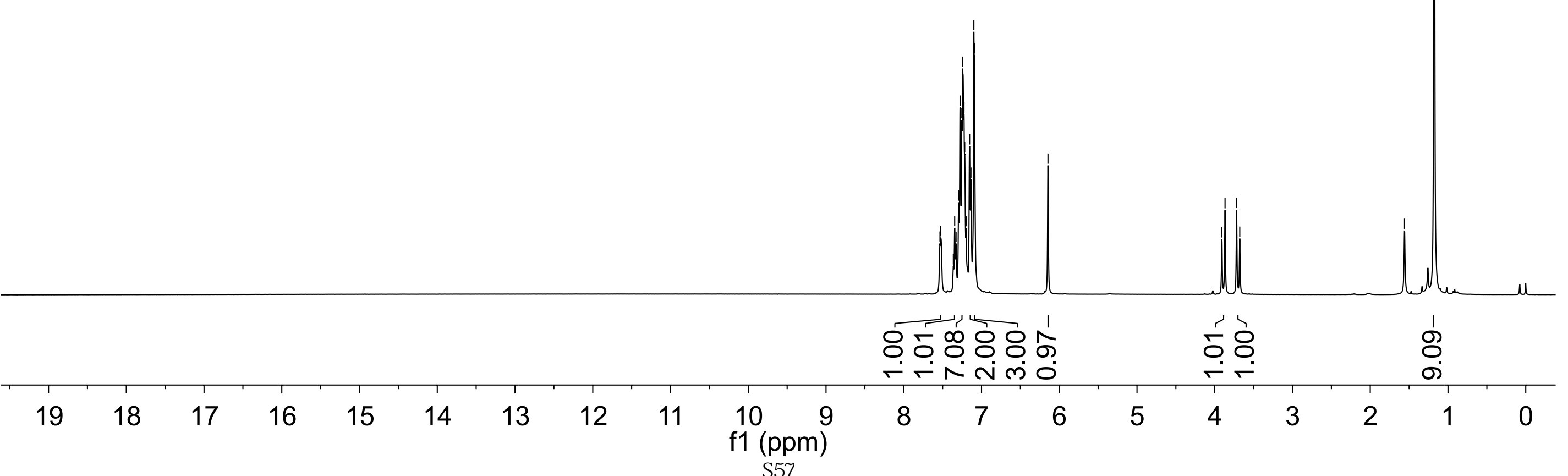




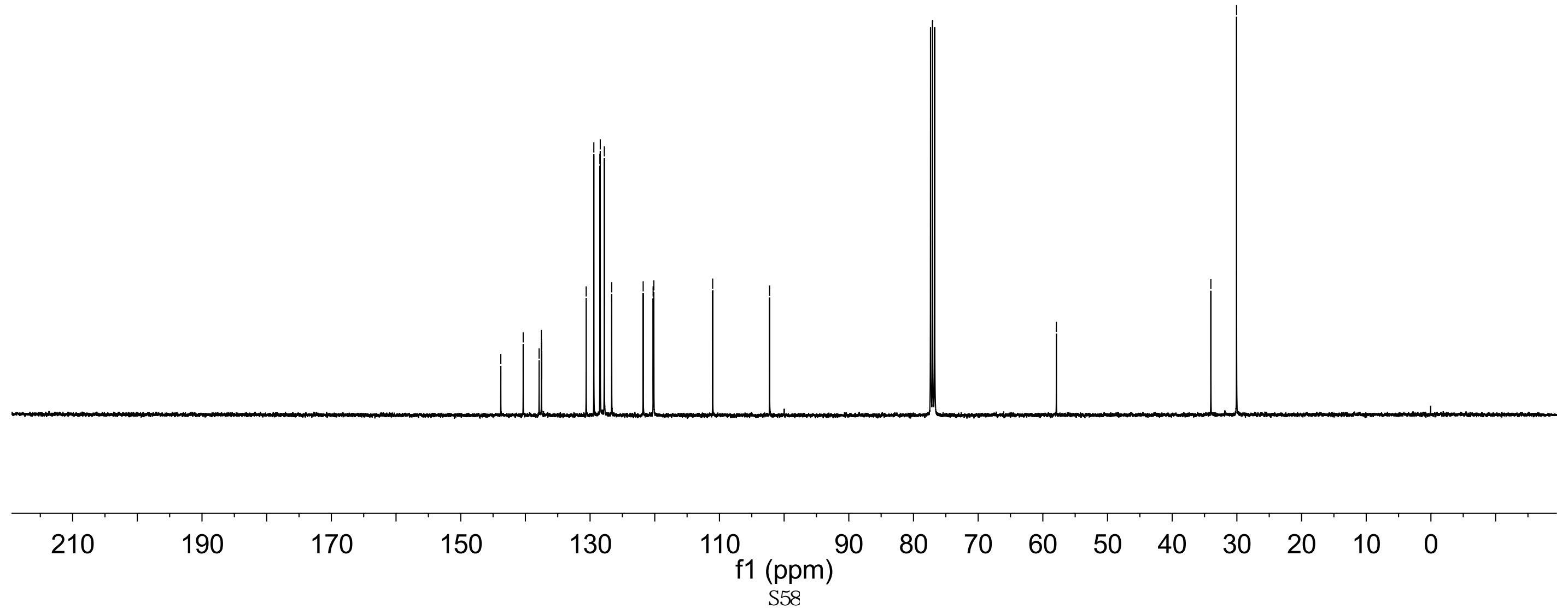




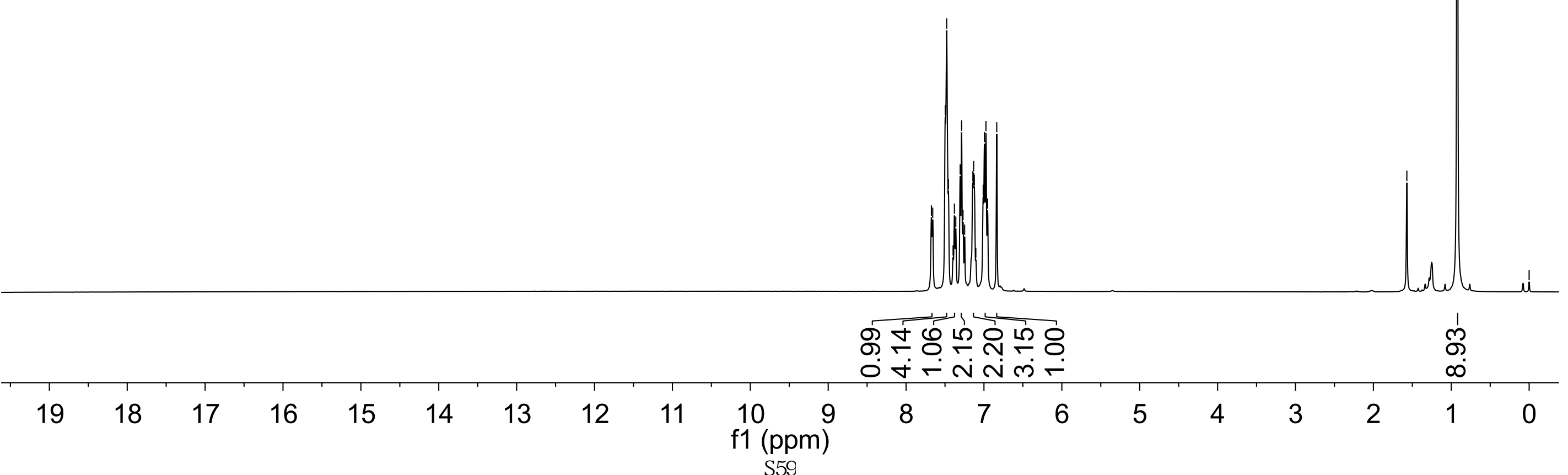




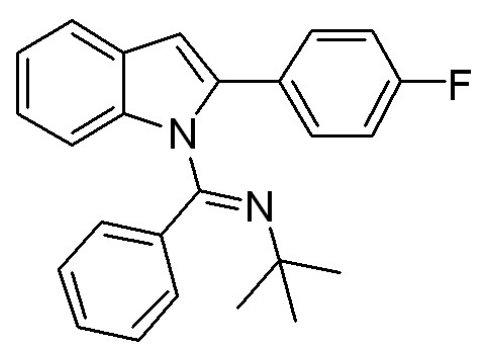

$4 f$

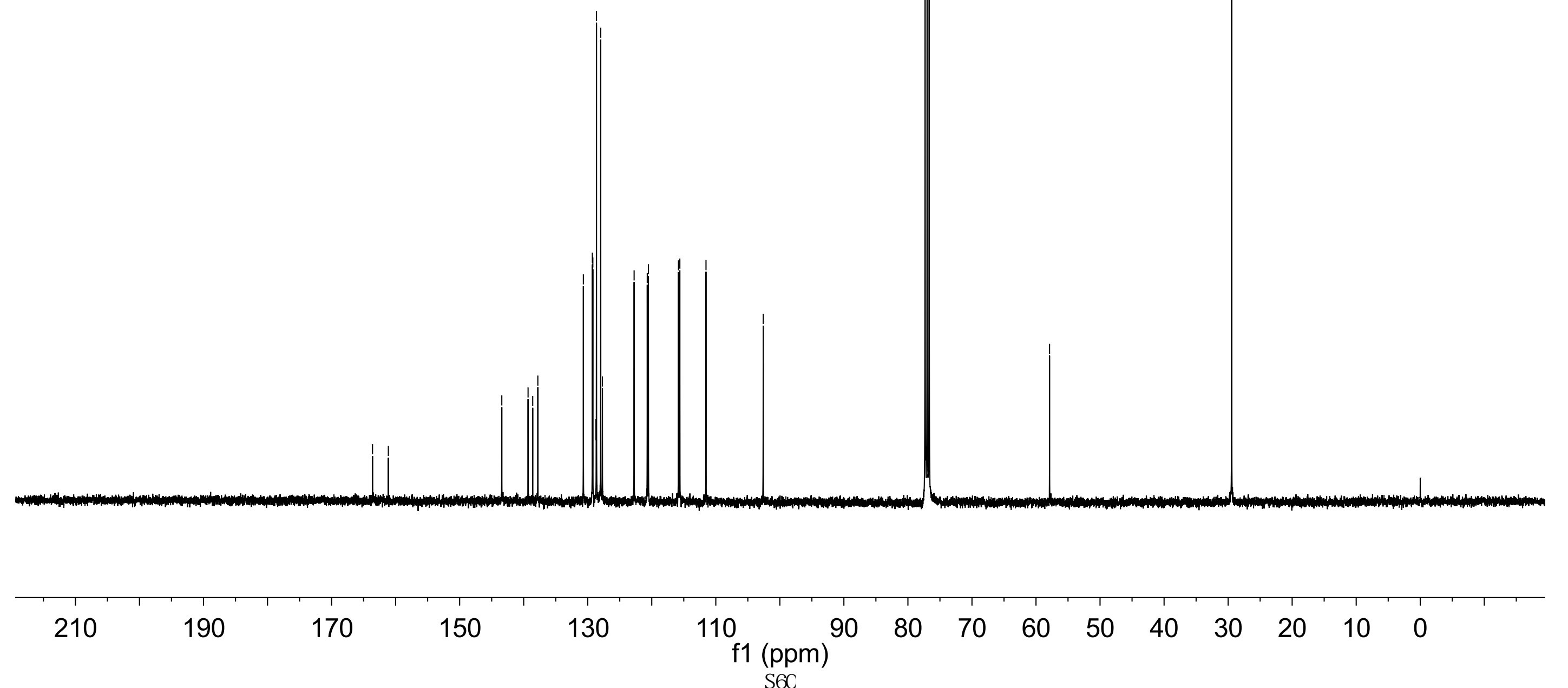


49

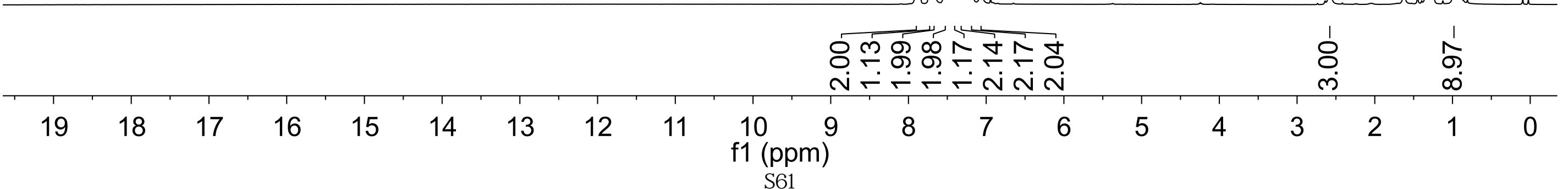




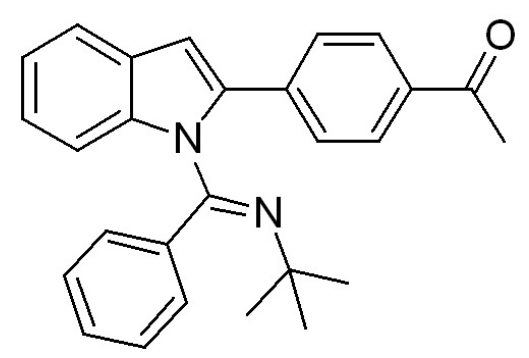

$4 g$

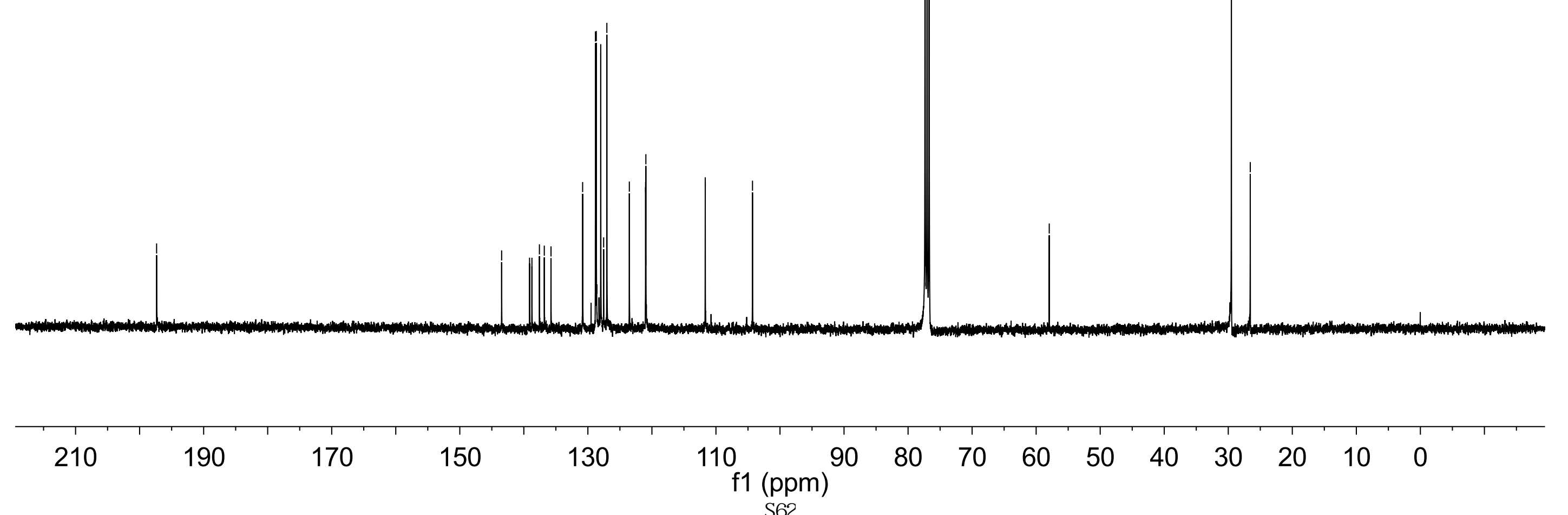




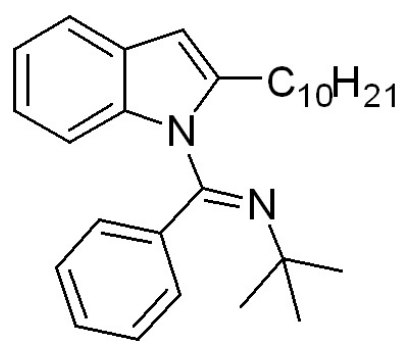

$4 h$

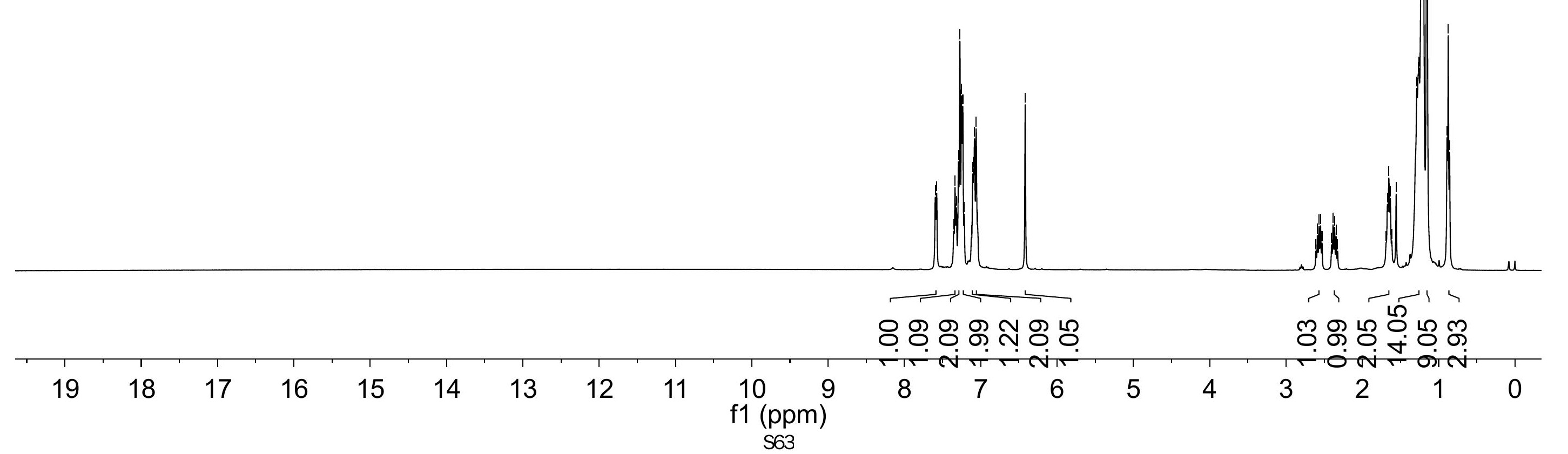




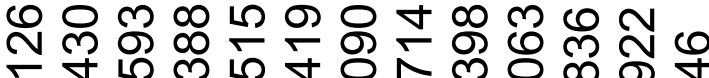
ㄴ.

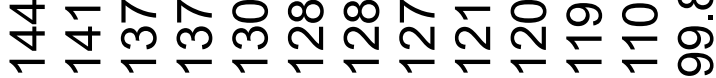

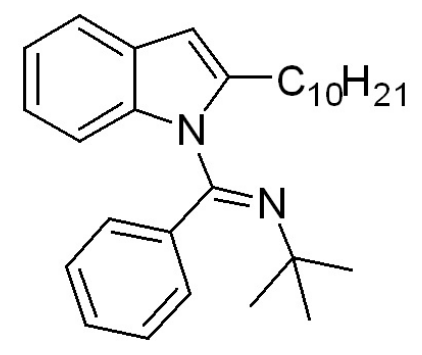

$4 h$

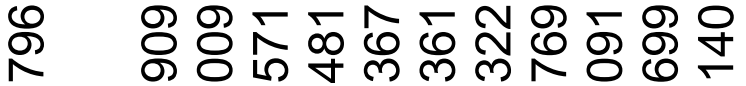

시

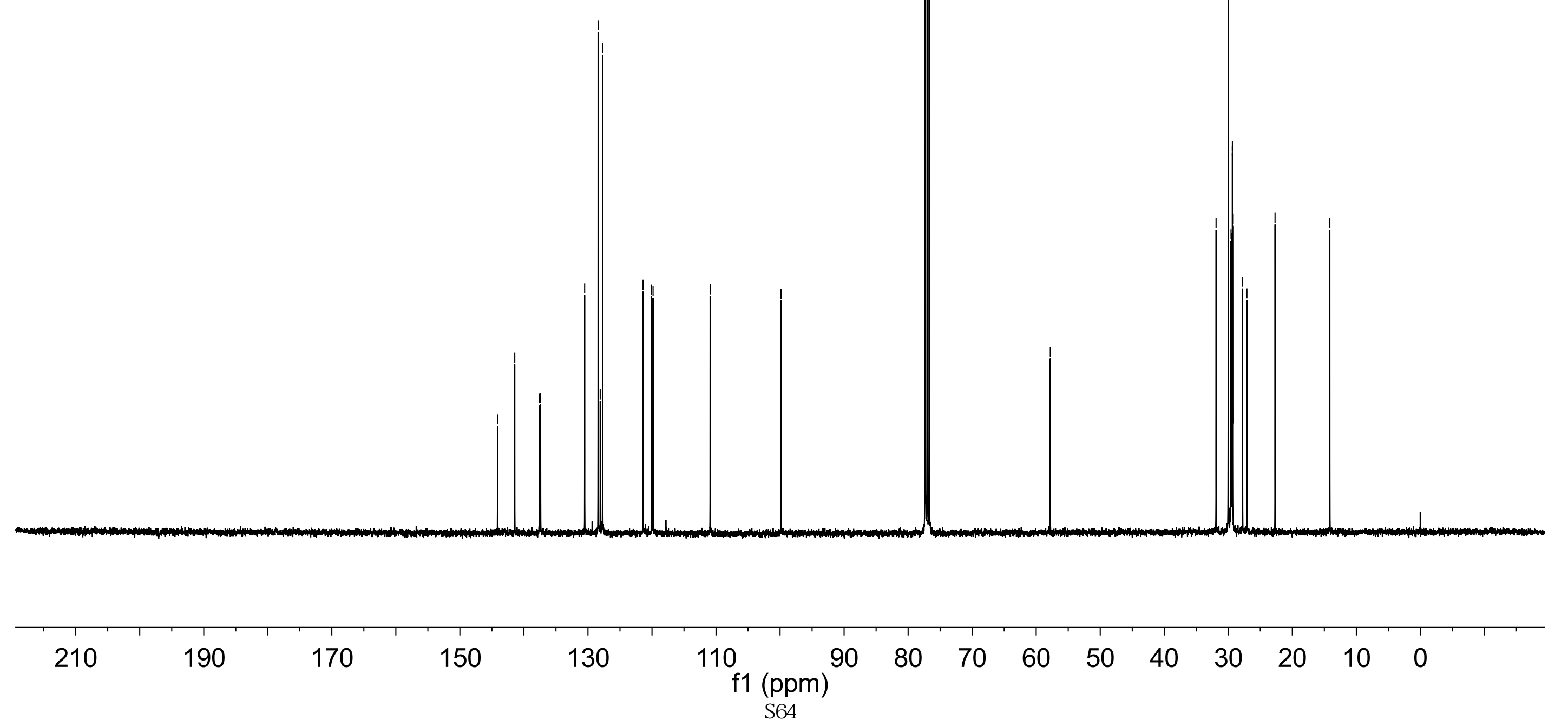



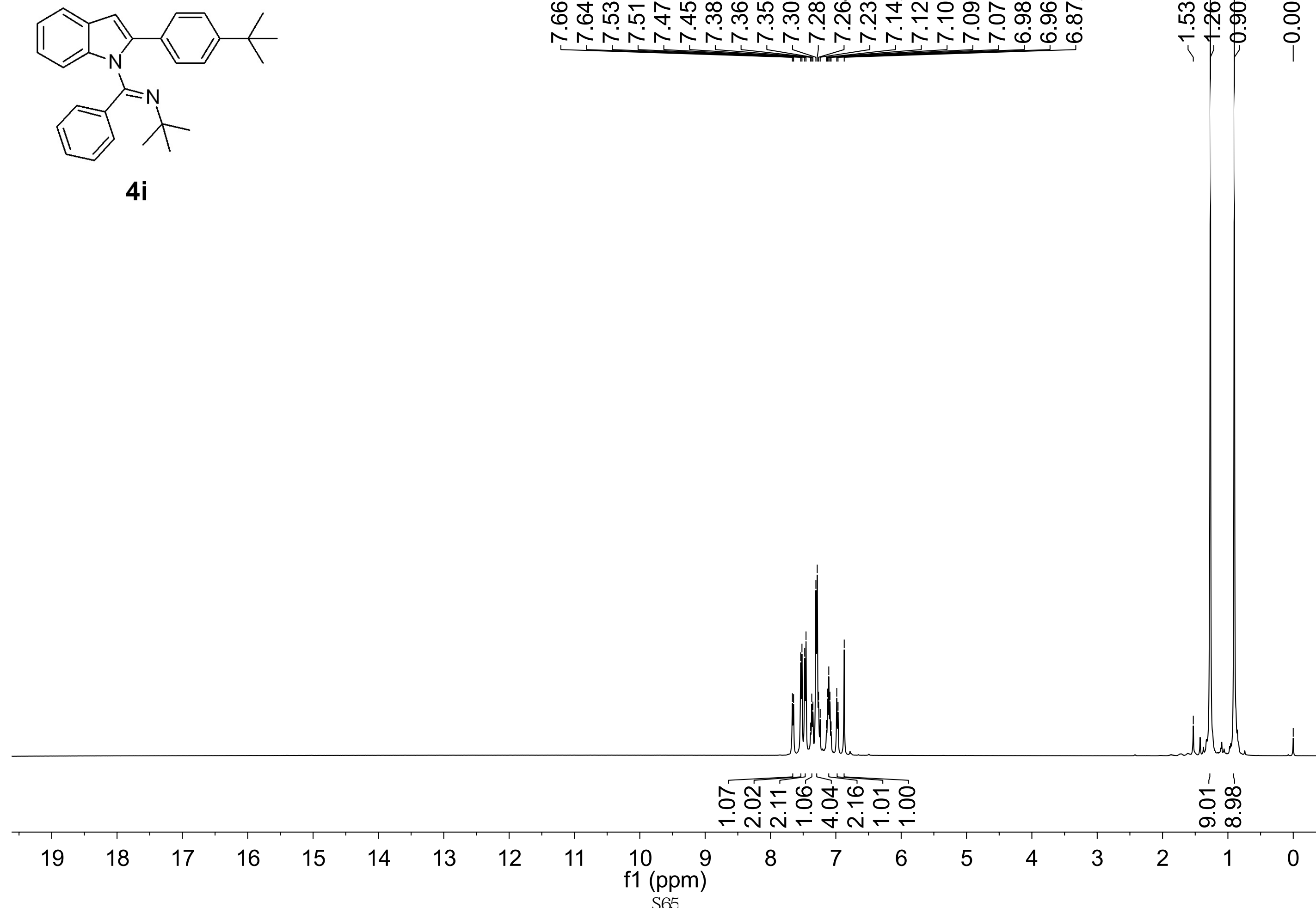


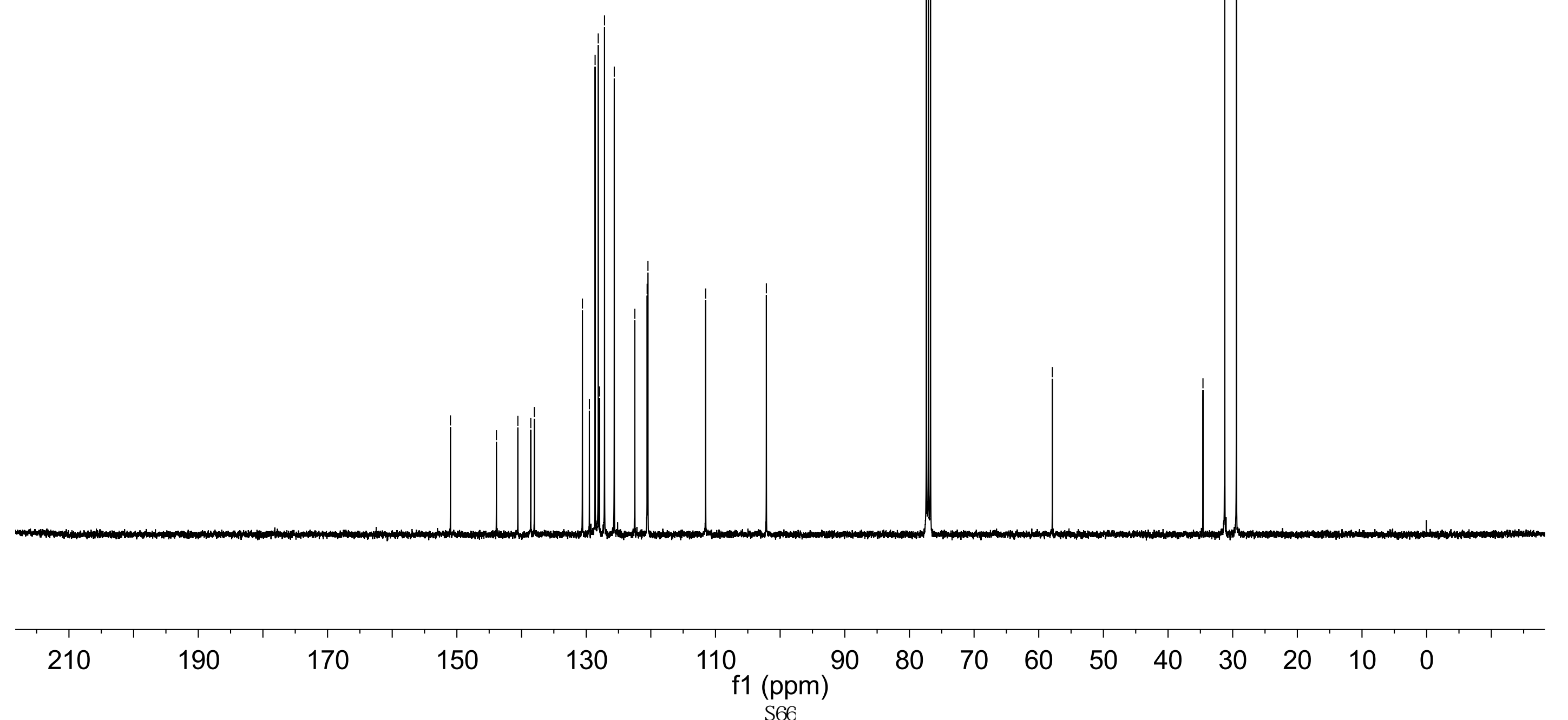




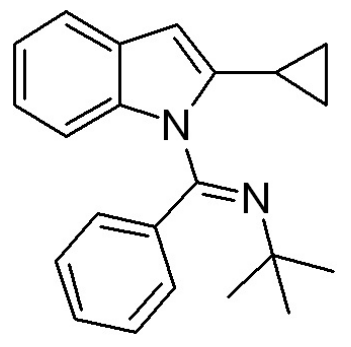

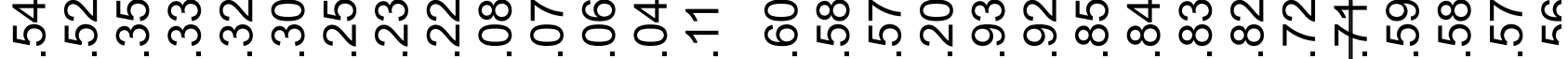
N N

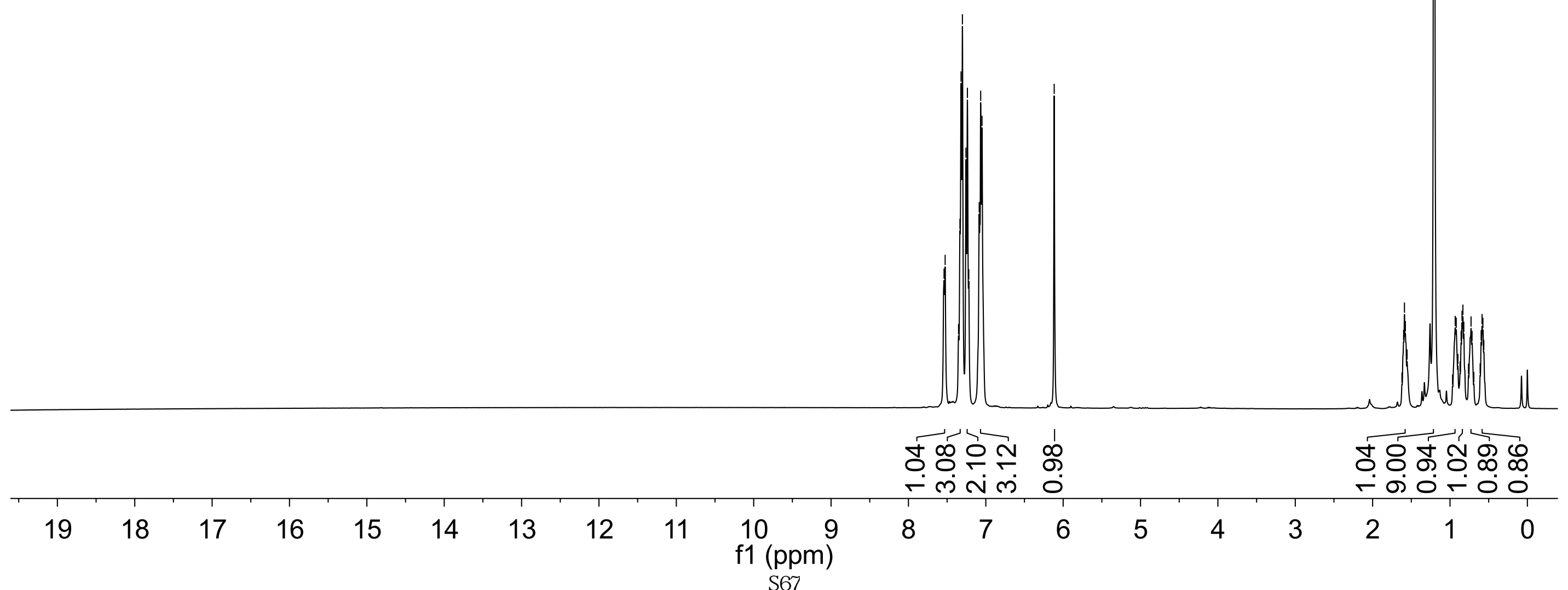


4j

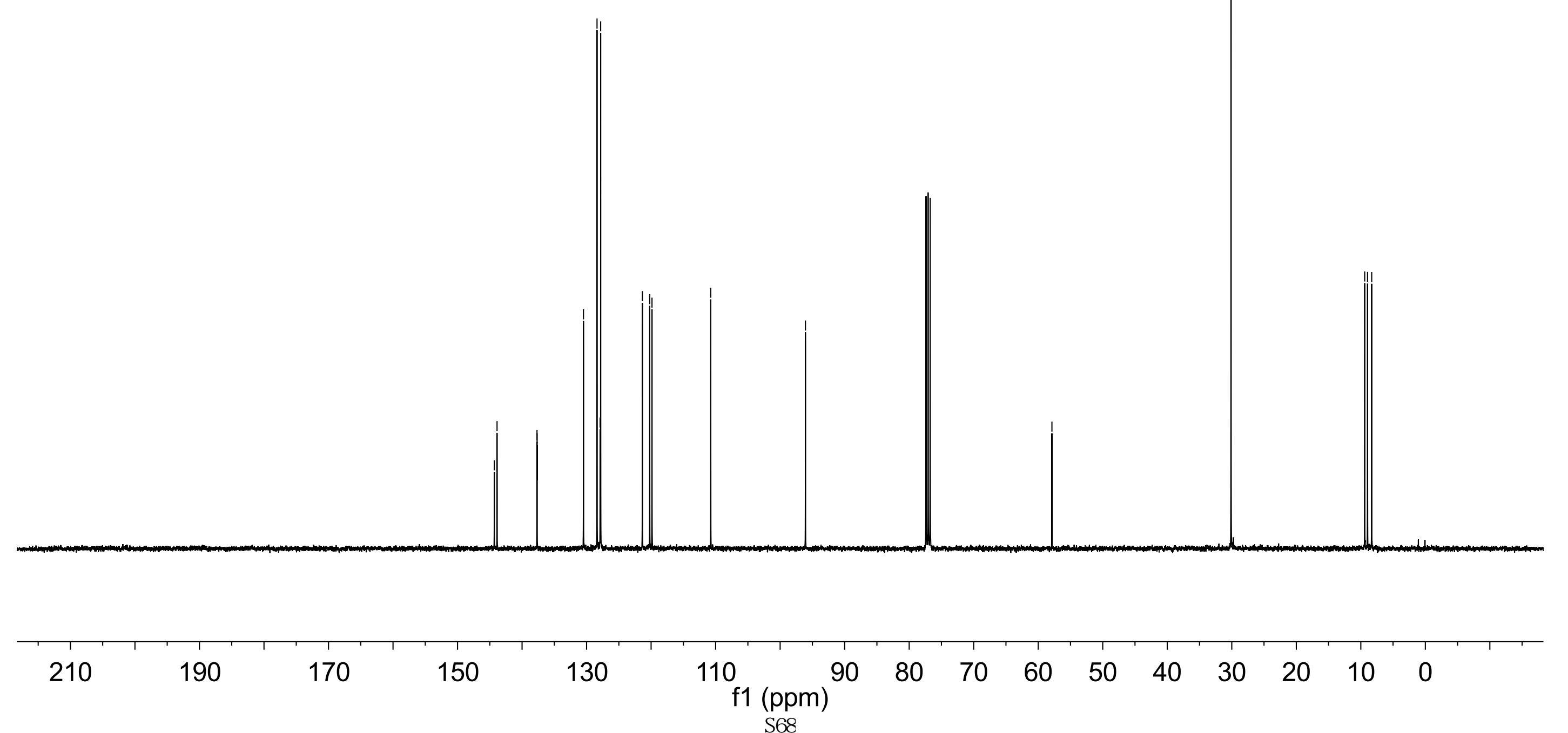



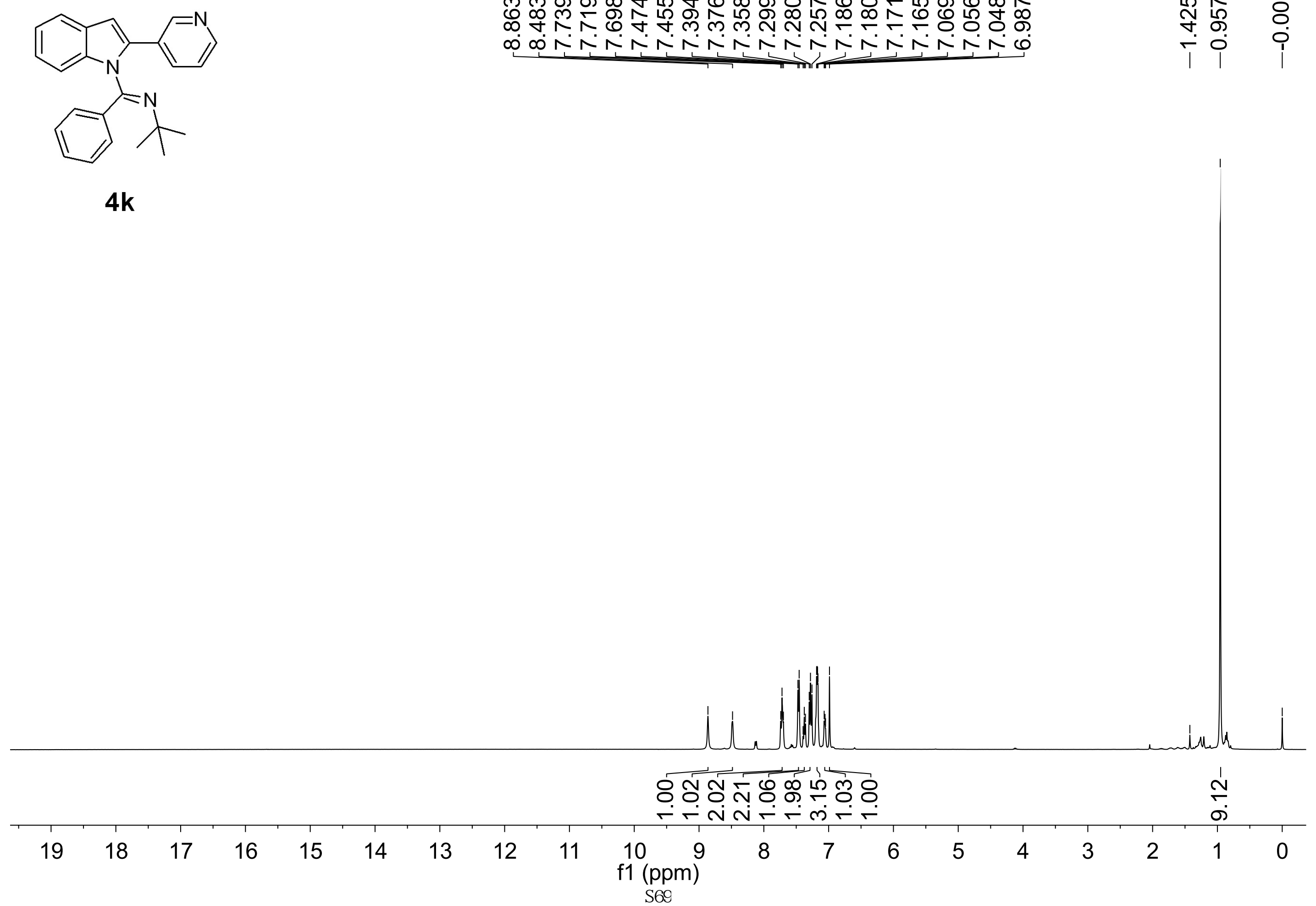


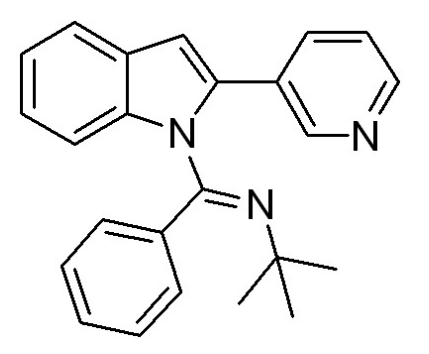

4k

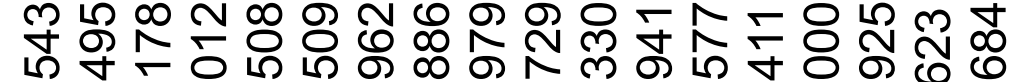
om o mis 西 于 J

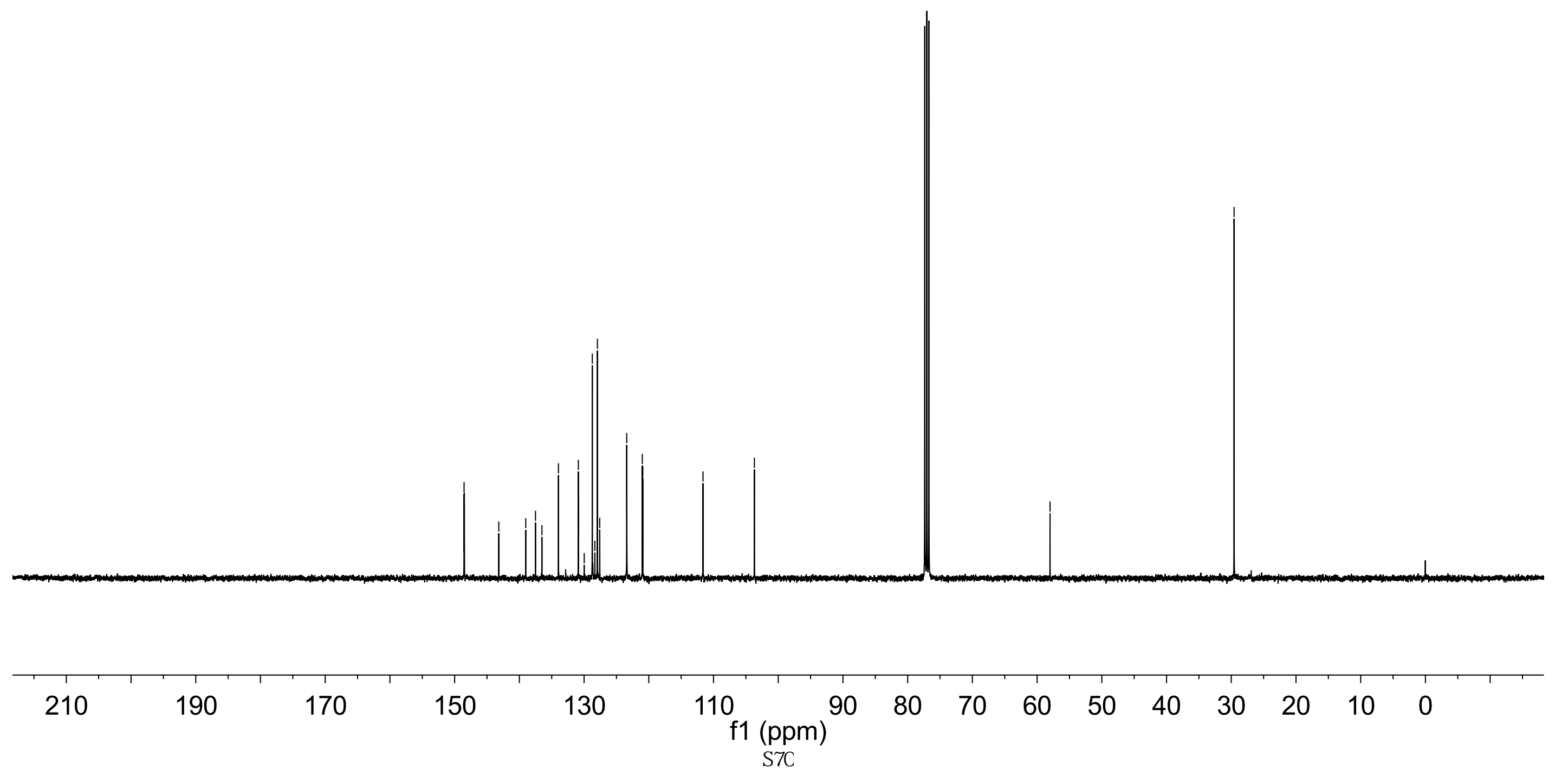



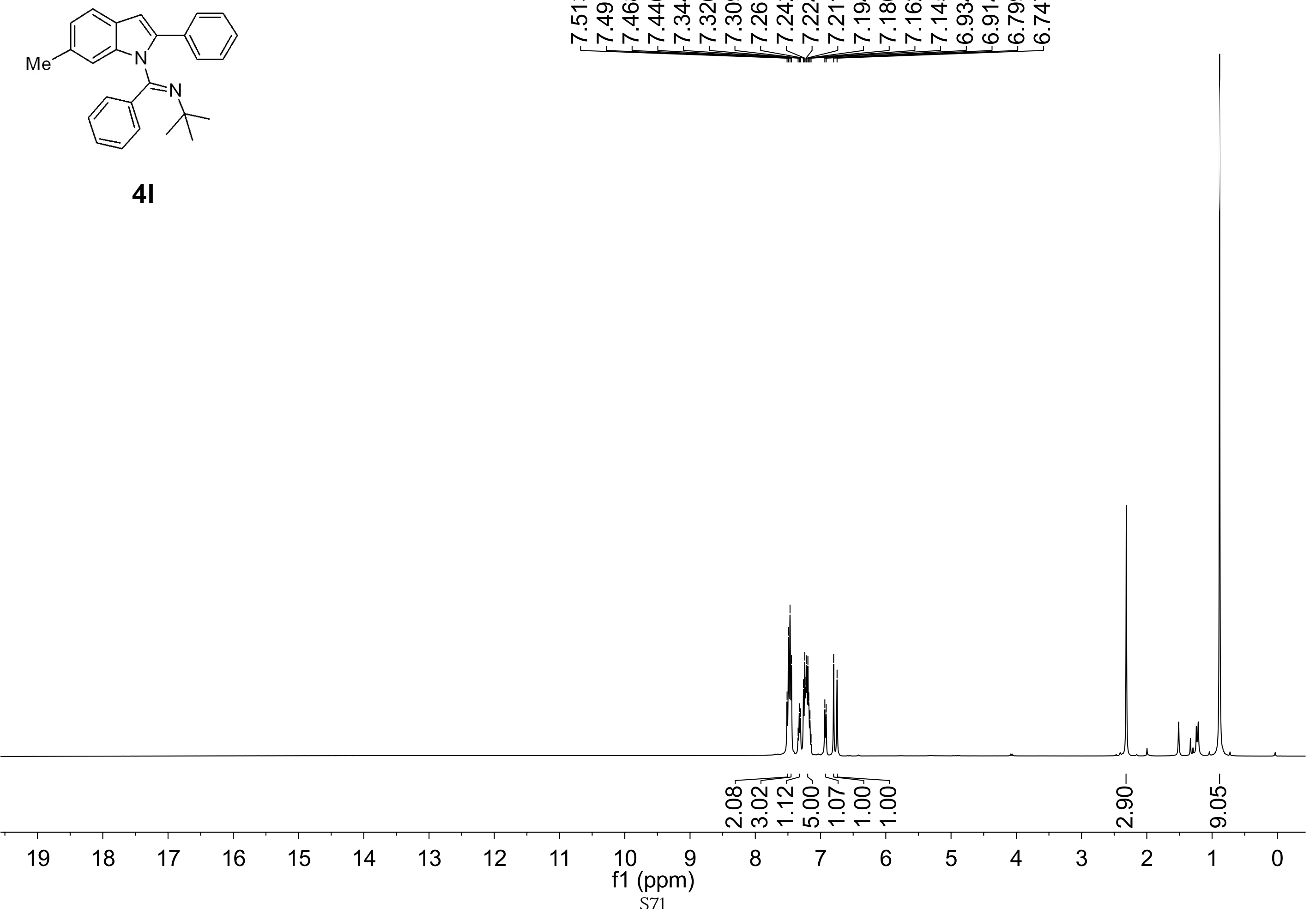


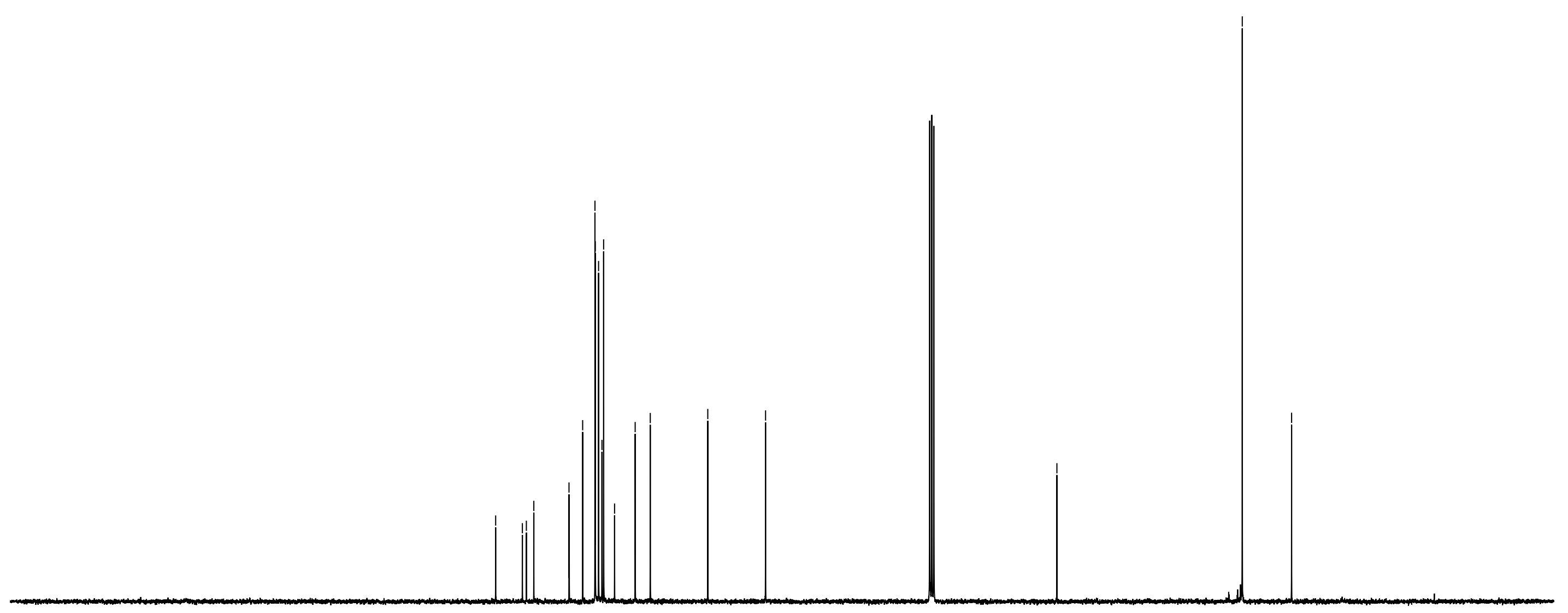

\begin{tabular}{|c|c|c|c|c|c|c|c|c|c|c|c|c|c|c|c|}
\hline 210 & 190 & 170 & 150 & 130 & ${ }_{\mathrm{f} 1}^{110}$ & & 80 & 70 & 60 & 50 & 40 & 30 & 20 & 10 & 0 \\
\hline
\end{tabular}




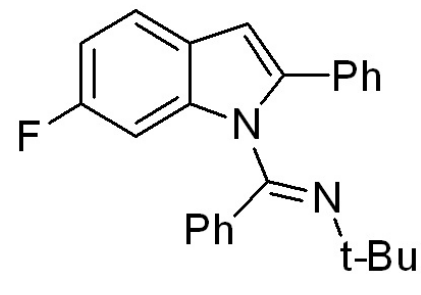

$4 \mathrm{~m}$

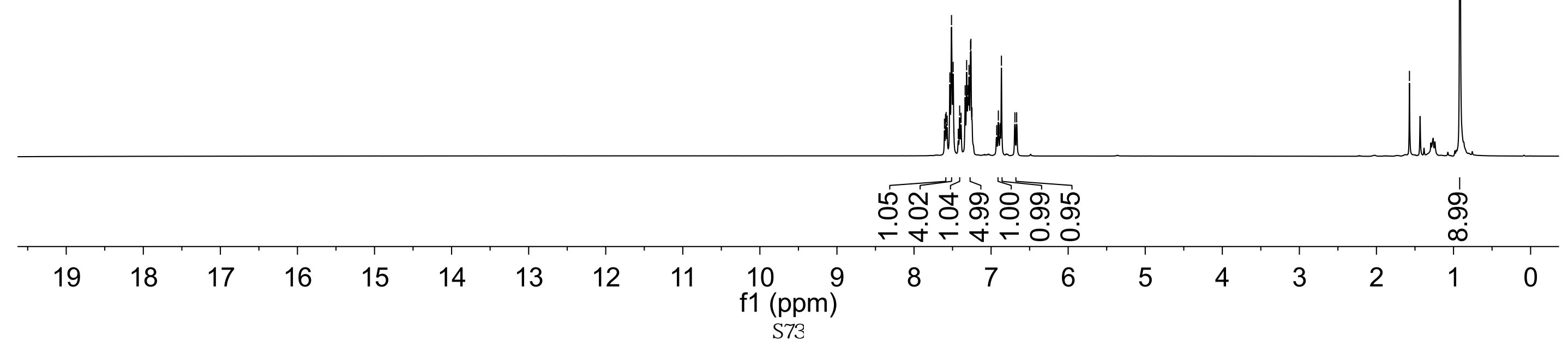




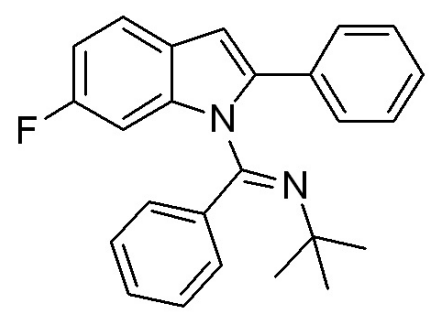

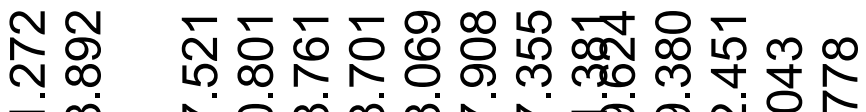
চ

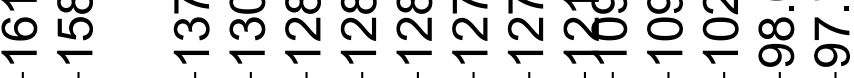

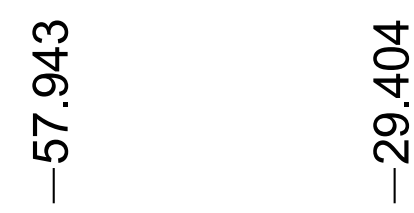

$4 m$

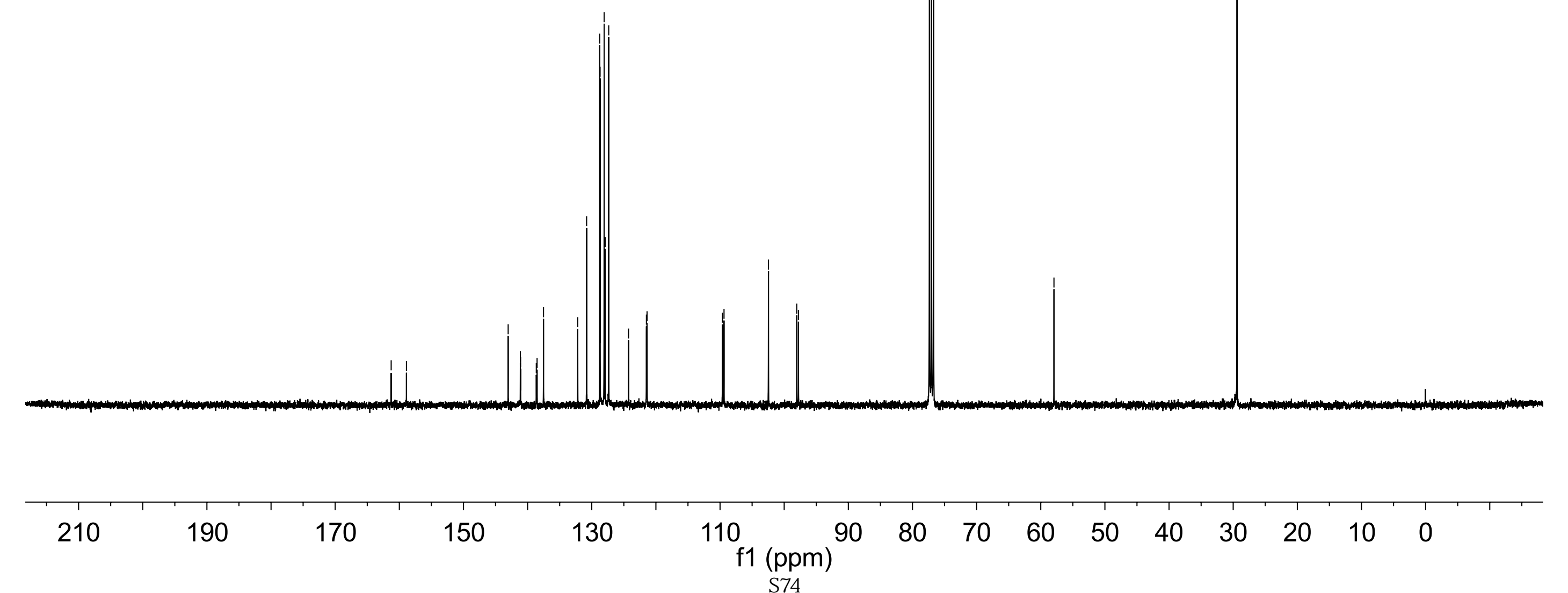




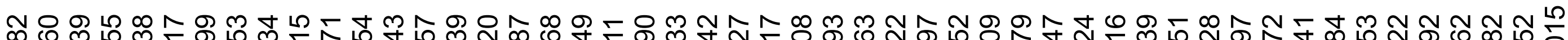

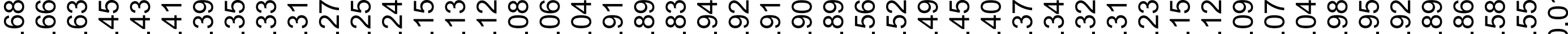

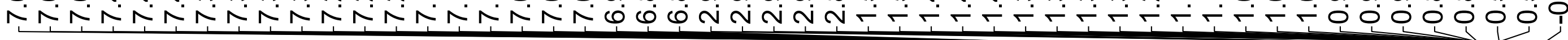

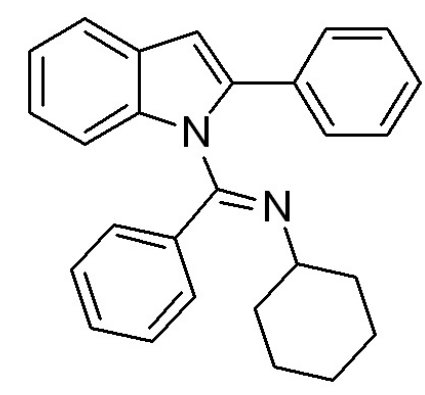

5b

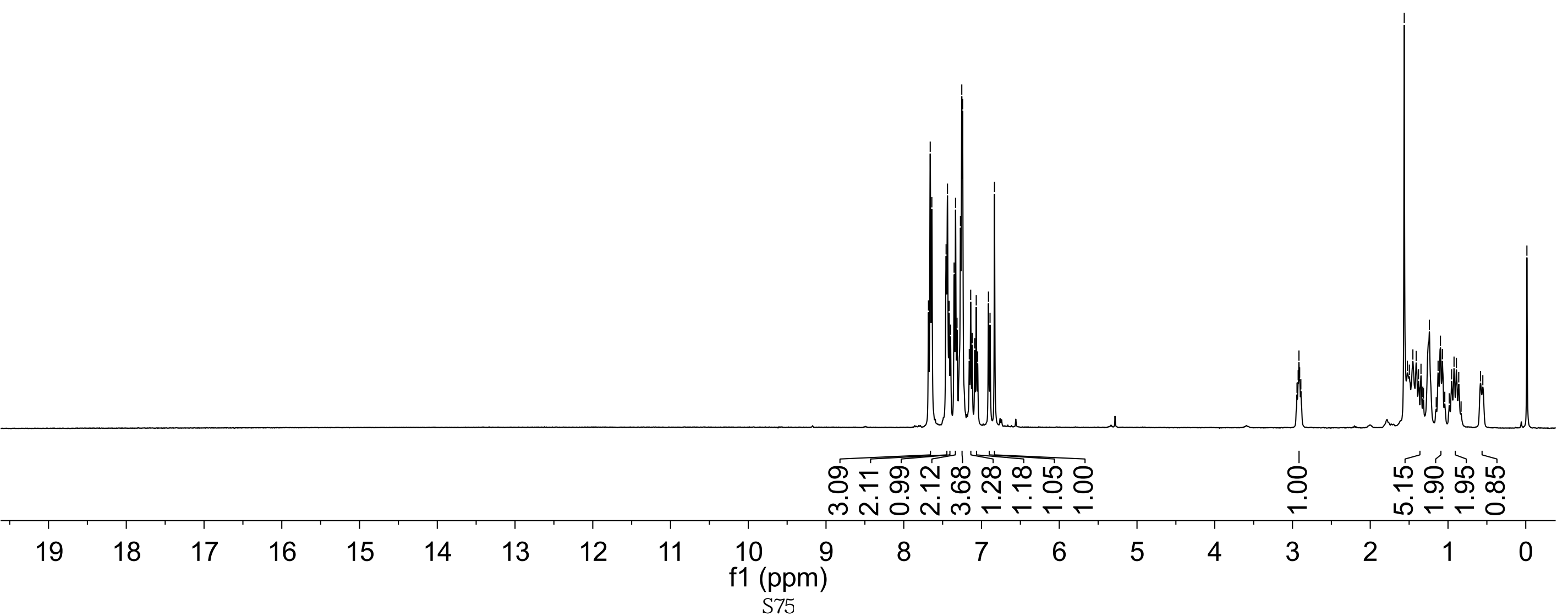




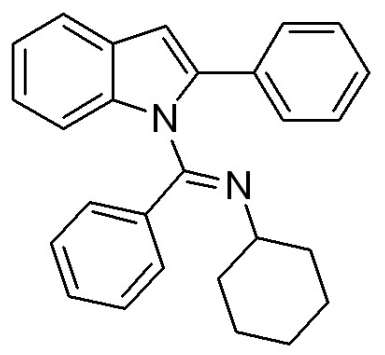

$5 b$

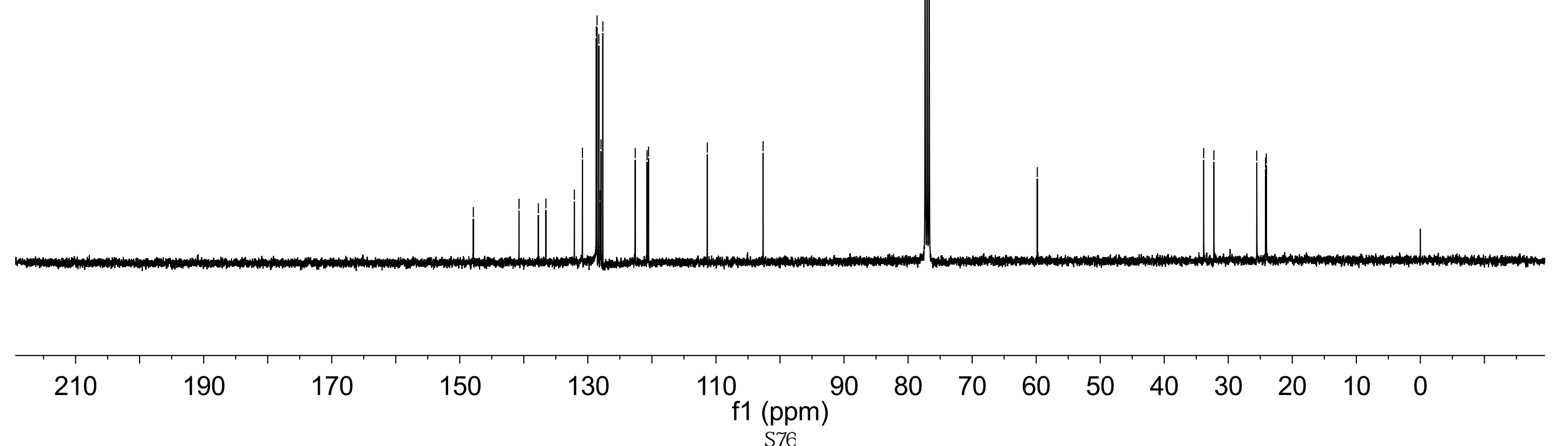




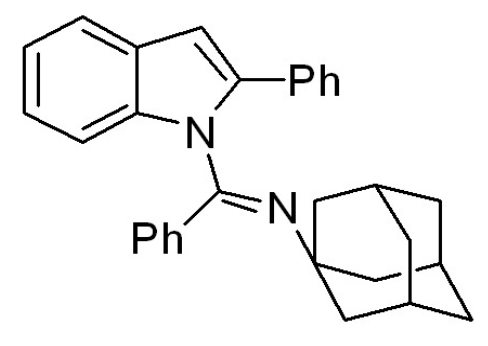

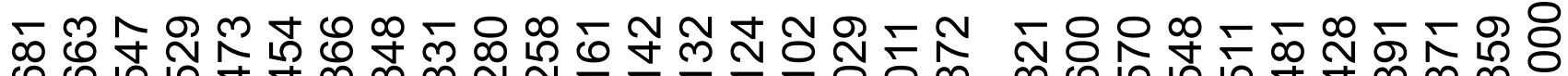

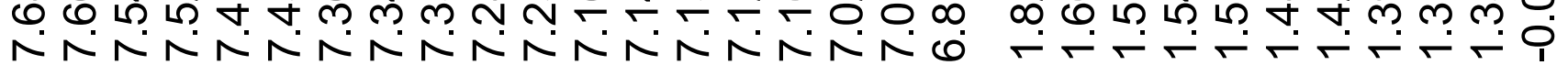

$5 c$

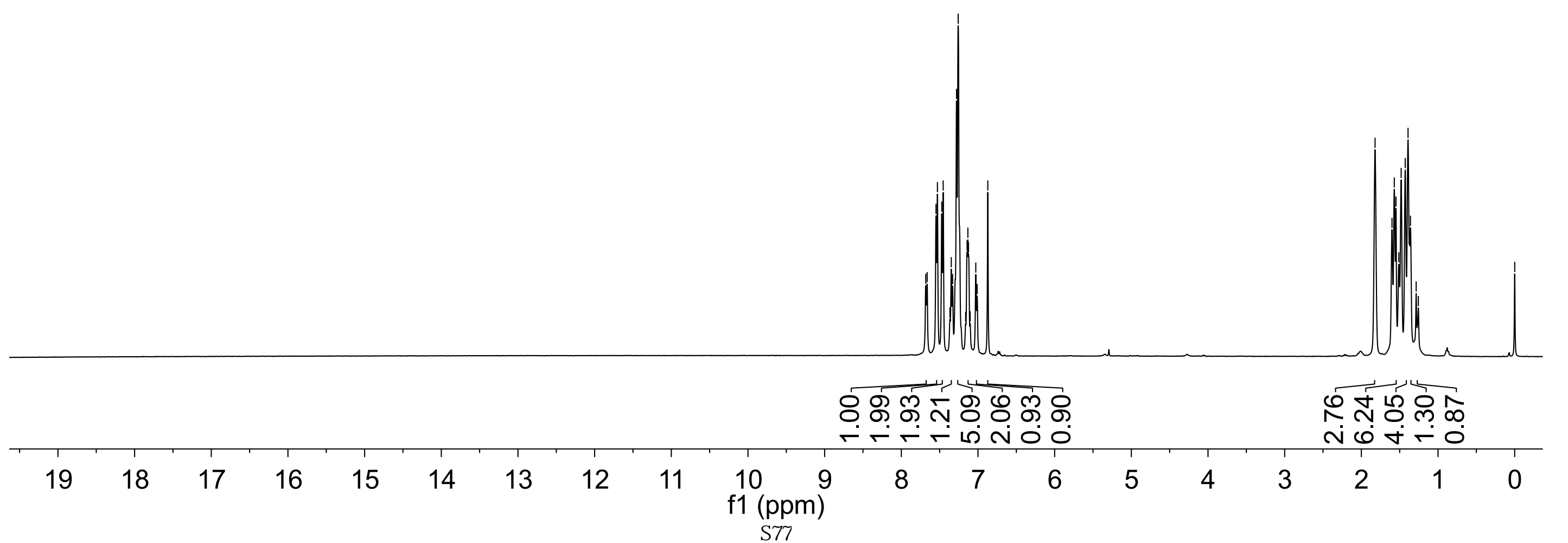


$5 c$

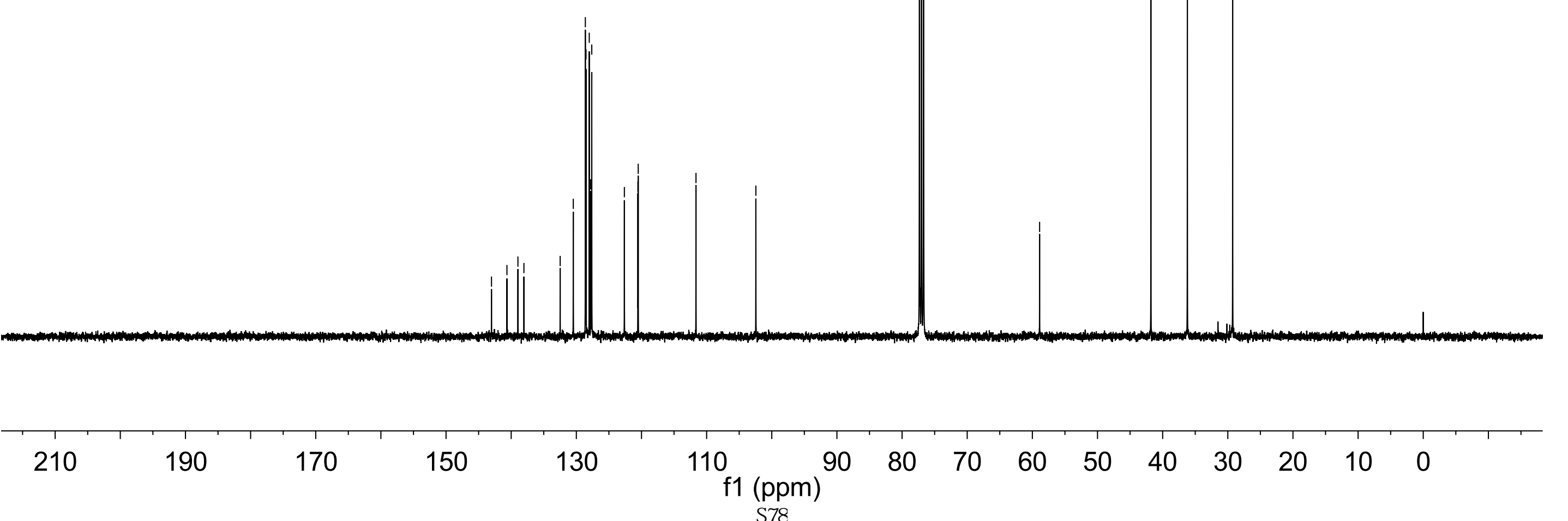

